MARCELO FANTINATO

Contribuições à gestão de processos de negócio

São Paulo

2015 


\section{Contribuições à gestão de processos de negócio}

Texto sistematizado apresentado à Escola de Artes, Ciências e Humanidades da Universidade de São Paulo como parte dos requisitos para obtenção do título de Livre Docente.

Área de conhecimento: Informação e Tecnologia.

Especialidade: Gestão e Desenvolvimento de Sistemas de Informação.

Versão corrigida contendo as alterações solicitadas pela comissão julgadora em 6 de junho de 2014. A versão original encontra-se em acervo reservado na Biblioteca da EACH-USP e na Biblioteca Digital de Teses e Dissertações da USP (BDTD), de acordo com a Resolução CoPGr 6018, de 13 de outubro de 2011.

São Paulo 
Autorizo a reprodução e divulgação total ou parcial deste trabalho, por qualquer meio convencional ou eletrônico, para fins de estudo e pesquisa, desde que citada a fonte.

CATALOGAÇÃO-NA-PUBLICAÇÃO

(Universidade de São Paulo. Escola de Artes, Ciências e Humanidades. Biblioteca)

Fantinato, Marcelo

Contribuições à gestão de processos de negócio / Marcelo

Fantinato. - São Paulo, 2015 79 f. : il.

Tese (Livre Docência em Gestão e Desenvolvimento de Sistemas de Informação) - Escola de Artes, Ciências e Humanidades, Universidade de São Paulo, em 2014 Área de conhecimento: Informação e Tecnologia.

1. Negócios - Processos - Gerenciamento. 2.

Engenharia de software. 3. Sistemas de Informação. II. Título 
Texto sistematizado de autoria de Marcelo Fantinato, sob o título "Contribuições à gestão de processos de negócio", apresentado à Escola de Artes, Ciências e Humanidades da Universidade de São Paulo, como parte dos requisitos para obtenção do título de Livre Docente na área de conhecimento Informação e Tecnologia e especialidade Gestão e Desenvolvimento de Sistemas de Informação, aprovado em 6 de junho de 2014 pela comissão julgadora constituída pelos doutores:

Prof. Dr. Candido Ferreira Xavier de Mendonça Neto Presidente

Escola de Artes, Ciências e Humanidades - Universidade de São Paulo

Profa. Dra. Fátima de Lourdes Santos Nunes Marques

Escola de Artes, Ciências e Humanidades - Universidade de São Paulo

Prof. Dr. João Eduardo Ferreira

Instituto de Matemática e Estatística - Universidade de São Paulo

Prof. Dr. Márcio Eduardo Delamaro

Instituto de Ciências Matemáticas e de Computação - Universidade de São Paulo

Profa. Dra. Eliane Martins

Instituto de Computação - Universidade Estadual de Campinas 


\section{Resumo}

FANTINATO, Marcelo. Contribuições à gestão de processos de negócio. 2015. 78 f. Texto sistematizado (Livre docência) - Escola de Artes, Ciências e Humanidades, Universidade de São Paulo, São Paulo, 2014.

Este texto foi elaborado para a participação do autor no Concurso Público de Professor Livre Docente junto à Escola de Artes, Ciências e Humanidades da Universidade de São Paulo (EACH-USP). No texto, é apresentada uma sistematização das pesquisas e dos trabalhos realizados pelo autor, delineando seu foco de pesquisa em Gestão de Processos de Negócio. Primeiramente, são descritas as contribuições na linha de pesquisa específica de Linha de Produto para Gestão de Processos de Negócio, que concentra os principais esforços do autor e o maior número de publicações. Na sequência, são descritas as contribuições na linha de pesquisa de Contratos Eletrônicos para Gestão de Processos de Negócio, que caracteriza a segunda linha de atuação do autor. Por fim, são apresentadas contribuições em outras linhas de pesquisa também relacionadas a Gestão de Processos de Negócio nas quais o autor tem atuado.

Neste documento, são descritos os fundamentos e os pressupostos com os quais as abordagens têm sido exploradas pelo autor, destacando as contribuições e os desenvolvimentos realizados nos últimos seis anos de trabalho acadêmico, o que corresponde ao período posterior à conclusão do doutorado. Além disso, são também discutidos os trabalhos em andamento assim como as perspectivas futuras de pesquisa nessa área. No período relatado, o autor publicou nove artigos completos em periódicos, 18 artigos completos em anais de conferência, dois artigos curtos em anais de conferência, e três artigos como capítulo de livro. Do total de 29 artigos publicados em periódicos e anais de conferências, $38 \%$ deles foram publicados em veículos com Qualis nos extratos de A1 a B2, de acordo com o comitê de área de Ciência da Computação da Capes.

Palavras-chaves: Gestão de processos de negócio. Engenharia de software. Sistemas de informação. 


\begin{abstract}
FANTINATO, Marcelo. Contributions to the business process management. 2015. 78 p. Systematic text (Habilitation) - School of Arts, Sciences and Humanities, University of São Paulo, São Paulo, 2014.

This document was elaborated to fulfill the requirements of the author's application for a position of Associate Professor in Information Systems at the School of Arts, Sciences and Humanities of the University of São Paulo (EACH-USP). The text systematizes the author's research contribution, focused on studies about Business Process Management. First, it presents the contributions on the specific research line named Product Line in Business Process Management, which represents the core of the author's contributions and publications. Then, it presents the contributions on Electronic Contracts for Business Process Management, which represents his second main topic of investigation. Finally, it presents the contributions on other research lines also related to Business Process Management in which the author has been working.

This text describes the background and the assumptions which are the basis for the research done by the author, highlighting the contributions and developments in the last six years, i.e. after the conclusion of the Ph.D. thesis. Moreover, the ongoing works as well as the future research perspectives in this area are also discussed. In the reported period, the author published nine complete papers in journals, 18 complete papers in conference's proceedings, two short papers in conference's proceedings, and three papers as book chapters. From the total of 29 papers published in journals and in conference's proceedings, $38 \%$ of them were published in vehicles evaluated as Qualis A1 to B2 according to the Capes' area committee in Computer Science.
\end{abstract}

Keywords: Business process management. Software engineering. Information systems. 


\section{Lista de figuras}

Figura 1 - Tela principal da ferramenta FeatureContract como plug-in do ambiente

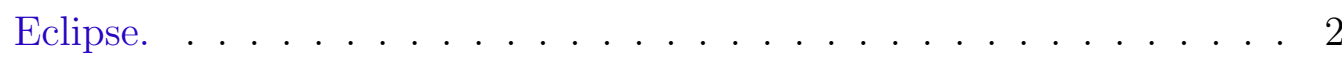

Figura 2 - Arquitetura da ferramenta FeatureContract, em Diagrama de Classes da UML. . . . . . . . . . . . . . . . . . . . . 26

Figura 3 - Metamodelo de características da PL4BPM estendido com características de preço, em Diagrama de Classes da UML. As entidades em cinza representam os elementos incluídos com a extensão para o tratamento de preço. . . . . . . . . . . . . . . . . 28

Figura 4 - Processo proposto para a negociação entre as partes envolvidas na contratação de serviços eletrônicos a serem usados no processo de desenvolvimento de software, em BPMN . . . . . . . . . . . . . .

Figura 5 - Metamodelo proposto para a negociação entre as partes envolvidas na contratação de serviços eletrônicos a serem usados no processo de desenvolvimento de software, em Diagrama de Classes da UML. . . . .

Figura 6 - Metamodelo de características da PL4BPM estendido com características de "operações de controle" úteis à negociação, em Diagrama de Classes da UML. As entidades em cinza representam os elementos incluídos com a extensão para o tratamento de negociação. . . . . . . . . . . . .

Figura 7 - Mapeamento entre os elementos de "operação de controle" do metamodelo de características da PL4BPM e do metamodelo da especificação WS-Agreement, em Diagrama de Classes da UML. . . . . . . . . . . . 34

Figura 8 - Infraestrutura para BPM baseada em contratos eletrônicos e LP, incluindo a estrutura "Monitoramento de WS-Contract", em Diagrama de Pacotes da UML. . . . . . . . . . . . . . . . . . . . .

Figura 9 - Fluxo de execução do componente WS-Monitor desenvolvido para a estrutura "Monitoramento de WS-Contract", em Diagrama de Sequências da UML. . . . . . . . . . . . . . . . . . . . 36

Figura 10 - Processo da abordagem PL4BPM estendido com tratamento de BLA, em Diagrama de Atividades da UML. . . . . . . . . . . . . . . . .

Figura 11 - Metamodelo de características para definição de processo de negócio e BLAs associados, em Diagrama de Classes da UML. . . . . . . . . . . . 
Figura 12 - Processos de LP para BPM proposto para a abordagem DynPL4BPM, em notação livre. . . . . . . . . . . . . . . . . . . . . . . . 41

Figura 13 - Comparação sistemática entre a abordagem DynPL4BPM e 15 outras abordagens similares. . . . . . . . . . . . . . . . . . 42

Figura 14 - Metamodelo genérico de contratos eletrônicos, em Diagrama de Classes da UML. . . . . . . . . . . . . . . . . . . . . . . . 44

Figura 15 - Metamodelo de WS-Contract, em Diagrama de Classes da UML. . . . 46

Figura 16 - Metamodelo de WS-Contract estendido com Aspectos Monitores, em Diagrama de Classes da UML. . . . . . . . . . . . . . . . . . . . 49

Figura 17 - Arquitetura proposta para o Projeto WebInVivo, em notação livre. . . 52

Figura 18 - Exemplo de protocolo médico como processo, em BPMN. . . . . . . . . 53

Figura 19 - Framework conceitual da abordagem StrAli-BPM (novos elementos adicionados para BLA destacados em cinza), em notação livre. . . . . . 56

Figura 20 - Exemplo de modelo de processo de negócio com novo elemento BLA ("Criação de contratos em até 6 horas"), em BPMN. . . . . . . . . . . 57

Figura 21 - Metamodelo de BPMN resumido estendido com novo elemento BLA (novos elementos adicionados para BLA destacados em cinza), em Diagramas de Classes da UML. . . . . . . . . . . . . . . . . . . 58

Figura 22 - Estágios e passos do processo proposto para a técnica BPPA, em notação livre. . . . . . . . . . . . . . . . . . 6 61

Figura 23 - Framework da abordagem sendo proposta: extensão da RGPS baseada em framework i* e linguagens WS-BPEL/WSDL, em notação livre. . . 63 


\section{Lista de tabelas}

Tabela 1 - Resumo das Publicações - de 2008 a 2013. Publicações em negrito: destaque para as 11 mais relevantes; publicações sublinhadas: destaque para as nove realizadas em periódicos. . . . . . . . . . . . . . . . 64 


\section{Sumário}

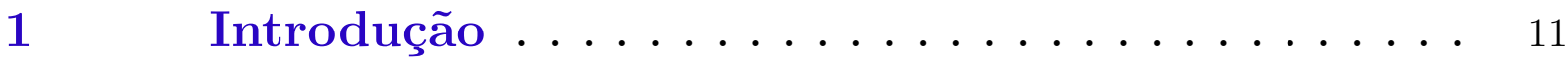

1.1 Contexto de pesquisa $\ldots \ldots \ldots \ldots \ldots 11$

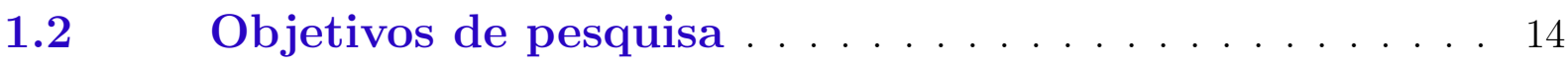

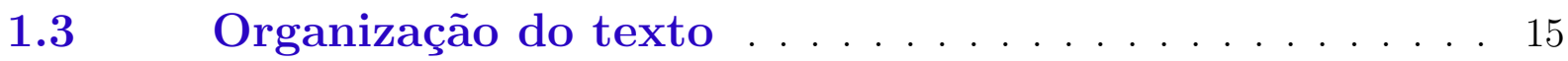

2 Contribuições à pesquisa em gestão de processos de negócio . . . . . . . . . . . . . . . 17

2.1 Linha de produto para gestão de processos de negócio 17

2.1.1 Formalização da abordagem PL4BPM . . . . . . . . . 20

2.1.2 Avaliação experimental da abordagem PL4BPM . . . . . . 22

2.1.3 Desenvolvimento da ferramenta FeatureContract para a abordagem PL4BPM . . . . . . . . . . . . . . . 24

2.1.4 Tratamento de preço na abordagem PL4BPM . . . . . . 26

2.1.5 Aplicação da PL4BPM no contexto de desenvolvimento distribuído de software . . . . . . . . . . . . . . . . . . . . 29

2.1.6 Negociação e renegociação para processos de negócio no contexto da PL4BPM . . . . . . . . . . . . . . . . . . . 30

2.1.7 Monitoramento de processos de negócio no contexto da

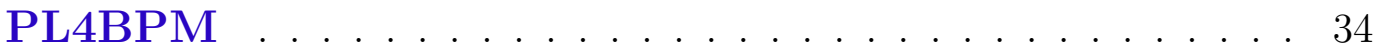

2.1.8 Estendendo a abordagem PL4BPM para lidar com alinhamento estratégico . . . . . . . . . . . . . . 36

2.1.9 LP dinâmica para BPM - DynPL4BPM . . . . . . . . . 39

2.2 Contratos eletrônicos para gestão de processos de negócio 43

2.2.1 Conceitualizações na área de contratos eletrônicos para BPM e SOA . . . . . . . . . . . . . . . . . 44

2.2.2 Uso de ontologias para estabelecimento de contratos eletrônicos 47

2.2.3 Uso de orientação a aspectos para monitoramento de contratos eletrônicos . . . . . . . . . . . . . . . 48

2.3 Outras linhas de pesquisa em gestão de processos de negócio . . . . . . . . . . . . . . . . . 50

2.3.1 Processos colaborativos para pesquisas médicas . . . . . . 51 
2.3.2 Alinhamento estratégico apoiado por BPM . . . . . . . 53

2.3.3 Análise de técnicas de reúso em BPM . . . . . . . . . 57

2.3.4 Métricas de tamanho para BPM . . . . . . . . . . . 59

2.3.5 Engenharia de requisitos para composição de serviços . . 62

2.4 Considerações finais . . . . . . . . . . . . 63

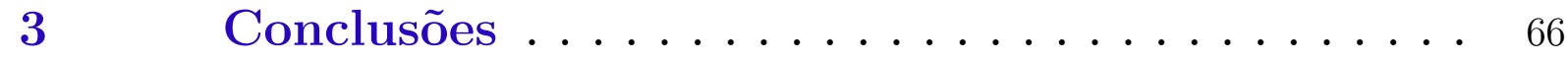

3.1 Discussão e reflexões . . . . . . . . . . . . 66

3.2 Trabalhos em andamento e trabalhos futuros . . . . . . 67

$3.3 \quad$ Agradecimentos . . . . . . . . . . . . . . . 70

$\operatorname{Referências~}^{1} \ldots \ldots \ldots \ldots \ldots \ldots \ldots$ 


\section{Introdução}

Este documento apresenta uma sistematização das pesquisas e dos trabalhos realizados por seu autor, delineando seu foco de pesquisa em Gestão de Processos de Negócio $\left(B P M^{1}\right)$. São apresentados os resultados de pesquisa dos últimos seis anos de trabalho acadêmico, o que corresponde ao período posterior à conclusão de seu doutorado.

Neste capítulo, é apresentada uma introdução à sistematização coberta no restante do documento. Para isso, as próximas subseções apresentam: (i) o contexto de pesquisa no qual a área de BPM está inserida, e mais especificamente o contexto no qual os trabalhos de pesquisa do autor têm sido realizados; (ii) os objetivos de pesquisa que o autor tem buscado alcançar dentro do contexto apresentado, divididos em algumas grandes linhas de pesquisa; e, por fim, (iii) a forma como o restante do documento está organizado.

\subsection{Contexto de pesquisa}

O dinamismo do mundo corporativo atual requer que organizações atuem de forma rápida para não perder parcerias e oportunidades de negócio. As organizações precisam ser flexíveis e adaptáveis a novas condições de mercado, ao aumento de competitividade e a novas exigências regulatórias (OVERBY; BHARADWAJ; SAMBAMURTHY, 2006). Essa alta taxa de mudanças em geral leva as organizações a adotar modelos organizacionais e processos de negócio cada vez mais complexos e interligados (TALLON, 2008). Neste contexto, a gestão conjunta de Sistemas de Informação (SI) e da Tecnologia da Informação (TI) possui um importante papel ao ser responsável por propiciar o ambiente computacional necessário para que as transações de negócio das organizações modernas possam ser realizadas efetivamente (LEE; CHU; TSENG, 2011).

BPM tem sido apresentada como elemento chave para o sucesso de infraestruturas de TI preparadas para as demandas de organizações atuais (WESKE; AALST; VERBEEK, 2004). Técnicas e ferramentas de BPM, consideradas uma evolução da tecnologia de workflow (WfMC, 2013), apoiam computacionalmente todo o ciclo de vida de processos de negócio envolvendo diferentes partes organizacionais que atuam cooperativamente e visam um objetivo comum de negócio (AALST; HOFSTEDE; WESKE, 2003). O ciclo de vida de BPM inclui atividades de: definição, negociação, execução, monitoramento, controle, 
análise e melhoria de processos de negócio (AALST; HOFSTEDE; WESKE, 2003; WESKE, 2007). Esses processos de negócio podem ser tanto do tipo intra-organizacionais, que são normalmente interdepartamentais, quanto do tipo interorganizacionais, considerados mais complexos que o primeiro tipo.

Como processos de negócio podem envolver várias partes de uma mesma organização ou de diferentes organizações, diferentes SIs de cada parte envolvida precisam ser integrados para tratar um mesmo processo de negócio. Considerando essa necessidade, o paradigma de Computação Orientada a Serviços $\left(\mathrm{SOC}^{2}\right)$ tem sido usado para tratar a interoperabilidade entre diferentes SIs por meio do fornecimento e consumo de serviços eletrônicos (ERL, 2007; PAPAZOGLOU, 2008). Dentro do paradigma SOC, a tecnologia de serviços web é a mais usada atualmente para a implementação de serviços eletrônicos (ALONSO et al., 2004; WEERAWARANA et al., 2005). A partir de serviços web simples, que disponibilizam funcionalidades em uma rede de computadores, processos de negócio podem ser criados por meio da composição de serviços. Esses processos de negócio podem, portanto, atuar como novos serviços web mais complexos.

Contratos eletrônicos podem ser usados no contexto de BPM e SOC para agregar sistematicamente as informações necessárias para que um processo de negócio seja realizado, por meio de serviços eletrônicos, de forma cooperativa entre departamentos ou organizações (KRISHNA; KARLAPALEM, 2008). Um contrato eletrônico inclui informações relacionadas a: (i) partes envolvidas - consumidor(es), fornecedor(es), e possivelmente monitor(es) externo(s); (ii) processo de negócio — sequência de atividades a serem executadas pelas partes envolvidas, como uma composição de serviços eletrônicos; e (iii) cláusulas contratuais - restrições sobre a execução do processo de negócio, na forma de obrigações, direitos ou proibições. As cláusulas contratuais podem ser definidas por meio de atributos de Qualidade de Serviço $\left(\mathrm{QoS}^{3}\right)$, usados para especificar níveis aceitáveis para propriedades não-funcionais. Um tipo específico de contrato eletrônico são os contratos eletrônicos para serviços web (WS-Contracts ${ }^{4}$ ) (FANTINATO; GIMENES; TOLEDO, 2010c).

Embora muitos avanços tenham sido alcançados neste contexto, ainda existem desafios a serem superados para que BPM cumpra satisfatoriamente seu papel no fornecimento da infraestrutura de TI desejada (AALST; LEYMANN; REISIG, 2007; PAPAZOGLOU et

do inglês "Service-oriented Computing"

3 do inglês "Quality of Service"

4 do inglês "Web Services E-Contracts" 
al., 2008). Buscando atingir esse objetivo, via maximização de benefícios e minimização de custos, abordagens já conhecidas da Engenharia de Software podem ser adaptadas para aplicação em BPM. Essencialmente, processos de negócio automatizados podem ser comparados a software. De fato, ambos os ciclos de vida - de BPM e da Engenharia de Software - são similares, apesar de existirem algumas diferenças importantes já que em BPM o ciclo de vida é consideravelmente menor, normalmente mais rápido e também mais dinâmico (FANTINATO et al., 2012). Assim, é esperado que diferentes soluções da Engenharia de Software possam ser mapeadas para resolver problemas equivalentes em BPM.

Um problema existente tanto em Engenharia de Software quanto em BPM é a necessidade de reúso de artefatos visando o aumento de flexibilidade, de dinamismo e de competitividade. Diferentes abordagens de reúso de software podem ser aplicadas com sucesso em BPM (FANTINATO et al., 2012). Alguns exemplos dessas abordagens de reúso são: Linha de Produto (LP) de Software (CLEMENTS; NORTHROP, 2001; ROCHA; FANTINATO, 2013), padrões de projeto (MIKKONEN, 1998; NORTA; GREFEN, 2007), orientação a aspectos (FILMAN et al., 2004; CAPPELLI et al., 2010) e desenvolvimento baseado em componentes (CRNKOVIC; LARSSON, 2002; AO; PIDD, 2006). Dessas, LP é uma das áreas que têm sido mais amplamente exploradas no contexto de BPM (ROCHA; FANTINATO, 2013).

LP racionaliza o reúso no desenvolvimento de sistemas (CLEMENTS; NORTHROP, 2001; POHL; BÖCKLE; LINDEN, 2005). Ela promove a geração de produtos específicos, a partir de uma família de produtos genérica, com base no reúso de uma arquitetura comum e de um conjunto de componentes. Exploram-se os pontos comuns e as variabilidades entre diferentes sistemas de um mesmo domínio, os quais devem ser representados por um mecanismo de modelagem, tal como modelos de características (KANG et al., 1990; CZARNECKI; HELSEN; EISENECKER, 2005). Modelos de características - a técnica mais usada para o gerenciamento de variabilidades em LPs - descrevem propriedades de entidades em diferentes níveis de abstração, por meio de diagramas que representam características em uma estrutura hierárquica de nós. Um tipo específico de LP que pode ser ainda mais útil para BPM, devido suas necessidades de dinamismo e flexibilidade, são as LP Dinâmicas (LPDs) (HALLSTEINSEN et al., 2008).

Outros conceitos da Engenharia de Software podem ser úteis em BPM. Isso se torna mais claro ao avaliar que, assim como o desenvolvimento de software possui técnicas e ferramentas bem definidas dentro de uma organização altamente dependente de software, a 
automação e a gestão de processos de negócio também possuem suas técnicas e ferramentas bem definidas em organizações que dependem de tais processos. Assim, por exemplo, técnicas de métricas de software, tal como a amplamente usada Análise de Pontos de Função (IFPUG, 2013), podem ser mapeadas para o contexto de BPM (GONZÁLEZ et al., 2010a). Como outro exemplo, conceitos relacionados a Requisitos Não funcionais no desenvolvimento de software (SIVESS, 1996) também podem ser mapeados para propriedades não funcionais durante a modelagem de processos de negócio e durante sua implementação por meio de composição de serviços web (ABURUB; ODEH; BEESON, 2007).

\subsection{Objetivos de pesquisa}

Considerando o contexto apresentado na seção anterior, os trabalhos de pesquisa desenvolvidos pelo autor, desde o término de seu doutorado, têm se concentrado principalmente na área de BPM. O autor tem buscado desenvolver e avaliar novas abordagens, técnicas e ferramentas de BPM que contribuam para oferecer às organizações maior flexibilidade, dinamismo e competitividade. Considerando o amplo conhecimento técnico e científico que o autor possui na área de Engenharia de Software, a maior parte de seus trabalhos na área de BPM, e na área de SI de uma forma geral, tem sido influenciada pela aplicação de seus conhecimentos na área de Engenharia de Software.

Considerando esse objetivo, a maior parte dos trabalhos de pesquisa do autor se inter-relaciona, mesmo que com objetivos específicos diferentes. Assim, é possível identificar três grandes focos de pesquisa que têm sido interesse do autor desde o término de seu doutorado. Esses três focos de pesquisa são apresentados a seguir:

1. LP para BPM: a maior parte dos trabalhos realizados pelo autor se refere a pesquisas sobre a aplicação de conceitos de LP, em conjunto com a técnica de modelos de características (ambos originalmente propostos para a Engenharia de Software), no contexto específico de BPM. Considerando que seu trabalho de doutorado já apontava para essa direção, e sendo um projeto inovador para as áreas tanto de Engenharia de Software quanto para as áreas de SI e de BPM, o autor ponderou como valioso aprofundar suas pesquisas nesta área, considerada promissora. Vários de seus trabalhos de pesquisa têm sido realizados desde então para refinar, implementar 
e avaliar diferentes aspectos da LP para BPM sendo proposta, incluindo, mais recentemente, a proposta de uma LPD para BPM.

2. Contratos eletrônicos para BPM: embora a grande maioria dos trabalhos relacionados a "LP para BPM" (foco delineado no item anterior) já incorpore "contratos eletrônicos", eles são conceitos independentes. E, assim, dada a importância de contratos eletrônicos para a área de BPM, o autor decidiu por também realizar alguns trabalhos de pesquisa focados exclusivamente nesse tópico, independentemente da abordagem de LP, o que se tornou seu segundo principal foco de atuação. Alguns trabalhos realizados com esse objetivo têm envolvido, por exemplo: (i) técnicas de orientação a aspecto, para reúso de artefatos; e, (ii) ontologias, para o Desenvolvimento Distribuído de Software (DDS).

3. Outras linhas de pesquisa para BPM: outros trabalhos têm sido realizados no âmbito de BPM, normalmente sob influência de abordagens de Engenharia de Software, porém sem estarem relacionados com LP ou com contratos eletrônicos. Esses trabalhos são normalmente independentes entre si. A maioria deles é recente e pode apontar para futuros projetos de pesquisa que podem se tornar, em alguns casos, grandes focos de pesquisa para os próximos anos, considerando alguns bons resultados que já têm sido alcançados. Exemplos de trabalhos de pesquisa aqui são: (i) métricas para medição de tamanho de processo de negócio; (ii) alinhamento estratégico entre negócios e TI; e, (iii) engenharia de requisitos orientada a serviços.

\subsection{Organização do texto}

O restante do texto está organizado em dois capítulos, além desta introdução e das referências bibliográficas que incluem tanto os trabalhos produzidos pelo autor, e discutidos neste texto, quanto os demais trabalhos usados como referências necessárias para o contexto. Em relação ao conteúdo propriamente dito, a organização do texto é discutida a seguir.

No Capítulo 2, são apresentados os trabalhos desenvolvidos pelo autor, ou sob sua orientação ou coorientação, na área de BPM, após a conclusão de seu doutorado. Além dos trabalhos de pesquisa de uma forma geral, são destacadas as publicações derivadas (na forma de artigos) a partir dos trabalhos realizados. Os trabalhos estão classificados de acordo com seu enfoque principal, divididos nas três grandes categorias apresentadas na 
seção anterior (Seção 1.2), que corresponde às três seções do Capítulo 2. Primeiramente, na Seção 2.1, são apresentados os trabalhos relacionados a abordagens de LP para BPM. Em seguida, na Seção 2.2, são apresentados os trabalhos relacionados puramente a contratos eletrônicos para BPM. Por fim, na Seção 2.3, são apresentados outros trabalhos relevantes desenvolvidos pelo autor na área de BPM, porém não relacionados diretamente nem a LP nem a contratos eletrônicos.

No Capítulo 3, são apresentadas as conclusões, no formato de discussão e reflexões, e indicados os trabalhos em andamento e trabalhos futuros vislumbrados. 


\section{Contribuições à pesquisa em gestão de processos de negócio}

Neste capítulo, são apresentados os trabalhos realizados pelo autor, sob sua orientação ou coorientação, e outras parcerias, em Gestão de Processos de Negócio (BPM $\left.{ }^{1}\right)$, após a conclusão de seu doutorado. As publicações derivadas dos trabalhos realizados estão indicadas ao longo do texto e resumidas no final do capítulo.

Os trabalhos estão classificados em função de seu enfoque principal, divididos em três categorias, correspondentes às seções deste capítulo. Primeiramente, são apresentados os trabalhos relacionados a abordagens de LP para BPM, que representa a maior parte dos trabalhos desenvolvidos pelo autor. Em seguida, são apresentados os trabalhos relacionados puramente a contratos eletrônicos para BPM, sem envolver LP, que pode ser considerada uma segunda principal área de atuação. Por fim, são apresentados outros trabalhos relevantes desenvolvidos pelo autor na área de BPM, porém não relacionados diretamente nem a LP nem a contratos eletrônicos.

Os trabalhos são apresentados de forma resumida. Apenas os objetivos e conceitos principais de cada trabalho são apresentados, assim como os aspectos que distinguem cada contribuição especificamente em termos de publicação derivada; já que, para alguns casos, a partir de um mesmo trabalho de pesquisa, diferentes publicações complementares podem ter sido derivadas. Com o objetivo de facilitar o acompanhamento da leitura do texto, a referência de cada publicação é apresentada também como nota de rodapé. As 11 publicações mais relevantes, em termos de impacto do veículo em que elas foram publicadas, quando apresentadas em nota de rodapé, são precedidas por três asteriscos entre colchetes ${ }^{2}$. Além disso, o Qualis vigente, de acordo com o comitê de área da Ciência da Computação, também é apresentado para cada referência.

\subsection{Linha de produto para gestão de processos de negócio}

BPM inclui uma série de atividades, técnicas e ferramentas para lidar de forma eficiente com os processos de negócio de uma organização. Segundo Weske (2007), um processo de negócio consiste em um conjunto de tarefas ou atividades realizadas em uma sequência específica para alcançar um objetivo comum de negócio. Normalmente, esses

\footnotetext{
1 do inglês "Business Process Management"

2 desta forma: [***]
} 
processos de negócio são bastante complexos, envolvendo, além das próprias atividades, outros elementos, tais como: artefatos sendo consumidos pelas atividades; artefatos sendo produzidos pelas atividades; papéis da organização responsáveis pela realização das atividades; ferramentas de software ou SIs usados para apoio à realização automatizada das atividades; eventos que ocorrem durante a realização das atividades, antes, durante ou depois delas; e desvios que ocasionam decisões de caminhos alternativos ou paralelos na sequência de atividades.

De forma similar ao desenvolvimento de software, a gestão automatizada de processos de negócio também é realizada por meio de um ciclo de vida. O ciclo de vida de BPM envolve várias atividades, incluindo (WESKE, 2007): (i) modelagem de processo de negócio; (ii) instanciação do modelo de processo de negócio; (iii) apoio à execução de processos de negócio; (iv) monitoramento e auditoria de execução de processos de negócio; e, (v) análise do processo de negócio em execução. Nessa última etapa, o histórico de execução é analisado para identificação de problemas, o que pode levar à remodelagem de processos, começando todo ciclo novamente - o que precisa ser feito de forma rápida devido aos ambientes dinâmicos do mercado e das organizações em que BPM é usada.

Como os processos de negócio podem envolver várias partes de uma organização ou mesmo várias organizações, um desafio é a integração entre diferentes aplicações existentes em cada uma das partes envolvidas. A Arquitetura Orientada por Serviços $\left(\mathrm{SOA}^{3}\right)$ é a forma mais moderna para tratar a integração entre diferentes aplicações, por meio do fornecimento e consumo de serviços eletrônicos (ERL, 2007; PAPAZOGLOU et al., 2008). Atualmente, serviços web é a tecnologia mais promissora na realização dessa arquitetura (ALONSO et al., 2004; WEERAWARANA et al., 2005). A partir de serviços eletrônicos simples que disponibilizam funções de determinadas aplicações, processos de negócio podem ser criados por meio da composição de serviços eletrônicos (possivelmente serviços web). Esses processos de negócio, por sua vez, podem atuar como novos serviços eletrônicos mais complexos.

Devido à complexidade inerente da área de BPM, diversas abordagens têm sido propostas visando sistematizar as diferentes atividades do ciclo de vida de BPM. O autor tem focado seus esforços em aplicar conceitos de LP, da Engenharia de Software, na área de BPM. De acordo com Clements and Northrop (2001), LP é um conjunto de sistemas que usam software intensivamente, que compartilham um conjunto de características comuns,

3 do inglês "Service-oriented Architecture" 
que são gerenciadas para satisfazer as necessidades de um segmento particular de mercado ou objetivo, e que são desenvolvidos a partir de um conjunto comum de artefatos principais e de uma forma preestabelecida, seguindo um processo bem definido.

Como parte do processo de uma LP, uma técnica para capturar e gerenciar os pontos comuns e variáveis das propriedades existentes na família de produtos deve ser usada (CLEMENTS; NORTHROP, 2001; POHL; BÖCKLE; LINDEN, 2005). Uma das técnicas mais usadas para a gestão de variabilidades em LP são os modelos de características (KANG et al., 1998). Uma característica pode ser definida como uma propriedade de um sistema que é relevante para alguma entidade envolvida em seu desenvolvimento ou uso. Ela é usada para capturar pontos comuns ou estabelecer uma discriminação entre sistemas em uma família de sistemas. Uma característica pode denotar qualquer propriedade funcional ou não funcional em relação a requisitos, arquitetura, componentes ou plataformas computacionais.

Um tipo específico de LP, as LP Dinâmicas (LPDs), produz software capaz de adaptação às mudanças para atender a necessidade do usuário, levando em consideração as restrições de recursos. LPDs têm sido identificadas como uma estratégica promissora para endereçar o projeto e implementação de mudanças que precisam ser realizadas em tempo de execução em novas áreas de aplicação. Embora LPDs sejam construídas na ideia central de LP típica, existem diferenças entre ambas, visto que uma LPD possui a maioria das seguintes propriedades (HALLSTEINSEN et al., 2008): (i) variabilidade dinâmica - configuração e vínculo em tempo de execução; (ii) mudanças de vínculos várias vezes durante o tempo de vida; (iii) mudança de pontos de variação durante tempo de execução - adição de pontos de variação; (iv) tratamento de mudanças inesperadas (em algum caminho limitado); ( $v$ ) tratamento de mudanças dos usuários (requisitos funcionais ou de qualidade); (vi) sensibilidade ao contexto e percepção da situação; (vii) propriedades autônomas ou autoadaptativas; (viii) tomada de decisão automática; e, (ix) ambiente individual/situação de contexto em vez de um "mercado".

Essa linha de pesquisa busca aplicar os conceitos e técnicas de LP da Engenharia de Software no contexto de BPM, considerando as semelhanças que existem entre os dois contextos. Um tipo específico de LP tem sido investigado nesta linha de pesquisa, que são as LPDs. Também, dentro dessa linha de pesquisa, há trabalhos que usam conceitos de "contratos eletrônicos" sendo usados em LP para BPM. Dentro desta linha de pesquisa, vários trabalhos foram realizados pelo autor no período relatado aqui. Nove trabalhos diferentes podem ser identificados, normalmente envolvendo colaboradores 
também diferentes, com objetivos específicos diferentes, embora todos relacionados a LP para BPM. Alguns desses trabalhos são mais independentes entre si, outros possuem uma maior dependência, chegado a ser uma complementação, em alguns casos. Em média, para cada um desses nove trabalhos, houve a publicação de dois trabalhos científicos, entre anais de conferências e periódicos. As seções a seguir apresentam as contribuições específicas de cada um desses trabalhos. Os trabalhos são apresentados em função da ordem em que eles foram realizados, embora vários deles tenham sido realizados paralelamente em determinados momentos. Além disso, alguns trabalhos iniciados antes podem ter sido finalizados, incluindo suas publicações posteriormente.

\subsubsection{Formalização da abordagem PL4BPM}

O Projeto de Doutorado do autor, cuja defesa da tese foi realizada em final de 2007, teve como título "Uma Abordagem Baseada em Características para o Estabelecimento de Contratos Eletrônicos para Serviços Web”. Embora o desenvolvimento do trabalho durante os quatro anos do doutorado tenha sofrido grandes influências da área de LP, não houve naquele momento a intenção de caracterizá-lo formalmente como uma LP para BPM. O objetivo original, dentro do escopo do Projeto de Doutorado, foi principalmente o de usar a técnica de modelos de características, uma técnica amplamente usada em abordagens de LP, para gerenciar variabilidades no processo de estabelecimento de contratos eletrônicos envolvendo serviços web no contexto de BPM. Porém, com a conclusão do doutorado, verificou-se que havia um grande potencial de extensão na abordagem proposta para a que a mesma pudesse ser caracterizada como uma LP para BPM no sentido mais amplo. Assim, iniciou-se formalmente o primeiro trabalho de pesquisa após a conclusão do doutorado, embora tenha se tratado apenas de uma extensão do resultado do doutorado, ou uma adaptação. Apesar disso, essa extensão foi de grande importância para que, baseada nessa formalização, os demais trabalhos realizados a partir deste, conforme apresentados nas próximas subseções, pudessem ser realizados com sucesso.

Essa extensão buscou caracterizar melhor o cenário de BPM em que a abordagem proposta se encaixava, assim como formalizar os princípios e conceitos de LP sendo usados na abordagem. Com isso, a abordagem passou a ser nomeada formalmente de PL4BPM ${ }^{4}$. Esse trabalho demandou a adaptação de alguns modelos e diagramas já concluídos

4 do inglês "Product Line for Business Process Management" 
anteriormente. Essa extensão realizada na abordagem é considerada de grande importância para esta linha de pesquisa do autor, considerando que esta área de pesquisa cresceu consideravelmente nos últimos anos e os termos LP e BPM têm sido constantemente usados na literatura. Além disso, essa extensão permitiu colocar o autor como um dos pioneiros na área de LP para BPM. Uma Revisão Sistemática da Literatura (RSL) conduzida recentemente pelo próprio autor e um colaborador mostrou que de 63 trabalhos publicados nesta área, apenas um usa especificamente os termos PL e BPM antes do primeiro trabalho publicado pelo autor (ROCHA; FANTINATO, 2013).

Os trabalhos de extensão e criação da abordagem PL4BPM duraram aproximadamente dois anos, tendo gerado dois trabalhos. O primeiro, com os resultados preliminares foi publicado nos anais da principal conferência internacional na área de LP, na qualidade de artigo completo (GIMENES; FAntinato; TOLEDo, 2008) ${ }^{5}$. Com base nessa primeira publicação, pesquisadores de renome na área de LP, incluindo um dos criadores da técnica de modelos de características, fizeram um convite para uma submissão de um capítulo para um livro sendo preparado na área de LP, como uma versão estendida do artigo publicado na conferência SPLC 2008. O resultado final da extensão criação da abordagem PL4BPM foi então aceito para publicação neste livro (FANTINATO; GIMENES; TOLEDO, 2010b) ${ }^{6}$

Além dessas duas publicações, também nesse período, como resultado de melhorias no resultado final do Projeto de Doutorado, houve a publicação de um trabalho em um periódico internacional (FANTINATO; TOLEDO; GIMENES, 2008) ${ }^{7}$. Embora as extensões da abordagem para adaptação para o contexto de LP e BPM não tenham sido incorporadas neste artigo, outras melhorias realizadas no período pós-doutorado foram importantes para garantir o aceite do artigo.

$5 \quad[* * *]$ Gimenes, I. M. S.; Fantinato, M.; Toledo, M. B. F. A product line for business process management. In: Proceedings of the 12th International Software Product Line Conference (SPLC), Limerick, Irlanda: IEEE Computer Society, 2008, p. 265-274. (Qualis: A2, Capes-CC-2013)

6 Fantinato, M.; Gimenes, I. M. S.; Toledo, M. B. F. Product line in the business process management domain. In: Kang, K. C.; Sugumaran, V.; Park, S., eds. Applied Software Product Line Engineering, 1st ed, Boca Raton - EUA: Auerbach Publications, p. 497-530, 2010. (Qualis: N/A, Capes-CC-2013)

7 [***] Fantinato, M.; Toledo, M. B. F.; Gimenes, I. M. S. WS-contract establishment with QoS: An approach based on feature modeling. International Journal of Cooperative Information Systems (IJCIS), v. 17, n. 3, p. 373-407, 2008. (Qualis: B1, Capes-CC-2013) 


\subsubsection{Avaliação experimental da abordagem PL4BPM}

A abordagem PL4BPM havia sido avaliada de forma básica até então, por meio do que havia sido chamado um "estudo de caso". Esse estudo de caso, embora tenha contribuído para apresentar um conjunto importante de informações a respeito da abordagem sendo proposta, não foi realizado considerando as melhores práticas de um estudo experimental de acordo com as práticas de metodologia científica. Assim, durante os primeiros anos de atuação como doutor, um dos trabalhos em que o autor esteve envolvido foi a realização de dois experimentos, com um objetivo comum de avaliar mais sistematicamente a abordagem PL4BPM, referida na seção anterior. Esses experimentos foram executados seguindo algumas das diretrizes propostas por pesquisadores especialistas na área conhecida como Engenharia de Software Experimental (WOHLIN et al., 2000; SHULL; CARVER; TRAVASSOS, 2001; ZELKOWITZ; WALLACE; BINKLEY, 2003). Experimentos engenharia de software são realizados buscando definir, demonstrar, avaliar, prever, monitorar e melhorar teorias, processos, produtos e ferramentas de desenvolvimento. A análise experimental em Engenharia de Software é parte de uma importante pesquisa que pode revelar novas perspectivas em áreas tais como melhoria de processos e de produtos (ZELKOWITZ; WALLACE; BINKLEY, 2003).

Considerando as semelhanças existentes entre as áreas de Engenharia de Software e de BPM, os conceitos e técnicas previstas na Engenharia de Software Experimental podem, portanto, ser aplicadas também no contexto de BPM. Apesar na necessidade de realizar experimentos na área de BPM, é difícil encontrar dados experimentais sobre abordagens para LP para BPM já que esta área é considerada recente. Assim, dentro deste contexto, foi realizado um trabalho de pesquisa buscando avaliar sistematicamente de forma experimental a abordagem PL4BPM. Para isso, dois estudos experimentais foram realizados, mais especificamente com o objetivo de investigar os benefícios, a usabilidade e a viabilidade da abordagem PL4BPM, investigação esta que ainda não havia sido realizada. A diferença básica entre os dois estudos é que um focou sua aplicação com participantes da academia, envolvendo alunos da graduação e da pós-graduação, e o outro com participantes da indústria de software. Considerando a diferença dos tipos de participantes, os procedimentos de aplicação foram diferentes para ambos os estudos, embora os resultados buscados fossem os mesmos. O experimento com os alunos foi realizado em um ambiente controlado, incluindo uso da ferramenta de apoio desenvolvida 
para apoio computacional à abordagem; enquanto o experimento com os profissionais foi na base de apresentação resumida da abordagem e entrevistas.

Como resumo dos resultados, eles mostraram fortes evidências de que a abordagem PL4BPM tem vantagens e benefícios sobre abordagens ad-hoc. Essas vantagens incluem: mecanismos que podem economizar tempo e esforço que seria gasto em aprendizagem de sintaxe da linguagem de especificação, no caso de uso de procedimentos ad-hoc. Em relação à avaliação de usabilidade, PL4BPM foi considerada fácil de usar devido a suas etapas bem definidas. Além disso, o uso da técnica de modelos de características ajuda as funções envolvidas para compreender o processo envolvido. Por fim, PL4BPM, em geral, foi considerada uma abordagem viável. Além da avaliação da abordagem PL4BPM em si, os resultados e os conhecimentos adquiridos nesse processo experimental serviram de base para a proposição de um conjunto de atividades de apoio a estudos experimentais no domínio de BPM.

Este trabalho foi realizado no contexto de um projeto de mestrado, realizado no Programa de Pós-graduação em Ciência da Computação da Universidade Estadual de Maringá. Dada a complexidade de uma avaliação experimental dessa natureza, não haveria viabilidade em realizá-la por um aluno de Iniciação Científica e, considerando que no início de sua atuação como pesquisador na EACH-USP ainda não havia programa de pós-graduação, o autor buscou fortalecer suas parcerias para realização de pesquisas de seu interesse. Uma importante colaboração para a realização deste trabalho foi a participação do especialista em Engenharia de Software Experimental, o Prof. Dr. Guilherme Horta Travassos, da UFRJ (TRAVASSOS; GUROV; AMARAL, 2002).

Os resultados deste trabalho geraram duas publicações: a primeira delas, com resultados preliminares e resumidos, publicada em uma conferência latino-americana, na qualidade de artigo completo (GONCALVES et al., 2009) ${ }^{8}$. Posteriormente, com a finalização do trabalho, um artigo completo foi publicado em um periódico internacional (GONCALVES et al., 2011) $)^{9}$.

8 Gonçalves, T. L.; Gimenes, I. M. S.; Fantinato, M.; Travassos, G. H.; Toledo, M. B. F. Estabelecimento de contratos eletrônicos: Uma avaliação com estudos experimentais. In: Proceedings of the 35th Latin American Informatics Conference (CLEI), Pelotas, Brasil: SBC, 2009, p. ST.16.e.01-ST.16.e.10. (Qualis: B4, Capes-CC-2013)

$9 \quad[* * *]$ Gonçalves, T. L.; Gimenes, I. M. S.; Fantinato, M.; Travassos, G. H.; Toledo, M. B. F. Experimental studies of e-contract establishment in the PL4BPM context. International Journal of Web Engineering and Technology (IJWET), v. 6, n. 3, p. 243-265, 2011. (Qualis: B2, Capes-CC-2013) 


\subsubsection{Desenvolvimento da ferramenta FeatureContract para a abor- dagem PL4BPM}

Outro aspecto que ainda não havia sido tratado de forma completamente adequada para a abordagem PL4BPM era em relação ao apoio computacional para sua realização, o que foi então tratado em um novo projeto de pesquisa, no âmbito de um Projeto de Iniciação Científica. O que se tinha anteriormente era o apoio computacional por base de um conjunto de protótipos de ferramentas desenvolvidos diretamente pelo próprio autor durante suas pesquisas iniciais nesta área de LP e BPM. Porém, de modo a oferecer uma maior contribuição para essa área de pesquisa, assim como poder avaliar de forma mais completa a viabilidade computacional da abordagem PL4BPM, uma nova versão da ferramenta foi desenvolvida, sendo que para isso um projeto de pesquisa e aluno de graduação dedicado a esse trabalho foram alocados.

A ferramenta desenvolvida recebeu o nome de FeatureContract, considerando o importante papel direcionador que ambos conceitos - modelos de características ${ }^{10}$ e contratos eletrônicos ${ }^{11}$ - desempenham dentro da abordagem PL4BPM. A ferramenta FeatureContract, com sua tela principal apresenta na Figura 1, foi desenvolvida como um plug-in do ambiente Eclipse. Trata-se de um conjunto integrado de ferramentas, das quais, algumas ferramentas foram incorporadas a partir de outros fornecedores de uso livre com o ambiente Eclipse; outras ferramentas - na forma de componentes, específicas para o contexto da PL4BPM foram desenvolvidas exclusivamente para tornar a FeatureContract completa. As ferramentas existentes incorporadas à FeatureContract são editores e visualizadores de especificações em XML, mais especificamente aquelas relacionados a SOA e BPM, tais como WSDL (Web Service Description Language) e WS-BPEL (Web Service Business Process Execution Language).

A Figura 2 apresenta a arquitetura do ambiente FeatureContract estruturada nos seguintes pacotes: (i) plug-ins necessários - que contém as dependências que o ambiente possui em relação a plugins existentes, ou seja, aqueles relacionados às especificações XML; (ii) ambiente gráfico - que contém os componentes desenvolvidos para atender as principais funções da abordagem PL4BPM; e (iii) artefatos - que contém os principais artefatos gerados pelo ambiente e suas relações com as entidades negociantes. O ambiente gráfico,

10 do inglês "Feature Models"

11 do inglês "Electronic Contracts" ou simplesmente "E-Contracts" 
Figura 1 - Tela principal da ferramenta FeatureContract como plug-in do ambiente Eclipse.

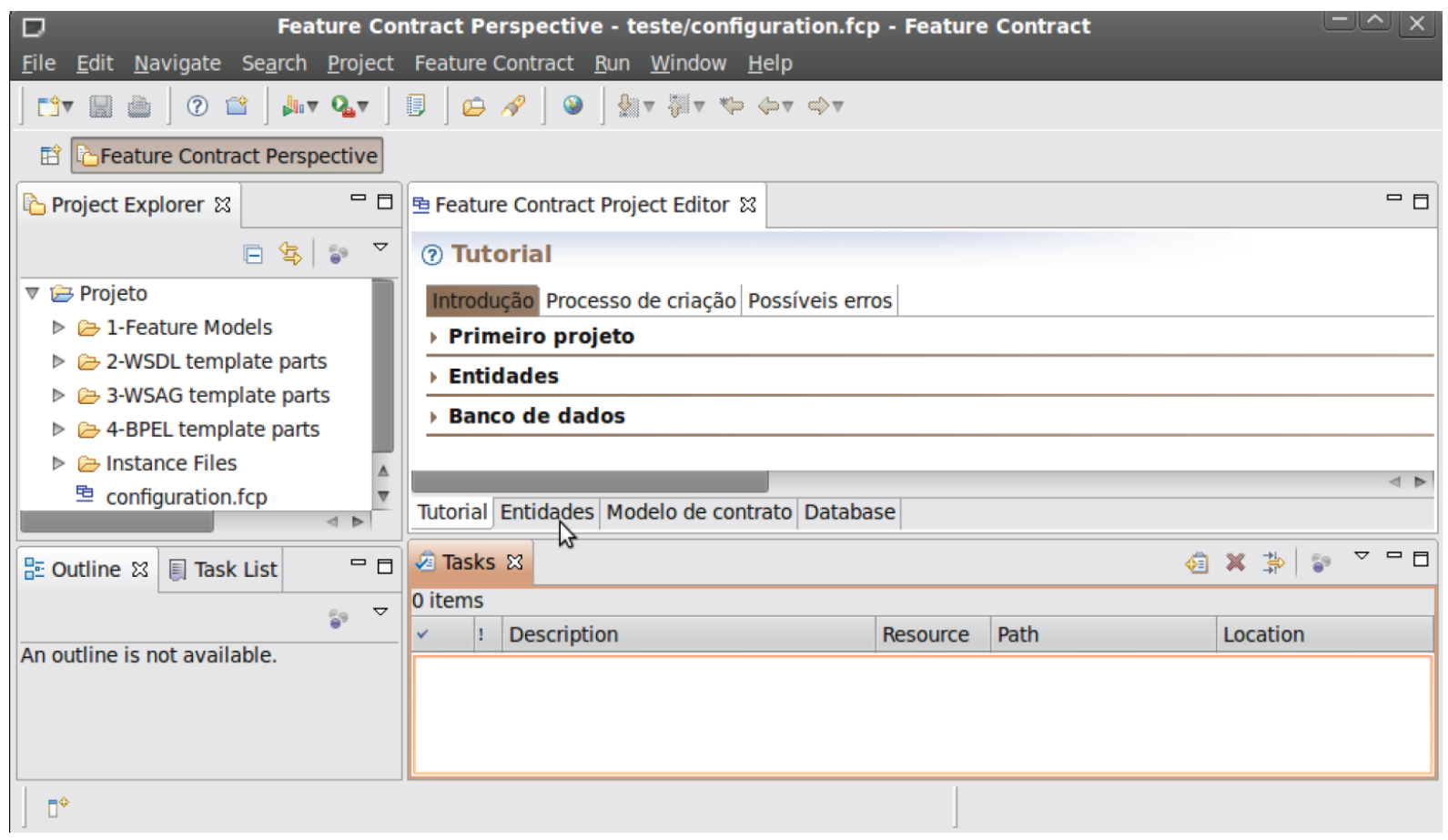

Fonte: (FRAGAL et al., 2011)

por sua vez, aproveita um plug-in existe - chamado Feature plug-in - desenvolvido por (ANTKIEWICZ; CZARNECKI, 2004).

Este trabalho foi realizado no contexto de um Projeto de Iniciação Científica, do curso de Bacharelado em Ciência da Computação da Universidade Estadual de Maringá. Como resultado, foi gerada uma publicação em um periódico nacional especializado em publicar trabalhos decorrentes de projetos relacionados a IC (FRAGAL et al., 2011) ${ }^{12}$. Além da produção desse artigo em si, o principal resultado deste trabalho foi a realização de uma prova de conceito de que a abordagem PL4BPM poderia ser realmente realizada de forma completa por meio de ações apoiadas por ferramentas computacionais. Alguns dos trabalhos realizados conforme descritos nas próximas seções puderem se beneficiar do desenvolvimento desta ferramenta, embora outros ainda não, considerando que muitos trabalhos foram realizados em paralelo.

12 Fragal, V. H.; Fantinato, M.; Gimenes, I. M. S.; Martimiano, L. A. F.; Toledo, M. B. F. O estabelecimento de contratos eletrônicos com o ambiente FeatureContract. Revista Eletrônica de Iniciação Científica (REIC), v. 11, n. 1, p. 1-15, 2011. (Qualis: B5, Capes-CC-2013) 


\subsubsection{Tratamento de preço na abordagem PL4BPM}

Durante o ano de 2009, um trabalho foi realizado no escopo de ações do autor com o objetivo de estabelecer um conjunto de requisitos que deveriam ser atendidos por abordagens relacionadas à negociação e contratação de serviços web, tal como a PL4BPM. Tratam-se de requisitos desejáveis para permitir que tais abordagens forneçam com um apoio automatizado bem sucedido. Os requisitos definidos consideram que todas as informações devem estar disponíveis para ambas as partes envolvidas na negociação, para que elas possam tomar suas decisões e evoluir juntas até chegarem ao estabelecimento de um contrato eletrônico.

Figura 2 - Arquitetura da ferramenta FeatureContract, em Diagrama de Classes da UML.

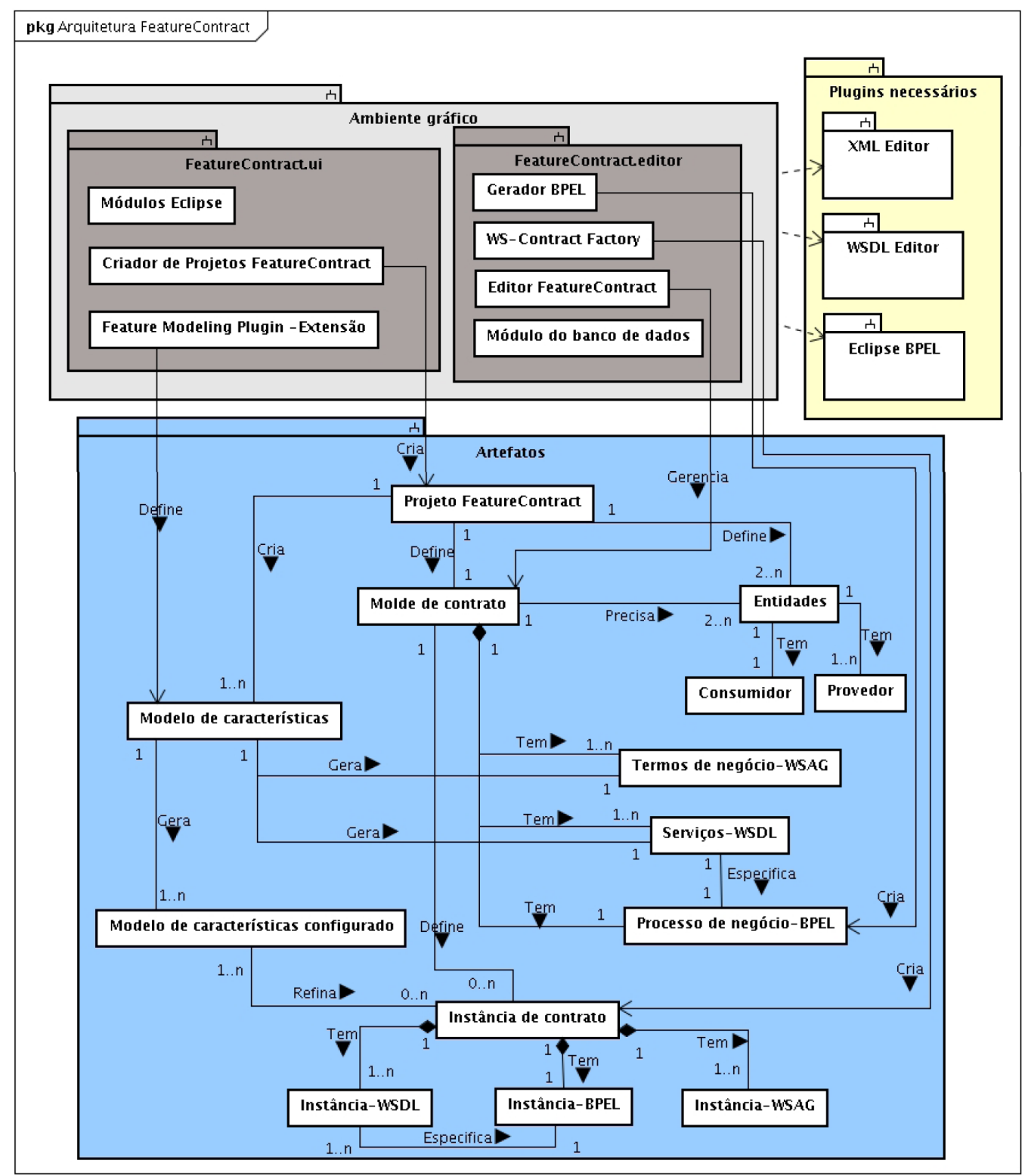

Fonte: (FRAGAL et al., 2011) 
Dentro desse conjunto de requisitos, um aspecto importante a ser considerado são os diferentes preços relacionados à negociação. Embora o preço do serviço web a ser contratato para a composição de um processo de negócio possa ser considerado um fator crucial na negociação e contratação de tais serviços (MATHEW; SHIELDS; VERMA, 2004; O'SULLIVAN; EDMOND; HOFSTEDE, 2005), poucas abordagens considerando preço haviam sido apresentadas na literatura até então. A própria abordagem PL4BPM, tal como proposta originalmente, não fazia nenhuma referência ao tratamento de preço. Após essa constatação, esse estudo evoluiu para a proposta de um tratamento de propriedades de preço na abordagem PL4BPM. De fato, a inclusão do tratamento dessa propriedade adicional na PL4BPM serviu para, além de estendê-la caminhando para sua completude, demonstrar que o framework no qual ela foi estabelecida, amplamente baseada em conceitos de LP, era perfeitamente extensível e adequado ao contexto de BPM.

Os princípios de LP, já usados na abordagem LP4BPM, principalmente relacionados aos dois processos - Engenharia de Domínio e Engenharia de Aplicação - para os quais existe um nível de "template" e um nível de diferentes instâncias, respectivamente, orientados por modelos de características, se mostrou bastante aderente ao tratamento de preços na contratação de serviços web. Os modelos de características foram usados, como resultado final deste trabalho, para representar no nível da Engenharia de Domínio quais são os diferentes preços associados a um mesmo serviço web que poderia ser contrato pela parte interessada, variando em função de outras características do modelo, tais como diferentes níveis de QoS a serem também escolhidos durante a Engenharia de Aplicação.

Um dos resultados em termos de artefatos produzidos por este trabalho está apresentado na Figura 3. A figura se refere ao metamodelo de características usado como base para a abordagem PL4BPM, usado na modelagem de características na Engenharia de Domínio e na configuração das características na Engenharia de Aplicação. As entidades em cinza representam os elementos que foram adicionados ao metamodelo de características originalmente definido para a PL4BPM. Eles foram incluídos após uma análise de trabalhos da literatura relacionados a preços associados a serviços e QoS. O metamodelo resultante buscou diferentes possibilidades de representação de preços, os quais podem estar associados tanto diretamente a um serviço sendo oferecido para contratação quanto a um nível de QoS também sendo oferecido para contratação. Para ambos os tipos, há ainda diferentes formas de pagamento associadas, representadas como características predefinidas e fixas, 
que podem ser escolhidas em tempo de configuração do modelo de características durante a Engenharia de Aplicação.

Figura 3 - Metamodelo de características da PL4BPM estendido com características de preço, em Diagrama de Classes da UML. As entidades em cinza representam os elementos incluídos com a extensão para o tratamento de preço.

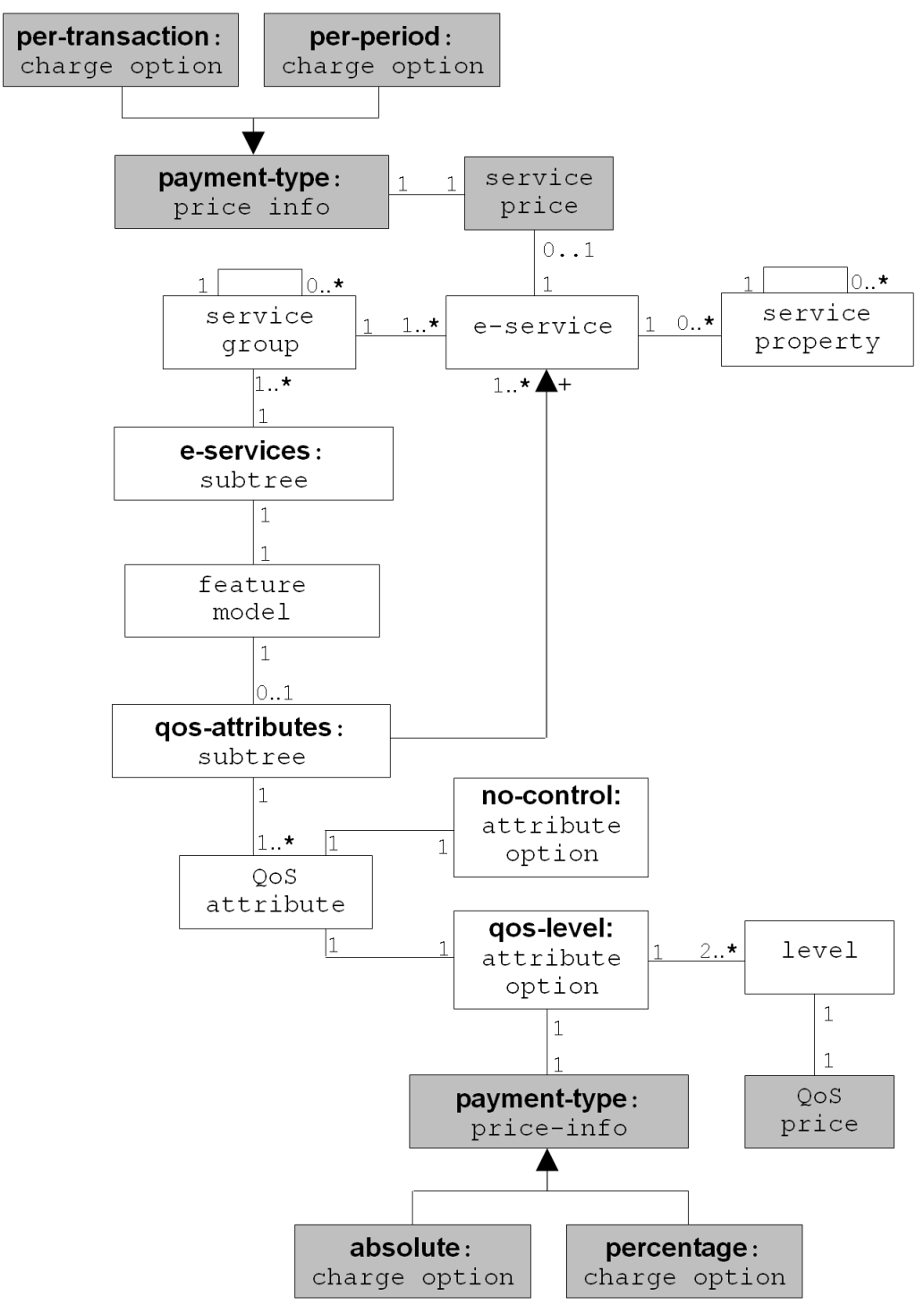

Fonte: (MARCHIONE et al., 2009; MARCHIONE et al., 2010)

Esta pesquisa foi realizada no contexto de um Trabalho de Conclusão de Curso, do curso de Bacharelado em Sistemas de Informação (BSI) da EACH-USP. Como resultado, três publicações foram geradas. A primeira delas, em um workshop brasileiro especializado na área de BPM (MARCHIONE; FANTINATO, 2009) ${ }^{13}$, contendo principalmente os resultados

13 Marchione, F. G.; Fantinato, M. Requisitos e apoio computacional para negociação e contratação de serviços web baseadas em preço. In: Anais do III Workshop de Gestão de Processos de Negócio (WBPM), Fortaleza, Brasil: SBC, 2009, p. 196-201. (Qualis: B5, Capes-CC-2013) 
da primeira fase da investigação, em que os requisitos citados anteriormente haviam sido levantados e confrontados com a abordagem PL4BPM.

As outras duas publicações resultantes deste trabalho, já contendo o resultado final, sendo um deles em uma conferência internacional, na qualidade de artigo completo (MARCHIONE et al., 2009) ${ }^{14}$, em que o artigo foi considerado um dos melhores artigos e, posteriormente, selecionado para ter uma versão estendida submetida para a avaliação para um periódico internacional, que aceitou o artigo submetido para publicação (MARCHIONE et al., 2010) ${ }^{15}$.

\subsubsection{Aplicação da PL4BPM no contexto de desenvolvimento dis- tribuído de software}

A sinergia entre as áreas de Engenharia de Software e BPM continuou sendo explorada em outros trabalhos de pesquisa. Se por um lado, conforme já apresentado anteriormente, a proximidade entre essas duas áreas motivou o uso de conceitos de LP da Engenharia de Software na área de BPM, dando origem à abordagem PL4BPM; por outro lado, o processo de Engenharia de Software em si, em uma dada organização, pode ser também considerado um processo de negócio para ela. Assim, a abordagem PL4BPM resultante pode, por sua vez, ser aplicada de volta no contexto de Engenharia de Software. Considerando essa possibilidade, um trabalho de pesquisa foi realizado para aplicar a abordagem PL4BPM especificamente no contexto de Desenvolvimento Distribuído de Software (DDS) (SENGUPTA; CHANDRA; SINHA, 2006), por envolver necessariamente diferentes organizações em um mesmo processo de negócio e, portanto, ter um melhor aproveitamento das vantagens oferecidas pelas propriedades da PL4BPM em relação ao aspecto interorganizacional amplamente explorado nela. Com o amadurecimento deste trabalho, optou-se por focar especialmente no subprocesso de negociação e renegociação para a contratação das partes envolvidas no DDS.

Este trabalho foi realizado no contexto de um projeto de mestrado, realizado no Programa de Pós-graduação em Ciência da Computação da Universidade Estadual de

14 Marchione, F. G.; Fantinato, M.; Toledo, M. B. F.; Gimenes, I. M. S. Price definition in the establishment of electronic contracts for web services. In: Proceedings of the 11th International Conference on Information Integration and Web-based Applications and Services (iiWAS), Kuala Lumpur, Malásia: ACM Press, 2009, p. 217-224. (Qualis: B3, Capes-CC-2013)

$15{ }^{[* * *]}$ Marchione, F. G.; Fantinato, M.; Toledo, M. B. F.; Gimenes, I. M. S. E-contracting with price configuration for web services and QoS. International Journal of Web and Grid Services (IJWGS), v. 6, n. 4, p. 357-384, 2010. (Qualis: B1, Capes-CC-2013) 
Maringá. Tratou-se de um trabalho evolutivo, que os próprios objetivos foram sendo refinados com sua realização em função dos conceitos sendo explorados. Os resultados parciais e finais deste trabalho geraram três publicações: as duas primeiras, com os primeiros resultados do projeto, focadas exclusivamente no contexto de DDS - uma delas tendo sido publicada em um workshop brasileiro específico da área de DDS (SILVA et al., 2009) ${ }^{16}$ e a outra publicada em uma conferência internacional da área de Engenharia de Software, na qualidade de artigo curto (SILVA et al., 2010) ${ }^{17}$.

Por fim, a terceira publicação, realizada em uma conferência brasileira, na qualidade de artigo completo (SILVA et al., 2012) ${ }^{18}$ apresentou os resultados mais completos do trabalho. Nesses resultados, a abordagem proposta foi apresentada de forma mais genérica, em termos de processo de negociação e renegociação de serviços para contratação eletrônica, com o uso da PL4BPM, tendo o cenário de DDS como uma das possibilidades de aplicação. Como principais artefatos gerados deste trabalho, a Figura 4 apresenta o processo proposto para negociações e a Figura 5 apresenta o metamodelo conceitual para embasar a realização de negociações, em que os conceitos de contratos eletrônicos e modelos de características (advindos da abordagem PL4BPM), e diversos itens específicos de negociação são usados.

\subsubsection{Negociação e renegociação para processos de negócio no con- texto da PL4BPM}

Durante a fase de modelagem do processo de negócio, no ciclo de vida de BPM, o aspecto de negociação deve certamente ser levado em consideração principalmente visto que, normalmente, diferentes partes estão envolvidas nesta atividade, culminando no estabelecimento de um contrato eletrônico. As organizações envolvidas em uma cooperação precisam oferecer garantias explícitas de quais são as opções sendo oferecidas por cada lado e o que será realmente contratado, o que é feito por meio de um processo de negociação eletrônica. Essas garantias podem envolver a renegociação de cláusulas contratuais, a

16 Silva, G. C.; Gimenes, I. M. S.; Fantinato, M.; Toledo, M. B. F. Aplicação de apoio computacional baseado em processos de negócio e serviços web para o DDS. In: Anais do III Workshop de Desenvolvimento Distribuído de Software (WDDS), Fortaleza, Brasil: SBC, 2009, p. 41-50. (Qualis: B5, calculado de acordo com as regras Capes-CC-2013)

17 [***] Silva, G. C.; Gimenes, I. M. S.; Fantinato, M.; Toledo, M. B. F. Negotiating software acquisition supported by web services in a distributed software development process. In: Proceedings of the 22nd International Conference on Software Engineering \& Knowledge Engineering (SEKE), Redwood City, San Francisco Bay, CA, EUA, 2010, p. 221-224. (Qualis: B1, Capes-CC-2013)

18 Silva, G. C.; Gimenes, I. M. S.; Fantinato, M.; Toledo, M. B. F. Towards a process for negotiation of e-contracts involving web services. In: Anais do VIII Simpósio Brasileiro de Sistemas de Informação : Trilhas Técnicas (SBSI), São Paulo, Brasil: SBC, 2012, p. 267-278. (Qualis: B4, Capes-CC-2013) 
aplicação de penalidades ou a intervenção na execução do processo de negócio em questão - todas em tempo de execução de processo, em caso de uma quebra de contrato ser identificada durante monitoramento (HANSON; MILOSEVIC, 2003; RINDERLE; BENYOUCEF, 2005).

Figura 4 - Processo proposto para a negociação entre as partes envolvidas na contratação de serviços eletrônicos a serem usados no processo de desenvolvimento de software, em BPMN.

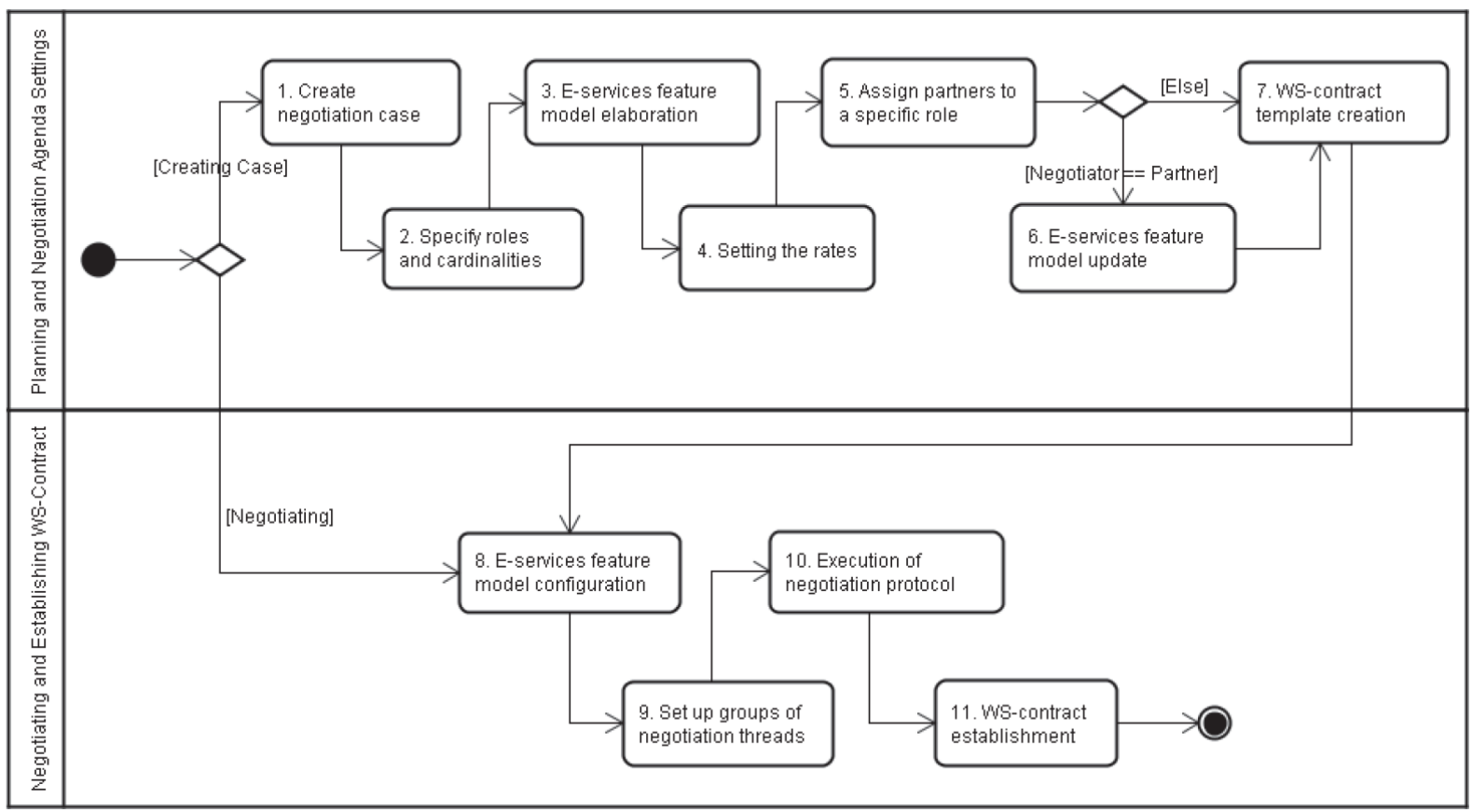

Fonte: (SILVA et al., 2012)

A abordagem PL4BPM, em sua forma original, não oferecia um tratamento adequado das possibilidades de negociação e renegociação dentro desse contexto apresentado. Por outro lado, os conceitos de LP usados, principalmente o uso da técnica de modelos de características, se mostraram plenamente adequados para que a PL4BPM tivesse nela os aspectos de negociação e renegociação incorporados. Considerando que esse contexto de negociação envolve diferentes opções sendo oferecidas pelas partes envolvidas, as quais devem ser escolhidas em tempo de contratação dos serviços, as mesmas poderiam ser representadas também como características via modelos de características, e serem tratadas de forma sistemática por meio da Engenharia de Domínio e da Engenharia de Aplicação da PL4BPM.

Assim, um trabalho de mestrado foi realizado visando propor uma abordagem baseada em modelos de características para estender a PL4BPM para representar também 
Figura 5 - Metamodelo proposto para a negociação entre as partes envolvidas na contratação de serviços eletrônicos a serem usados no processo de desenvolvimento de software, em Diagrama de Classes da UML.

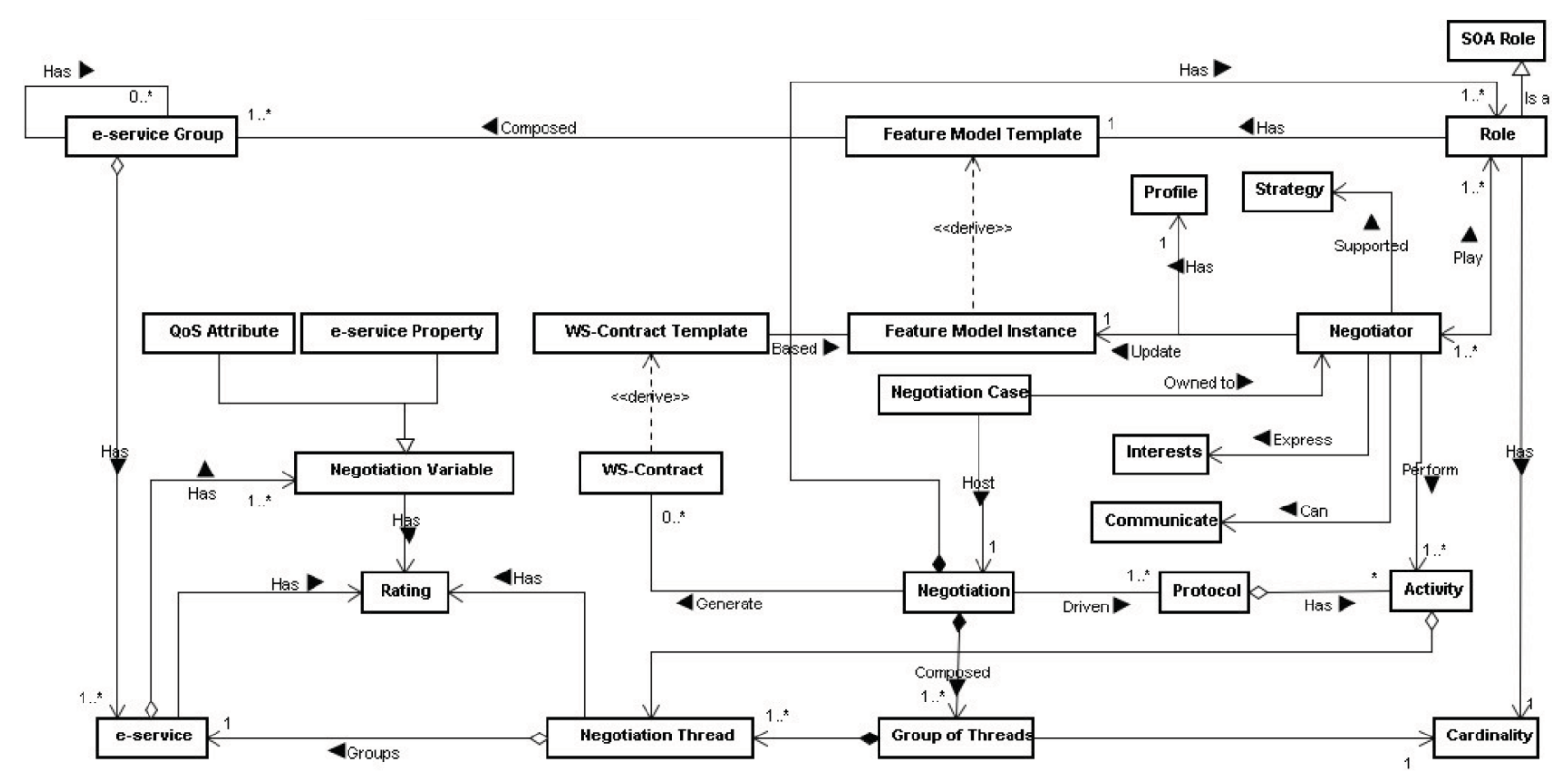

Fonte: (SILVA et al., 2012)

operações de controle a serem disparados caso os níveis contratados para os atributos de QoS não fossem satisfeitos. Esse mecanismo poderia então ser usado durante a negociação envolvendo as partes interessadas. Similarmente ao apresentado na Figura 6, um dos resultados deste projeto se refere à extensão do metamodelo de características usado na abordagem PL4BPM para que o mesmo pudesse considerar também outros tipos de propriedades durante a Engenharia de Domínio e a Engenharia de Aplicação no contexto de BPM, destacados na figura em cinza. Além disso, outro importante artefato gerado como resultado deste projeto de pesquisa está apresentado na Figura 7, que se refere ao mapeamento estabelecido entre os elementos de "operação de controle" do metamodelo de características da PL4BPM e do metamodelo da especificação WS-Agreement (Web Services Agreement Specification) (LUDWIG; DAN; KEARNEY, 2004), usado para especificação dos atributos de QoS nesta abordagem.

O projeto de mestrado foi realizado no Programa de Pós-graduação em Ciência da Computação da Universidade Estadual de Campinas. Três publicações incrementais foram geradas em função dos resultados parciais e finais deste trabalho. A primeira delas, contendo um resumo dos objetivos e resultados iniciais do projeto, em uma conferência internacional, 
na qualidade de artigo curto (VECCHIATO et al., 2010) ${ }^{19}$. A segunda publicação, com resultados finais do proejto, em outra conferência internacional, na qualidade de artigo completo (VECCHIATO et al., 2010) ${ }^{20}$. Essa segunda publicação foi considerada um dos melhores artigos publicados na conferência e, posteriormente, o conjunto de autores foi convidado para submeter uma versão estendida para um periódico internacional, tendo o artigo sido aceito e assim publicado com as informações mais completas da abordagem proposta (VECCHIATO et al., 2011) ${ }^{21}$.

Figura 6 - Metamodelo de características da PL4BPM estendido com características de "operações de controle" úteis à negociação, em Diagrama de Classes da UML. As entidades em cinza representam os elementos incluídos com a extensão para o tratamento de negociação.

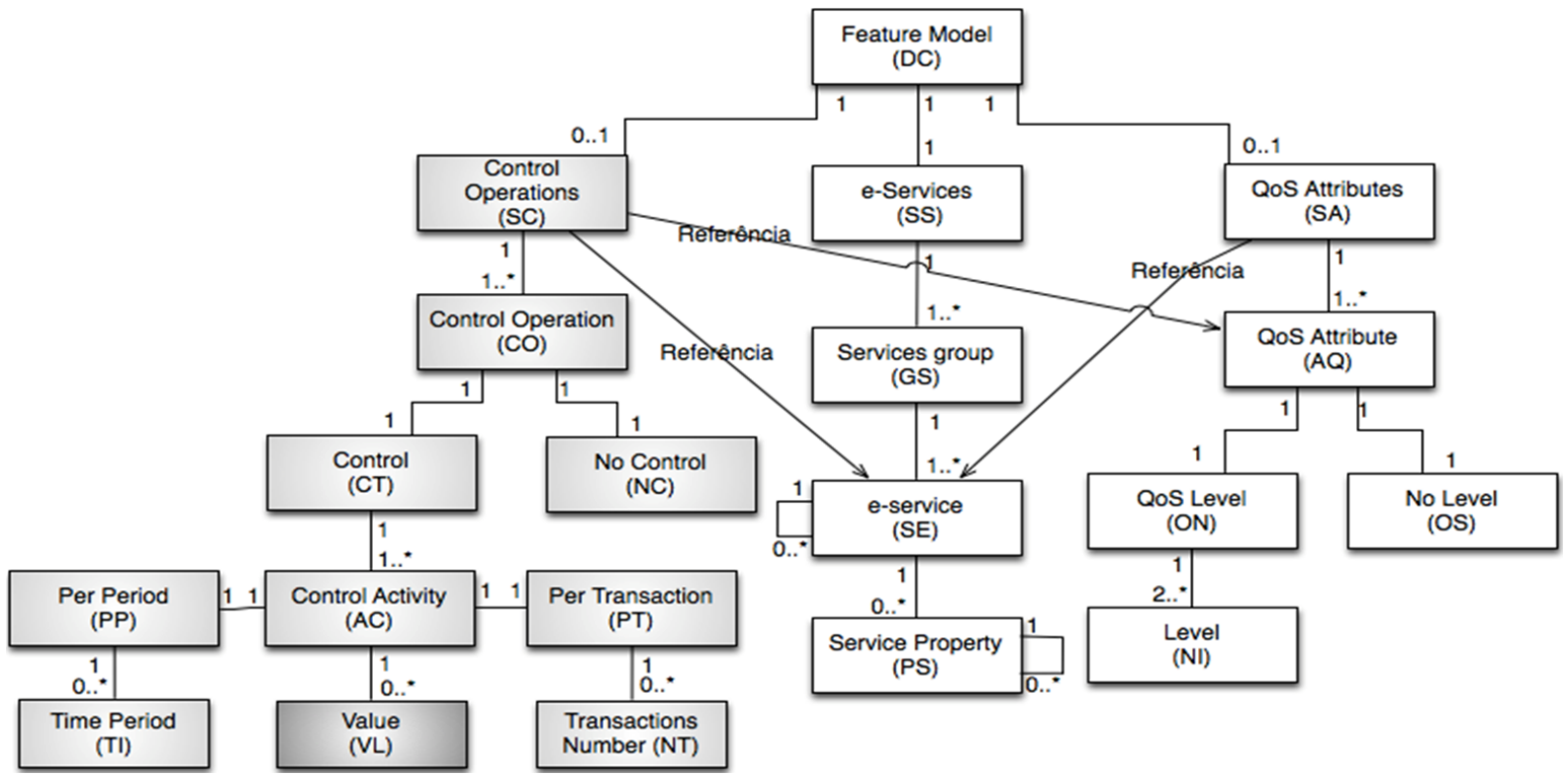

Fonte: (VECCHIATO et al., 2010; VECCHIATO et al., 2011)

19 Vecchiato, D. A.; de Toledo, M. B. F.; Fantinato, M.; de Souza Gimenes, I. M. Electronic contract negotiation and renegotiation using features. In: Proceedings of the 6th International Conference on Web Information Systems and Technologies (WEBIST), Valência, Espanha, 2010, p. 313-318. (Qualis: B3, Capes-CC-2013)

$20{ }^{[* * *]}$ Vecchiato, D. A.; Toledo, M. B. F.; Fantinato, M.; Gimenes, I. M. S. A feature-based toolkit for electronic contract negotiation and renegotiation. In: Proceedings of the IADIS International Conference WWW/Internet 2010 (ICWI), Timissoara, Romênia: IADIS Press, 2010, p. 3-10 (Qualis: B2, Capes-CC-2013)

21 Vecchiato, D. A.; Toledo, M. B. F.; Fantinato, M.; Gimenes, I. M. S. From negotiation to renegotiation using a feature-based BPM infrastructure. IADIS International Journal on WWW/Internet (IJWI), v. 9, n. 2, p. 1-16, 2011. (Qualis: B5, Capes-CC-2013) 
Figura 7 - Mapeamento entre os elementos de "operação de controle" do metamodelo de características da PL4BPM e do metamodelo da especificação WS-Agreement, em Diagrama de Classes da UML.

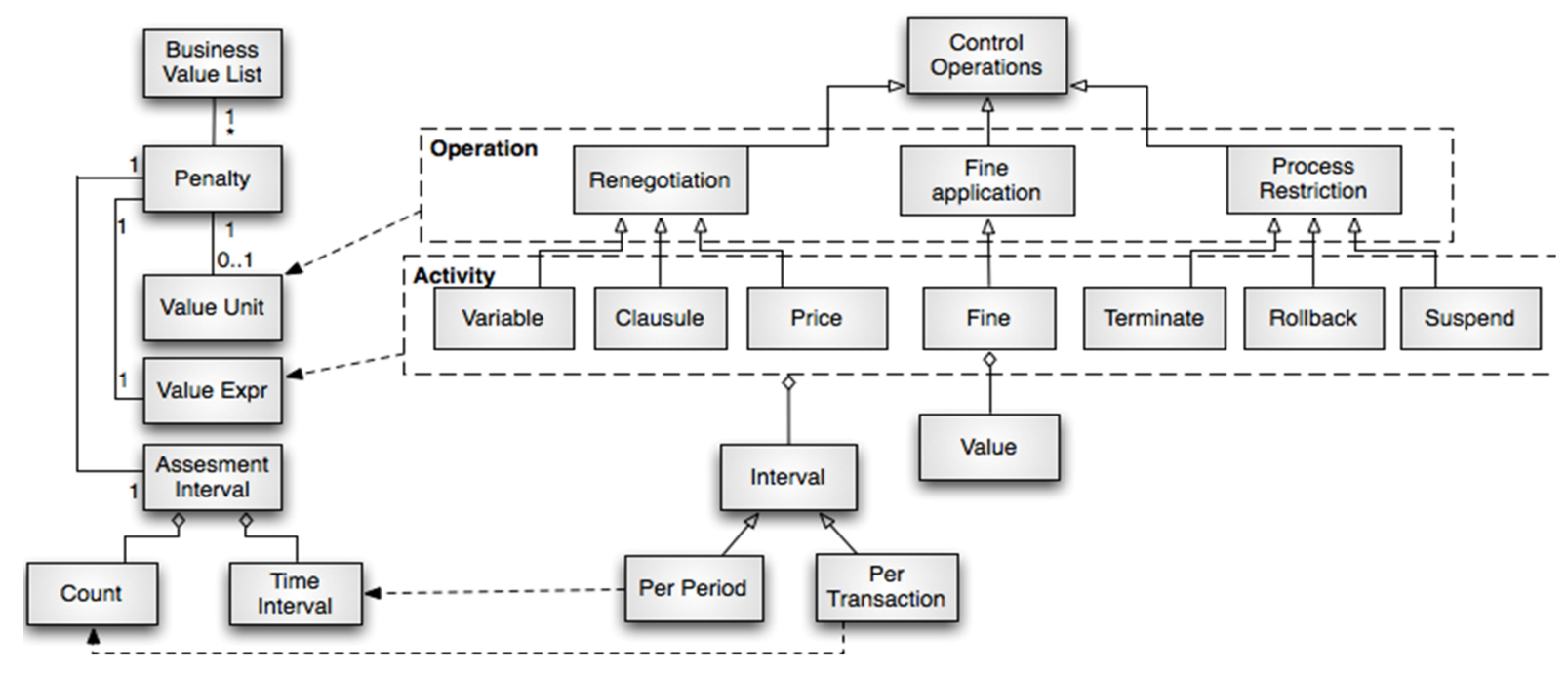

Fonte: (VECCHIATO et al., 2010; VECCHIATO et al., 2011)

\subsubsection{Monitoramento de processos de negócio no contexto da PL4BPM}

Uma das diferenças existentes entre os ciclos de vida de Engenharia de Software e o ciclo de vida de BPM é que, enquanto o primeiro normalmente termina com a implantação do software desenvolvido, o segundo avança depois da implementação do processo de negócio e sua disponibilização para execução. Assim, uma fase necessária a ser considerada pelos analistas e engenheiros de processo de negócio é o monitoramento dos processos de negócio em execução. Uma vez que os processos de negócio entrem em execução - por meio da execução dos serviços eletrônicos quem compõem tais processos, é necessário que haja um monitoramente das cláusulas de QoS contratadas, como resultado da fase de negociação, visando garantir o cumprimento dos termos estabelecidos no contrato eletrônico (LUDWIG; DAN; KEARNEY, 2004; BARESI; GUINEA; PLEBANI, 2005).

Considerando que a abordagem PL4BPM, tal como proposta inicialmente, não apresentava um tratamento adequado para o monitoramento das instâncias de processo de negócio sendo produzidas, houve portanto a realização deste trabalho com o objetivo de estabelecer uma infraestrutura de execução e monitoramente para os processos produzidos a partir da PL4BPM. Este trabalho foi realizado como complemento ao trabalho apresentado na seção 2.1.6. As Figuras 8 e 9 apresentam os principais resultados do trabalho realizado para esse fim. Primeiramente, a Figura 8 apresenta a infraestrutura geral de BPM, 
cobrindo o ciclo de vida de BPM de forma completamente baseada em conceitos de LP. Essa infraestrutura já existia anteriormente, tendo sido estendida, como resultado deste trabalho, com a estrutura "Monitoramento de WS-Contract". Além disso, a Figura 9 apresenta um detalhamento do fluxo de execução do componente WS-Monitor desenvolvido especificamente para a estrutura "Monitoramento de WS-Contract".

Figura 8 - Infraestrutura para BPM baseada em contratos eletrônicos e LP, incluindo a estrutura "Monitoramento de WS-Contract", em Diagrama de Pacotes da UML.

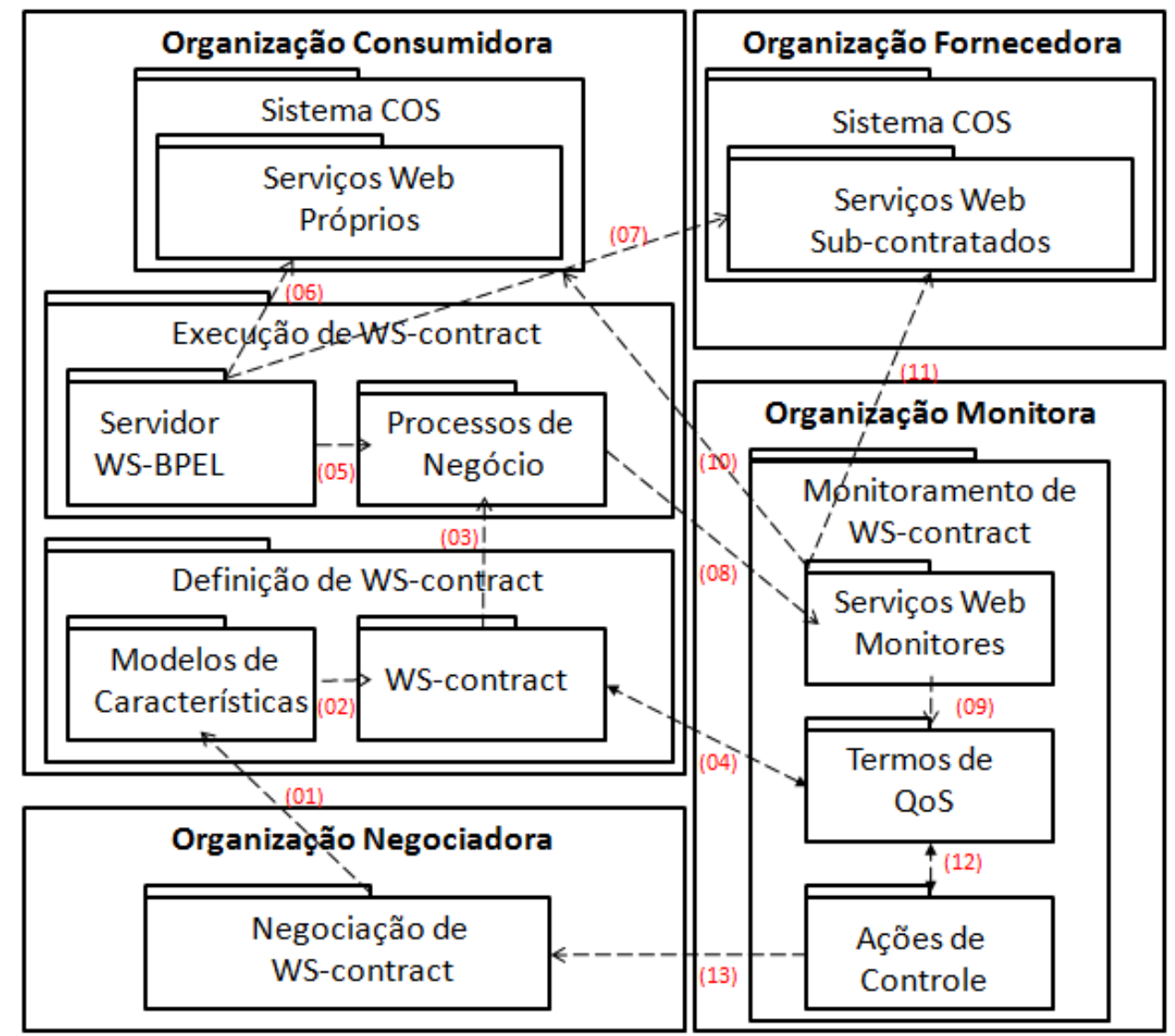

Fonte: (SANTOS et al., 2010)

Este trabalho foi realizado no contexto de um projeto de mestrado, realizado no Programa de Pós-graduação em Ciência da Computação da Universidade Estadual de Campinas. Uma publicação foi gerada em função dos resultados finais deste trabalho, em uma conferência internacional realizada no Brasil, na qualidade de artigo completo (SANTOS et al., 2010) $)^{22}$.

22 Santos, L. L.; Toledo, M. B. F.; Fantinato, M.; Gimenes, I. M. S. E-contract monitoring in an infrastructure for business process management. In: Proceedings of the 7th International Conference on Information Systems and Technology Management (CONTECSI), São Paulo, Brasil: USP, 2010, p. 2816-2836. (Qualis: B4, Capes-CC-2013) 
Figura 9 - Fluxo de execução do componente WS-Monitor desenvolvido para a estrutura "Monitoramento de WS-Contract", em Diagrama de Sequências da UML.

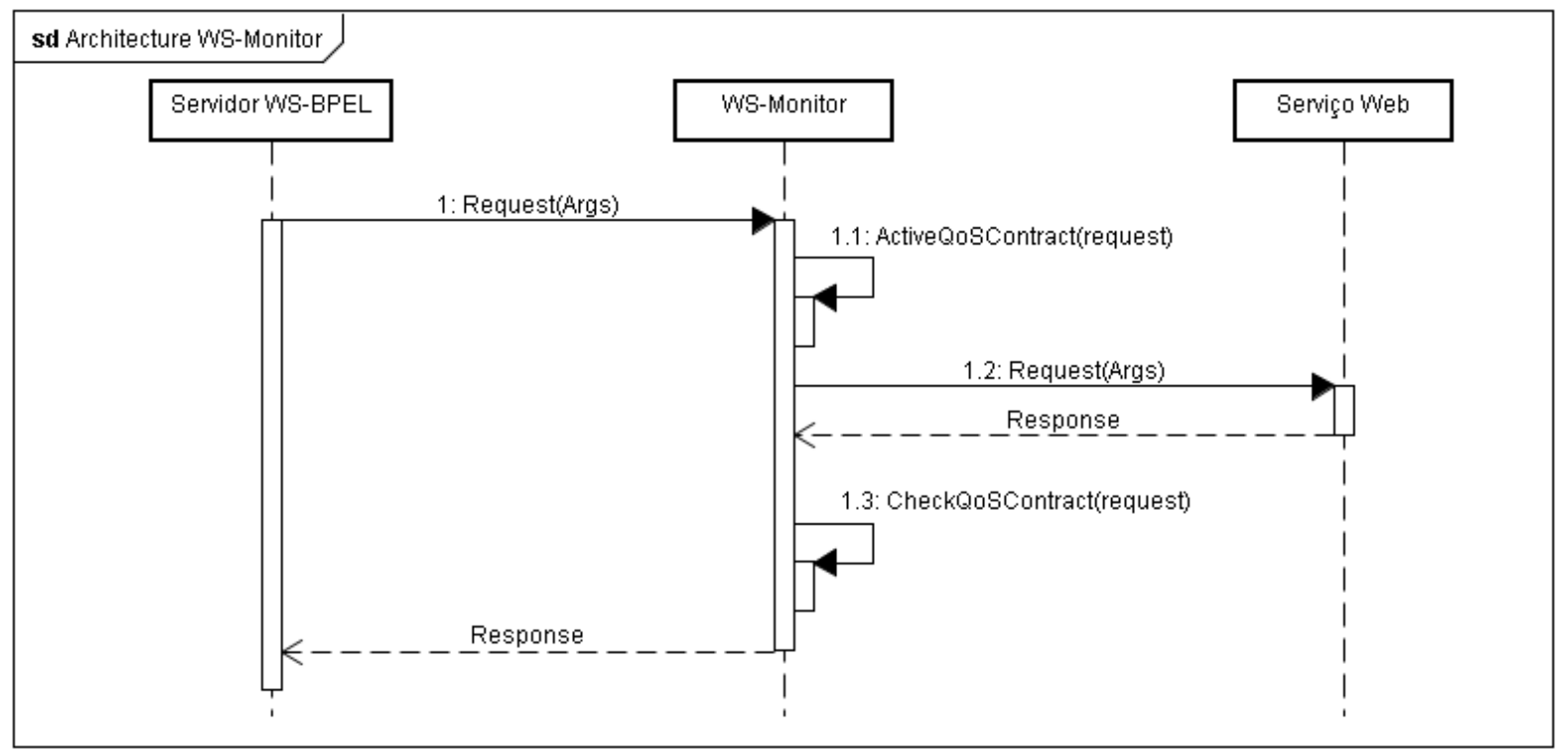

Fonte: (SANTOS et al., 2010)

\subsubsection{Estendendo a abordagem PL4BPM para lidar com alinhamento estratégico}

Uma das extensões mais recentes realizadas na abordagem PL4BPM se refere a inclusão do tratamento de "Acordos em Nível de Negócio" (BLA $\left.{ }^{23}\right)$ em adição ao já realizado tratamento de "Acordos em Nível de Serviços" (SLA ${ }^{24}$ ), que engloba os termos de QoS. O objetivo da incorporação BLAs na abordagem PL4BPM, além dos SLAs (ou seja, QoS), foi o de aumentar a possibilidade de alinhamento estratégico entre as áreas de negócio e a área de TI das organizações que estão trabalhando na gestão automatizada de processos de negócio. Apenas o uso dos conceitos de LP e de contratos eletrônicos, existentes na abordagem PL4BPM, não garante necessariamente esse alinhamento estratégico.

Assim, este trabalho buscou estender a abordagem PL4BPM, de modo a incluir o tratamento de acordos de qualidade em nível de negócio, os quais são usados para alinhar metas e objetivos de uma organização. O objetivo desta extensão foi facilitar que serviços técnicos de responsabilidade de TI não causem impactos negativos durante a realização dos processos de negócio necessários para as áreas de negócio das organizações.

23 do inglês "Business Level Agreement"
24 do inglês "Service Level Agreement" 
Assim como em outros trabalhos derivados da PL4BPM, o uso da técnica de modelos de características exerceu papel fundamental na incorporação das propriedades de BLA, tal como desejado pelo autor. Este trabalho, assim como outros similares realizados pelo autor, e já apresentados nesta seção, mostram o poder de extensão da abordagem PL4BPM, visto que o framework desenvolvido, em função de conceitos de LP e de contratos eletrônicos se mostrou amplamente expansível para a incorporação de outros conceitos adicionais necessários ou desejáveis.

Um BLA pode ser mapeado para um conjunto de SLAs e reflete as relações de negócio entre as organizações envolvidas. Em uma definição bastante ampla, BLA pode ser entendido como um acordo realizado no nível de negócio que define a forma como os parceiros devem negociar qualquer tipo de serviço eletrônico a ser fornecido ou usado entre eles (GRGIC; ROHNE, 2001). Enquanto SLA é um acordo para formalizar serviços a serem contratados e os índices que precisam ser atingidos para o cumprimento do conjunto de compromissos acordados (STURM; MORRIS, 2000), BLA é um acordo que estabelece padrões de qualidade para processos de negócio (PULIER; TAYLOE, 2008). Caso uma métrica de BLA deixe de ser cumprida, afetará diretamente o desempenho dos resultados da organização. Poucos trabalhos são encontrados que definam bem os objetivos e a estrutura esperada para representação e armazenamento do BLA. As organizações necessitam criar parcerias de negócio, estejam posicionadas como clientes ou fornecedores, precisando de um modelo de BLA como complemento ao SLA para garantir que os objetivos de negócio sejam atingidos (ALLEN, 2006).

Como principais resultados deste trabalho, alguns artefatos foram produzidos. Aqui é apresentado, na Figura 10, o processo resultante proposto para incorporação do tratamento de BLAs na abordagem PL4BPM.

O processo da abordagem PL4BPM, tal como originalmente proposto, é composto por cinco estágios, sendo que o segundo estágio é dividido em quatro tarefas. Com o novo processo sendo proposto, esse segundo estágio passa a ter duas novas tarefas, representada na figura pelas tarefas "2.e" e "2.f. Para a execução dessas duas tarefas adicionais, alguns artefatos de apoio da PL4BPM foram estendidos ou adicionados, tal como o apresentado na Figura 11, que define um metamodelo de características específico para a representação das regras estruturas do processo de negócio sendo definido para que os atributos e níveis de qualidade associados aos BLAs possam ser amarrados aos elementos do processo. 
Figura 10 - Processo da abordagem PL4BPM estendido com tratamento de BLA, em Diagrama de Atividades da UML.

\begin{tabular}{|c|c|c|c|c|c|c|}
\hline Feature Plugin & XML Transformer & WSDL Editor & XML Editor & Business Process Editor & Ws-Contract Factory & (Ferramentas de SW) \\
\hline 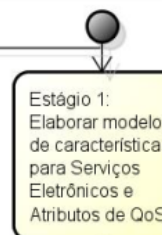 & & & & & & \\
\hline & 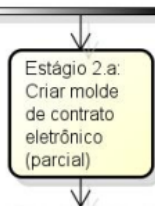 & & & & & \multirow{5}{*}{ 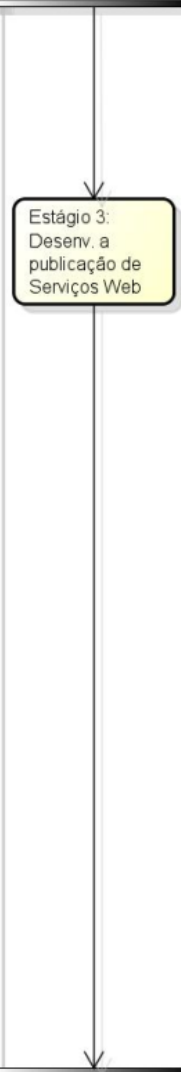 } \\
\hline & & 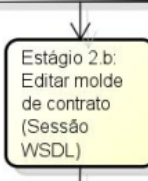 & 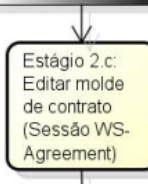 & $\begin{aligned} \frac{}{\text { Estágio 2d }} \\
\text { Editar molde } \\
\text { de contrato } \\
\text { (Sessáo WS. } \\
\text { BPEL) }\end{aligned}$ & & \\
\hline 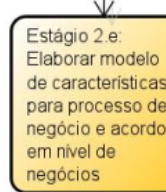 & & & & & & \\
\hline \multirow{4}{*}{ 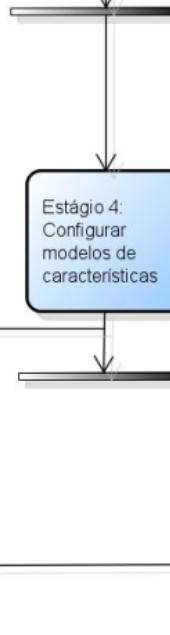 } & 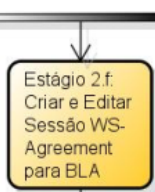 & & & & & \\
\hline & & & & & & \\
\hline & & & & & \begin{tabular}{|l}
$\downarrow$ \\
$\qquad \begin{array}{l}\text { Estágio } 5 \\
\text { Criar } \\
\text { instância de } \\
\text { contrato }\end{array}$
\end{tabular} & \\
\hline & & & & & (อ) & \\
\hline
\end{tabular}

Fonte: (SILVA; FANTINATO; SALLES, 2012; FANTINATO; SILVA; SALLES, 2012)

Esta pesquisa foi realizada no contexto de um Trabalho de Conclusão de Curso, do curso de BSI da EACH-USP. Como resultado, duas publicações foram geradas. A primeira delas, em uma conferência brasileira, na qualidade de artigo completo (SILVA; FAntinAtO; SALLES, 2012)25. Esse artigo foi escolhido como o "Melhor Artigo" da Trilha 25 Silva, L. F.; Fantinato, M.; Salles, G. B. M. Apoiando alinhamento estratégico em organizações usando contratos eletrônicos estendidos com BLA. In: Anais do VIII Simpósio Brasileiro de Sistemas 
de Artigos Técnicos do evento, tendo sido convidado posteriormente para a submissão de uma versão estendida que foi avaliada e aceita para a publicação em um periódico nacional (FANTINATO; SILVA; SALLES, 2012) ${ }^{26}$.

Figura 11 - Metamodelo de características para definição de processo de negócio e BLAs associados, em Diagrama de Classes da UML.

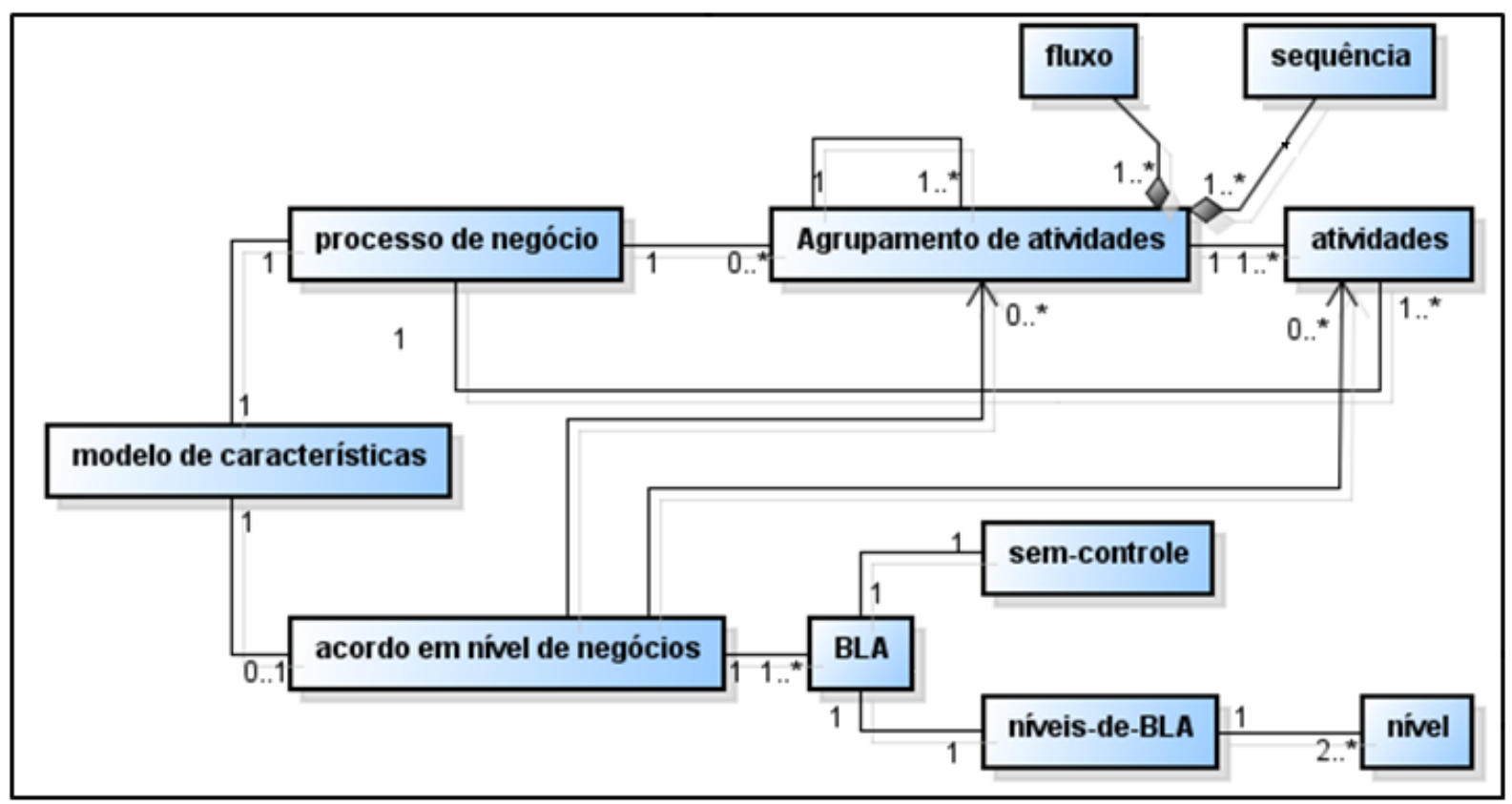

Fonte: (SILVA; FANTINATO; SALLES, 2012; FANTINATO; SILVA; SALLES, 2012)

\subsubsection{LP dinâmica para BPM - DynPL4BPM}

Dentro desta linha de pesquisa, o trabalho mais relevante realizado até este momento é a proposta de uma abordagem de LP Dinâmica (LPD) para BPM - chamada de DynPL4BPM ${ }^{27}$, como uma evolução da PL4BPM. Este trabalho se iniciou no contexto de um projeto de mestrado do então recém-criado Programa de Pós-graduação em Sistemas de Informação (PPgSI) da EACH-USP, no final de ano de 2010, sendo também o principal objetivo de um Projeto de Pesquisa financiado pela Fapesp dentro de seu programa Jovem Pesquisador, com duração de 2009 a 2013.

de Informação : Trilhas Técnicas (SBSI), São Paulo, Brasil: SBC, 2012, p. 348-359. (Qualis: B4, Capes-CC-2013)

26 Fantinato, M.; Silva, L. F.; Salles, G. B. M. Contratos eletrônicos estendidos com acordos em nível de negócio visando apoiar o alinhamento estratégico entre negócio e TI. Revista Eletrônica de Sistemas de Informação (RESI), v. 11, n. 2, p. 2.01-2.21, 2012. (Qualis: B4, Capes-CC-2013)

27 do inglês "Dynamic Product Line for Business Process Management" 
Embora os conceitos de LP aplicados ao domínio de BPM já tivessem apresentados resultados significativos para esta área de pesquisa de uma forma geral, incluindo a abordagem PL4BPM desenvolvida por este autor, o escopo de aplicação e os benefícios ainda eram considerados limitados. Essas limitações eram creditadas ao fato de que as abordagens de LP existentes para BPM normalmente não cobrirem realmente todo o ciclo de vida de BPM e não oferecerem o devido tratamento aos aspectos dinâmicos que as organizações demandam para esse domínio. Durante os trabalhos de investigação, LPD foi identificada como uma evolução das LPs tradicionais com a diferença de proporcionar uma forma eficiente para lidar com adaptações de produtos em tempo de execução. LPDs podem ser aplicadas, por exemplo, em arquiteturas SOA, que por sua vez podem ser usadas como base tecnológica para viabilizar BPM nas organizações.

Dentro desse contexto, este trabalho propôs uma abordagem de LPD para atender as necessidades de organizações interessadas em realizar processos de negócio, por meio de um alinhamento entre conceitos de BPM e SOA. A abordagem proposta - DynPL4BPM teve o objetivo de ser abrangente o suficiente para cobrir todo o ciclo de vida de BPM, sendo previsto o tratamento de aspectos dinâmicos que o domínio de BPM requer. Uma avaliação sistemática e comparativa demonstrou que a abordagem proposta é bem sucedida em apresentar processos de LP bem mais abrangentes que outras soluções similares já propostas na literatura para o mesmo fim.

Este trabalho se dividiu em algumas etapas. Primeiramente, houve a definição de uma abordagem de LP para BPM, em termos de três macroprocessos, em alto nível, que contemplasse todo o ciclo de vida de BPM, considerando que as atuais abordagens de LP para BPM contemplam apenas parte do ciclo de vida de BPM. Essa abordagem de LP para BPM deve ser ampla e genérica o suficiente, como um framework, para permitir que aspectos dinâmicos fossem posteriormente incorporados nela. A Figura 12 apresenta o artefato resultado dessa etapa. Ele mostra os três processos propostos para a nova LP para BPM, considerando todas fases do ciclo de vida de BPM (destacados com as cores "vermelho", "verde", "amarelo" e "azul" - incluindo os tons claros e escuros). Para isso, os três processos tradicionalmente existentes em LPs foram incluídos: Engenharia de Domínio, Engenharia de Aplicação e Gestão da LP. Os processos propostos fazem, portanto, as devidas correlações entre os processos de LP e as fases do ciclo de vida de LP, além de sistematizar o caminho em que os artefatos gerados realizam por esses processos. 
Figura 12 - Processos de LP para BPM proposto para a abordagem DynPL4BPM, em notação livre.

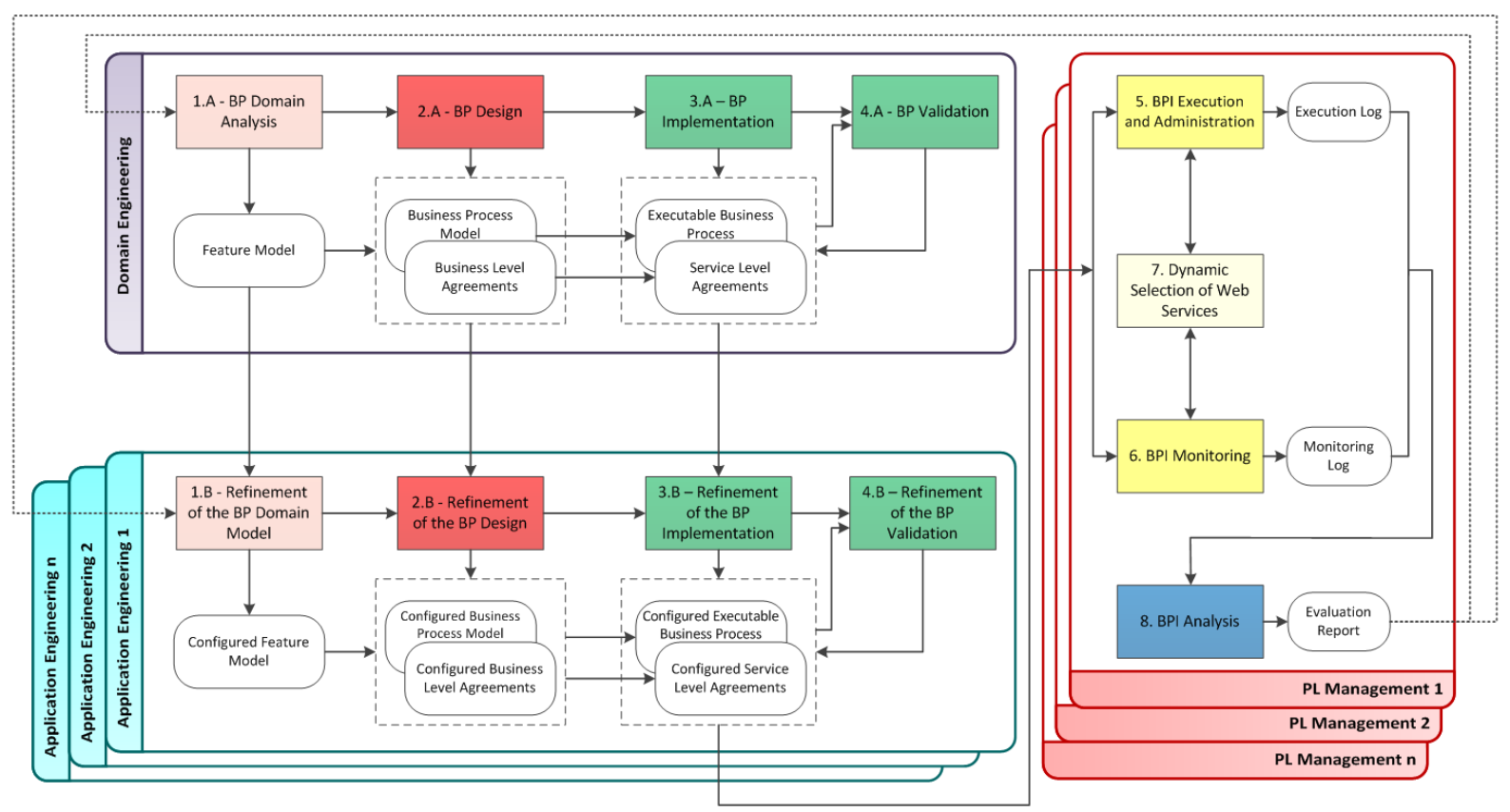

Fonte: (ROCHA, 2012)

Após a definição dos processos para a nova LP para BPM, tornando-se agora completa, houve o avanço para o tratamento dos aspectos dinâmicos propriamente ditos. Para isso, as nove propriedades de LPD conforme definidas por Hallsteinsen et al. (2008) foram consideradas. Tendo essas propriedades como alvo, buscou-se identificar técnicas existentes que realizavam tratamento de aspectos dinâmicos em diferentes fases do ciclo de vida de BPM considerando principalmente a base tecnológica do paradigma SOA, tais como: seleção dinâmica dos serviços web; composição dinâmica de processos de negócio; e monitoramento dinâmico da execução do processo, considerando os níveis contratados para os atributos de QoS. Baseadas nas técnicas encontradas, após estudo detalhado, foi proposto o uso conjunto e sistemático de um conjunto delas de forma associada aos processos apresentados na Figura 12.

A abordagem resultante DynPL4BPM, proposta no escopo deste trabalho, foi avaliada sistematicamente a partir de um procedimento de classificação criado por meio de uma série de atributos específicos, que possibilitaram sua categorização e comparação com trabalhos relacionados que foram selecionados por meio de uma Revisão Sistemática da Literatura (RSL). Essa RSL buscou encontrar todos os trabalhos já publicados com o 
objetivo de propor LPs de para BPM, tendo localizado e analisado 63 estudos primários. Desses estudos primários, apenas 15 trabalhos foram identificados como tratando aspectos dinâmicos. Além disso, confirmou-se que as LPs resolvem apenas parcialmente o ciclo de vida BPM, verificando que a última fase do processo de negócio não é uma preocupação atual das abordagens encontradas. O quadro apresentado na Figura 13 apresenta um resumo dos resultados da comparação sistemática realizada, em que a DynPL4BPM é a única que - em relação aos 15 estudos mais bem classificados dos 63 identificados - cobre as quatro fases do ciclo de vida de BPM (B1, B2, B3, B4), os cinco conceitos principais de LP (P1, P2, P3, P4, P5), e a maioria das propriedades de LPD (D1, D2, D3, D4, D5, D7, D8).

Figura 13 - Comparação sistemática entre a abordagem DynPL4BPM e 15 outras abordagens similares.

\begin{tabular}{|c|c|c|c|c|c|c|c|c|c|c|c|c|c|c|c|c|c|}
\hline \multirow[t]{2}{*}{ Related works } & \multicolumn{4}{|c|}{ BPM Lifecycle } & \multicolumn{5}{|c|}{ PL Concepts } & \multicolumn{8}{|c|}{ DPL Properties } \\
\hline & B1 & B2 & B3 & B4 & P1 & $\mathrm{P} 2$ & P3 & P4 & P5 & D1 & D2 & D3 & D4 & D5 D6 & D7 & D8 & D9 \\
\hline Work - 01 & $\mathrm{x}$ & $\mathrm{x}$ & $\mathrm{x}$ & & & & $\mathrm{x}$ & $\mathrm{x}$ & $\mathrm{x}$ & $\mathrm{x}$ & & $\mathrm{x}$ & & & & & \\
\hline Work - 02 & $\mathrm{x}$ & $\mathrm{x}$ & & & $\mathrm{x}$ & $\mathrm{x}$ & $\mathrm{x}$ & $\mathrm{x}$ & $\mathrm{x}$ & & & & $\mathrm{x}$ & & $\mathrm{x}$ & $\mathrm{x}$ & \\
\hline Work - 03 & $\mathrm{x}$ & & & & & & $\mathrm{x}$ & & & & & & $\mathrm{x}$ & $\mathrm{x}$ & $\mathrm{x}$ & $\mathrm{x}$ & $\mathrm{x}$ \\
\hline Work - 04 & $\mathrm{x}$ & $\mathrm{x}$ & & & & & $\mathrm{x}$ & $\mathrm{x}$ & $\mathrm{x}$ & $\mathrm{x}$ & & & & & & & \\
\hline Work - 05 & $\mathrm{x}$ & $\mathrm{x}$ & & & & & $\mathrm{x}$ & $\mathrm{x}$ & $\mathrm{x}$ & $\mathrm{x}$ & & & & & & & \\
\hline Work - 06 & $\mathrm{x}$ & $\mathrm{x}$ & $\mathrm{x}$ & & $\mathrm{x}$ & $\mathrm{x}$ & & $\mathrm{x}$ & $\mathrm{x}$ & $\mathrm{x}$ & & & & & & & \\
\hline Work - 07 & $\mathrm{x}$ & $\mathrm{x}$ & & & $\mathrm{x}$ & $\mathrm{x}$ & $\mathrm{x}$ & $\mathrm{x}$ & & & & & $\mathrm{x}$ & & & $\mathrm{x}$ & \\
\hline Work - 08 & $\mathrm{x}$ & & & & $\mathrm{x}$ & $\mathrm{x}$ & & $\mathrm{x}$ & & $\mathrm{x}$ & $\mathrm{x}$ & $\mathrm{x}$ & $\mathrm{x}$ & & & & \\
\hline Work - 09 & $\mathrm{x}$ & & & & & & & $\mathrm{x}$ & $\mathrm{x}$ & $\mathrm{x}$ & & $\mathrm{x}$ & & & & & \\
\hline Work -10 & $\mathrm{x}$ & $\mathrm{x}$ & & & $\mathrm{x}$ & $\mathrm{x}$ & $\mathrm{x}$ & $\mathrm{x}$ & $\mathrm{x}$ & $\mathrm{x}$ & & $\mathrm{x}$ & & & & & \\
\hline Work - 11 & $\mathrm{x}$ & $\mathrm{x}$ & $\mathrm{x}$ & & & & & $\mathrm{x}$ & $\mathrm{x}$ & $\mathrm{x}$ & & $\mathrm{x}$ & & & & & \\
\hline Work - 12 & $\mathrm{x}$ & & & & & & & $\mathrm{x}$ & & $\mathrm{x}$ & & $\mathrm{x}$ & & & & & \\
\hline Work -13 & $\mathrm{x}$ & $\mathrm{x}$ & $\mathrm{x}$ & & $\mathrm{x}$ & $\mathrm{x}$ & $\mathrm{x}$ & $\mathrm{x}$ & $\mathrm{x}$ & $\mathrm{x}$ & & & & & & & \\
\hline Work - 14 & $\mathrm{x}$ & & & & & & $\mathrm{x}$ & $\mathrm{x}$ & & $\mathrm{x}$ & & $\mathrm{x}$ & & & & & \\
\hline Work -15 & $\mathrm{x}$ & $\mathrm{x}$ & & & & & & $\mathrm{x}$ & $\mathrm{x}$ & $\mathrm{x}$ & & & & & & & \\
\hline DynPL4BPM & $\mathbf{x}$ & $\mathbf{x}$ & $\mathbf{x}$ & $\mathbf{x}$ & $\mathbf{x}$ & $\mathbf{x}$ & $\mathbf{x}$ & $\mathbf{x}$ & $\mathbf{x}$ & $\mathbf{x}$ & $\mathbf{x}$ & $\mathbf{x}$ & $\mathbf{x}$ & $\mathbf{x}$ & $\mathbf{x}$ & $\mathbf{x}$ & \\
\hline
\end{tabular}

Fonte: (ROCHA; FANTINATO, 2013)

Três publicações foram geradas até este momento exclusivamente como resultados deste trabalho. Duas dessas publicações são relativas a RSLs, sendo a primeira delas um revisão realizada no contexto de LP e SOA, que serviu de base inicial para a identificação de técnicas de tratamento dinâmico em relação a SOA para o contexto deste trabalho, e que foi publicada em uma conferência brasileira, na qualidade de artigo completo (ROCHA; 
FANTINATO; BARROS, 2012) ${ }^{28}$. A segunda RSL se refere ao estudo mencionado anteriormente, especificamente a LP para BPM, buscando tratamento de aspectos dinâmicos neste contexto. Essa segunda RSL foi publicada em um periódico internacional (ROCHA; FAnTINATO, 2013 ${ }^{29}$. Por fim, formalmente o projeto de mestrado referido neste trabalho se encerrou, e com a defesa do projeto associado, foi gerada a publicação de uma dissertação de mestrado associada a EACH-USP (ROCHA, 2012) ${ }^{30}$.

\subsection{Contratos eletrônicos para gestão de processos de negócio}

Contratos eletrônicos são uma entidade importante no contexto de BPM e SOA. Eles podem ser usados para agregar sistematicamente as informações necessárias para que um processo de negócio seja realizado, por meio de serviços eletrônicos - que podem eventualmente ser serviços web, de forma cooperativa entre departamentos ou organizações (KRISHNA; KARLAPALEM, 2008). Contratos eletrônicos costumar ser tratados por organizações mesmo que de forma informal, já que o tratamento conjunto de uma série de diferentes especificações no contexto de BPM e SOA já podem ser considerados um contrato eletrônico.

As informações que devem ser tratadas por contratos eletrônicos costumam ser estabelecidas por meio de metamodelos, que ajudam a estabelecer de forma clara quais são os elementos que devem fazer parte de um processo de negociação e execução de processo de negócio interorganizacional. Essas informações normalmente incluem, conforme representadas na Figura 14: (i) as partes envolvidas, tais como consumidores, fornecedores e, possivelmente, monitores externos; (ii) o processo de negócio a ser executado pelas partes envolvidas, representado na forma de uma sequência de atividades que é finalmente traduzido como uma composição de serviços eletrônicos; e (iii) as cláusulas contratuais que representam quaisquer tipos de restrições sobre a execução do processo de negócio e, consequentemente, sobre os serviços compostos, na forma de obrigações, direitos ou

28 Rocha, R. S.; Fantinato, M.; Barros, V. A. Contribuições de linha de produto e orientação a serviços no desenvolvimento de sistemas de informação. In: Anais do VIII Simpósio Brasileiro de Sistemas de Informação : Trilhas Técnicas (SBSI), São Paulo, Brasil: SBC, 2012, p. 91-102. (Qualis: B4, Capes-CC-2013)

$\left.29{ }^{* * *}\right]$ Rocha, R. S.; Fantinato, M. The use of software product lines for business process management: A systematic literature review. Information and Software Technology (INFSOF), v. 55, n. 8, p. 1355-1373, 2013. (Qualis: A2, Capes-CC-2013)

30 Rocha, R. S. Linha de produto para gestão de processos de negócio incluindo aspectos dinâmicos. Dissertação de mestrado, Escola de Artes, Ciências e Humanidades, Universidade de São Paulo (EACH-USP), São Paulo, Brasil, 2012. 
proibições. As cláusulas contratuais podem ser definidas por meio de atributos de QoS, usados para especificar níveis aceitáveis para propriedades não-funcionais.

Figura 14 - Metamodelo genérico de contratos eletrônicos, em Diagrama de Classes da UML.

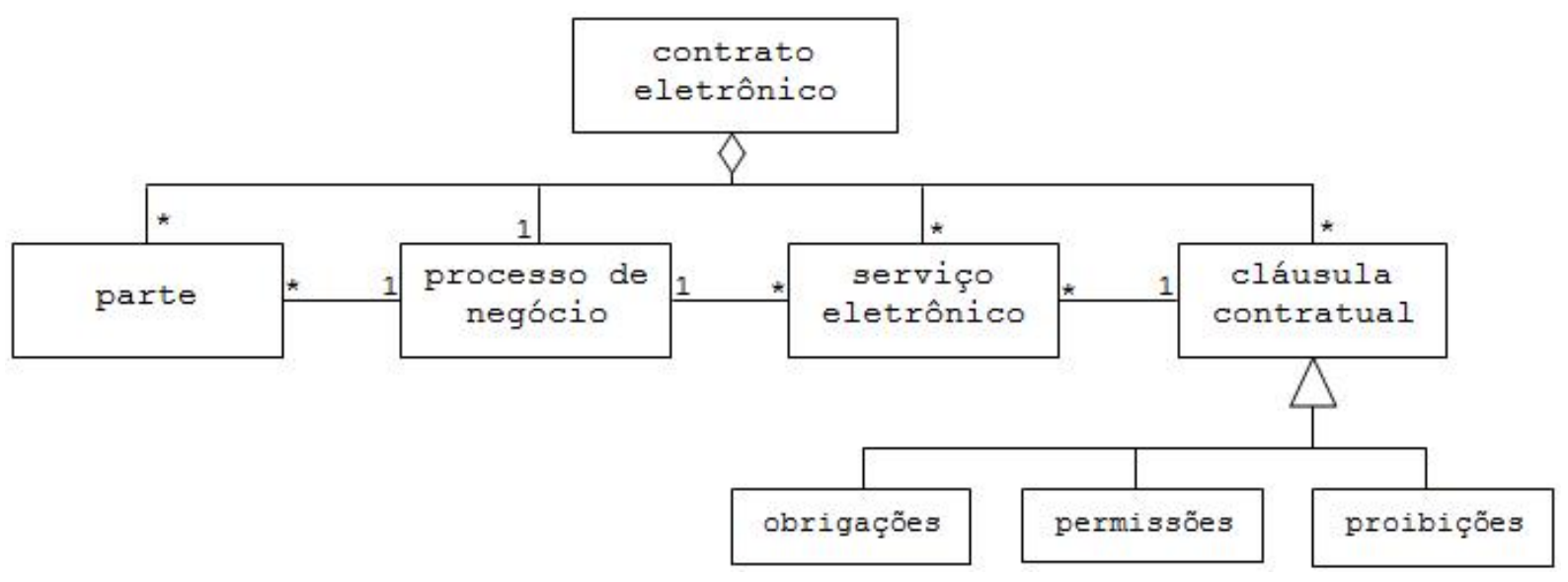

Fonte: (FAnTinato; GimEnes; TOLEDo, 2010c)

Contratos eletrônicos foram usados como um elemento importante na grande maioria dos trabalhos realizados pelo autor e apresentado na seção anterior. Porém, considerando a importância desse conceito para área de BPM e seu interesse no mesmo, o autor desenvolveu alguns outros trabalhos que focaram no uso exclusive de contratos eletrônicos, sem estarem relacionados ao contexto de LP, ou seja, sem estarem associadas a abordagem PL4BPM. Basicamente, quatro trabalhos semi-independentes foram realizados nesta segunda linha de pesquisa do autor, os quais são apresentados nas subseções a seguir, seguindo o mesmo modelo de apresentação usado na seção anterior.

\subsubsection{Conceitualizações na área de contratos eletrônicos para BPM e SOA}

Considerando o interesse do autor na área de contratos eletrônicos, alguns trabalhos foram desenvolvidos por ele buscando a conceitualização de contratos eletrônicos especificamente no contexto de BPM e SOA, principalmente em relação a composição de serviços web para a definição de processos de negócio executáveis. Esses conceitos puderam então ser usados em vários outros trabalhos correlatos deste autor. 
Este trabalho buscou consolidar vários conceitos relacionados a contratos eletrônicos, apresentados em outros trabalhos anteriores, de diversos outros autores - alguns deles não especificamente relacionados ao contexto de BPM e SOA, mas sim relacionados a contratos eletrônicos de uma forma geral. Assim, este trabalhou buscou definir uma série de conceitos relacionados a área de contratos eletrônicos para BPM e SOA, de forma sistemática, incluindo: (i) os elementos gerais contidos em um contrato eletrônico; (ii) análise básica de aspectos legais sobre contratos eletrônicos; (iii) requisitos funcionais e não funcionais para contratos eletrônicos; (iv) ciclo de vida de contratos eletrônicos; (v) metamodelos para contratos eletrônicos; (vi) moldes (ou templates) para contratos eletrônicos; e (vii) linguagens de especificação para as diferentes seções de um contrato eletrônico.

Além dessa conceitualização em si, este trabalho foi um dos pioneiros em apresentar um metamodelo especificamente para WS-Contracts, usado para representar contratos eletrônicos estabelecidos especificamente para o contexto de serviços web, ou seja, os Web Service E-Contracts. A definição desse metamodelo já havia sido iniciada anteriormente, tendo versões preliminares dele sido publicadas anteriormente em outros trabalhos em que ele foi necessário. Porém, após isso, foi realizado um esforço especificamente com o objetivo de refinar o metamodelo e publicá-lo com os detalhes necessários para seu úso por outros pesquisadores interessados nesta área de pesquisa. A Figura 15 apresenta a última versão do metamodelo de contrato eletrônico para serviços web (WS-Contract) produzida por este trabalho. O metamodelo apresentado estende aquele apresentado na Figura 14 com três seções específicas relacionadas a três linguagens de especificação: (i) WS-BPEL - para a descrição das partes envolvidas e do processo de negócio contratado; (ii) WSDL - para a descrição dos serviços web que compõe o serviço web contratado e devem ser executados pelas partes envolvidas; e (iii) WS-Agreement - para a descrição dos atributos e níveis de QoS associados aos serviços web contratados.

Este trabalho foi realizado pelo próprio autor, com a cooperação de outros pesquisadores, mas sem a colaboração de alunos, sejam de graduação ou de pós-graduação. Um dos objetivos principais deste trabalho era poder publicar as conceitualizações realizadas, o que foi feito via duas publicações. A primeira delas, via um capítulo de livro, após a submissão e seleção para apresentação de um minicurso em um evento regional realizado pela 
Figura 15 - Metamodelo de WS-Contract, em Diagrama de Classes da UML.

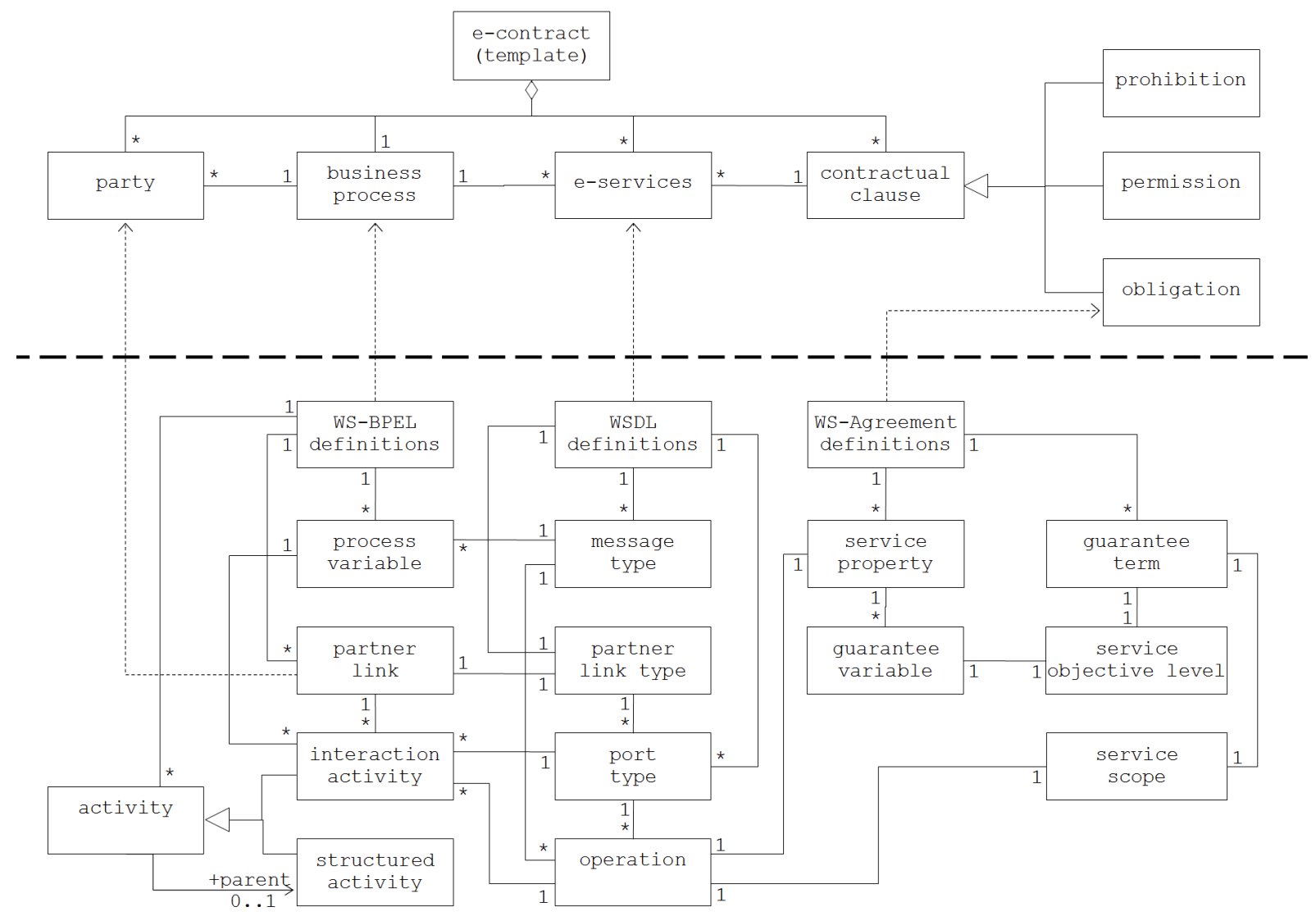

Fonte: (FAnTinAto; GIMENES; TOLEDO, 2010c)

Sociedade Brasileira de Computação (SBC) (FAntinato; GIMEnES; TOlEdo, 2010a) ${ }^{31}$. Essa primeira publicação foi mais detalhada que a segunda, e incluiu, por exemplo, uma comparação sistemática entre diferentes abordagens de tratamento de contratos eletrônicos e aquela apresentada pelo autor para WS-Contract. A segunda publicação foi realizada também como um capítulo de livro, após submissão, revisão por pares, e seleção para publicação (FANTINATO; GIMENES; TOLEDO, 2010c) ${ }^{32}$. Essa segunda publicação, embora mais resumida que a primeira, buscou dar um enfoque maior no grande potencial para reúso que existe em relação a aplicação de contratos eletrônicos no contexto de BPM e SOA.

31 Fantinato, M.; Gimenes, I. M. S.; Toledo, M. B. F. Contratos eletrônicos no contexto de BPM e SOA. In: Prado, S. G. D.; et al., eds. VII Escola Regional de Informática - São Paulo/Oeste 2010, v. 1 de 1a edição, Bauru, Brasil: SBC, p. 19-40, 2010. (Qualis: N/A, Capes-CC-2013)

32 Fantinato, M.; Gimenes, I. M. S.; Toledo, M. B. F. Web services e-contract and reuse. In: Lee, I., ed. Encyclopedia of E-business Development and Management in the Global Economy, v. 1 de 1st edition, Hershey - EUA: IGI Global, p. 883-891, 2010. (Qualis: N/A, Capes-CC-2013) 


\subsubsection{Uso de ontologias para estabelecimento de contratos eletrônicos}

Conforme apresentado na Seção 2.1.5, o uso de processos de negócio e, consequentemente, de contratos eletrônicos pode ocorrer inclusive no contexto da Engenharia de Software e, ainda mais especificamente, no contexto de Desenvolvimento Distribuído de Software (DDS). O processo de Engenharia de Software é composto por atividades que englobam desde a definição de requisitos até a implantação e a manutenção do software. Em um cenário de DDS, essas atividades são delegadas a diferentes organizações que devem colaborar para o desenvolvimento de software. Essa colaboração pode ser beneficiada com o uso da tecnologia de serviços web compostos em um processo de negócio específico para o desenvolvimento de software. Assim, nesse cenário, as organizações atuam como fornecedoras e consumidoras de serviços aplicados ao desenvolvimento de software. Neste cenário, os contratos eletrônicos são essenciais, para representar os detalhes do processo de negócio envolvendo todos os envolvidos na subcontratação a ser realizada.

O DDS pode envolver a contratação de diversos fornecedores. Além disso, vários projetos de desenvolvimento de diferentes sistemas podem envolver os mesmos ou diferentes fornecedores. Os contratos estabelecidos em cada caso podem diferir entre si, mas de modo geral são semelhantes. Portanto o uso de mecanismos de reúso de informações e artefatos no estabelecimento de contratos eletrônicos é essencial para a viabilização dessa abordagem no contexto de DDS. Este trabalho explorou o uso de ontologias computacionais como um mecanismo para possibilitar o reúso de informações nesse processo. A contribuição que se buscou com este trabalho foi de apresentar o potencial de ontologias para reúso de informações no estabelecimento de contratos eletrônicos no domínio de DDS. O uso de ontologias neste contexto foi comparado com o uso da técnica de modelos de características, um mecanismo similar para objetivos similares.

Ontologias podem ser definidas como um conjunto de termos ordenados hierarquicamente para descrever um domínio que pode ser usado como um esqueleto para uma base de conhecimento. Uma ontologia deve ser uma especificação formal e explícita de um conceito compartilhado, sendo que "formal" remete a processável por máquinas, "explícita" remete a conceitos determinados e "compartilhado" remete a conhecimento comum (BORST, 1997). Os componentes básicos de uma ontologia normalmente são: classes (conjunto de objetos); atributos (características que os objetos podem ter e compartilhar); propriedades de objeto (relacionamentos entre objetos); e indivíduos ou instâncias (os 
objetos básicos propriamente ditos). As ontologias computacionais (GUARINO, 1998) são normalmente acompanhadas de mecanismos de inferência, que computam o que há de informação explícita na ontologia e usam essas mesmas informações para inferir novas informações. Um tipo especial de classe usada pelos mecanismos de inferência são as classes definidas, que possuem regras explícitas (chamadas de condições necessárias e suficientes) para a criação de relacionamentos inferidos de outras classes para elas.

Esta pesquisa foi realizada no contexto de um Trabalho de Conclusão de Curso, do curso de BSI da EACH-USP. Como resultado, uma publicação foi gerada, em um workshop brasileiro especializado na área de DDS (SILVA; FANTINATO, 2010) ${ }^{33}$. Essa publicação apresentou o relato da aplicação de ontologias na fase de negociação eletrônica, que visa culminar no estabelecimento de um contrato eletrônico, tendo para isso o metamodelo já apresentado na Figura 15 como parâmetro final.

\subsubsection{Uso de orientação a aspectos para monitoramento de contratos eletrônicos}

Este foi um importante trabalho de pesquisa que explorou conceitos do paradigma de Orientação a Aspectos no domínio de BPM e SOA, mais especificamente ao estabelecimento de WS-Contracts. O paradigma de Orientação a Aspectos (FILMAN et al., 2004) pode ser usado para separar interesses ortogonais, os quais existem em vários domínios, inclusive no domínio de BPM. Em BPM, interesses como o monitoramento pode ser encapsulado em Aspectos e executados quando cortes de pontos (pointcuts) bem definidos são alcançados no processo de negócio sendo executado. No entanto, mecanismos convencionais de Aspectos não podem ser diretamente aplicados ao monitoramento de contratos eletrônicos. Assim, este trabalho buscou apresentar uma abordagem baseada em Aspectos para monitorar atributos e níveis de QoS, a qual recebeu o nome de Aspect-Monitor.

Na abordagem Aspect-Monitor proposta, um contrato eletrônico é formado de forma similar ao apresentado na Seção 2.2.1, porém com a diferença substancial que a linguagem de especificação WS-BPEL foi substituída pela AO4BPEL (Aspect-Oriented extension for WS-BPEL) (CHARFI; MEZINI, 2004). Aspectos de monitoramento foram então

33 Silva, Y. R. M.; Fantinato, M. Uso de ontologia no estabelecimento de contratos eletrônicos para processos interorganizacionais em DDS. In: Anais do IV Workshop de Desenvolvimento Distribuído de Software (WDDS), Salvador, Brasil: SBC, 2010, p. 18-25. (Qualis: B5, calculado de acordo com as regras Capes-CC-2013) 
projetados para lidar com os serviços web e seus atributos e níveis de QoS relacionados a esses serviços. Assim, os Aspectos não só são aplicadas à especificação do processo, mas também para melhorar o ambiente de execução do processo.

Para a definição sistemática dos Aspectos monitores, os mesmos passaram a fazer parte do contrato eletrônico sendo estabelecido entre as partes, considerando uma terceira parte responsável exclusivamente pelo monitoramento do processo de negócio em execução. Como resultado dessa constatação, o principal resultado em termos de artefato produzido por este trabalho foi a extensão do metamodelo de WS-Contract apresentado anteriormente na Figura 15. O resultado dessa extensão está apresentado na Figura 16, em que uma nova seção foi adicionada ao metamodelo - a seção "Aspect Section".

Figura 16 - Metamodelo de WS-Contract estendido com Aspectos Monitores, em Diagrama de Classes da UML.

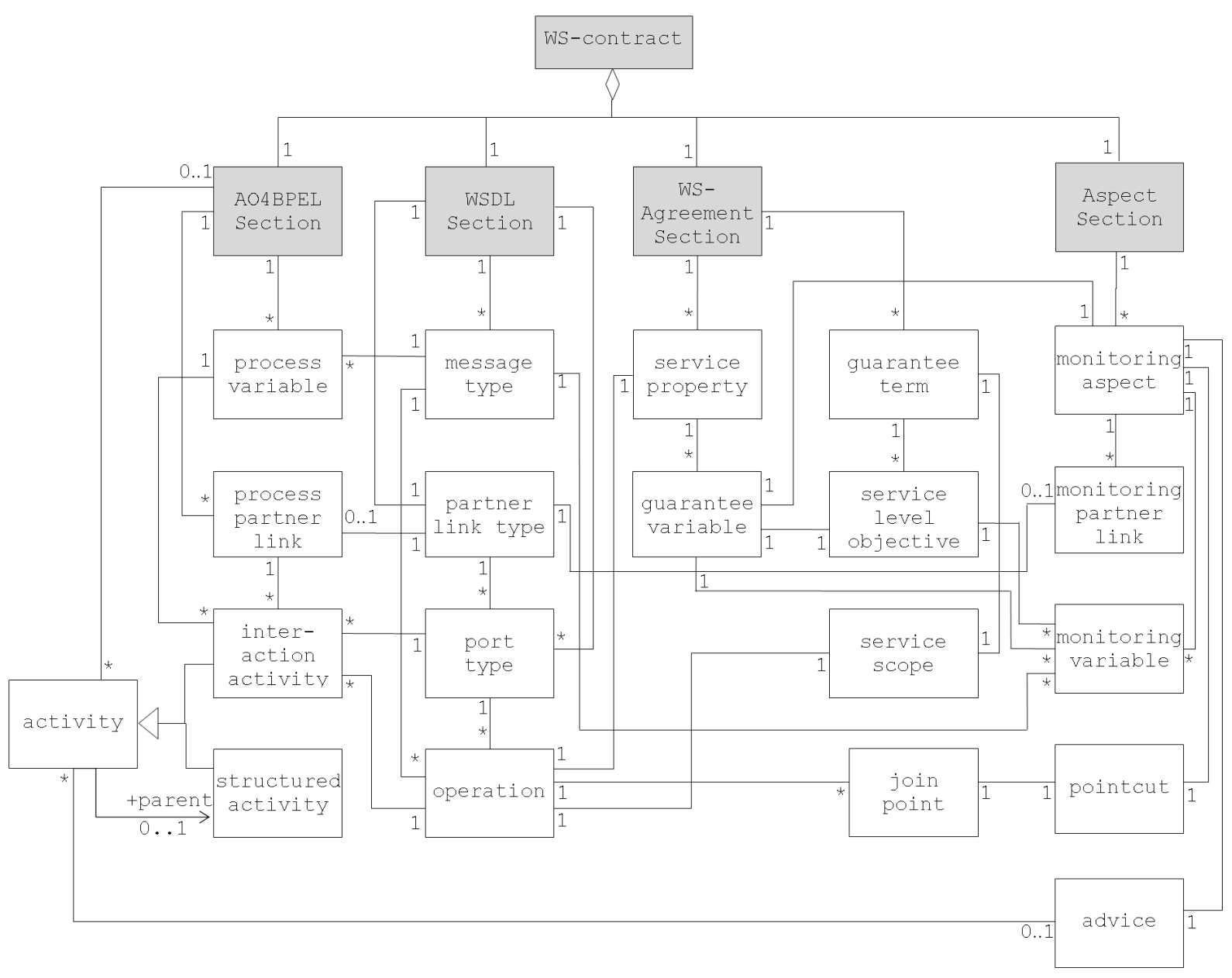

Fonte: (SILVA et al., 2010; SILVA et al., 2011) 
Este trabalho foi realizado no contexto de um projeto de mestrado, realizado no Programa de Pós-graduação em Ciência da Computação da Universidade Estadual de Maringá. Uma importante colaboração para a realização deste trabalho foi a participação do especialista no paradigma de Orientação a Aspectos, o Prof. Dr. Alessandro F. Garcia, da PUC-Rio (GARCIA et al., 2006). Os resultados deste trabalho geraram duas publicações: a primeira delas, publicada em uma conferência internacional, na qualidade de artigo completo (SILVA et al., 2010) ${ }^{34}$. Esta primeira publicação foi considerada um das melhores publicações da conferência e, posteriormente, os autores foram convidados a submeter uma versão estendida para nova avaliação a fim de ser publicada em uma edição especial da série LNCS (Lecture Notes in Computer Science) da editora Springer Verlag, o que ocorreu de forma bem sucedida (SILVA et al., 2011) ${ }^{35}$.

\subsection{Outras linhas de pesquisa em gestão de processos de negócio}

Considerando que a área de BPM é bastante rica e importante para o desenvolvimento de SIs, alguns trabalhos adicionais têm sido realizados pelo autor, porém não associados nem aos conceitos de LP nem de contratos eletrônicos. Muitas vezes, esses trabalhos usam conceitos da área de Engenharia de Software, considerando a formação básica do autor nessa disciplina, conforme apresentado inicialmente neste documento. Os trabalhos realizados neste contexto são uma tentativa, que tem se mostrado bem sucedida, de identificar potenciais novas linhas de pesquisa para que o autor inicie futuramente novos projetos de pesquisa na área de BPM. Essa estratégia pode ser verificada pelos anos de publicação dos artigos derivados desses trabalhos, em sua grande maioria bastante recentes. A grande maioria dos trabalhos apresentados nas subseções a seguir não possui relação direta entre si, o que era comum nas duas seções anteriores.

$34 \quad\left[{ }^{* * *}\right]$ Silva, M. F.; Gimenes, I. M. S.; Fantinato, M.; Toledo, M. B. F.; Garcia, A. F. Aspect-monitor: An aspect-based approach to WS-contract monitoring. In: Proceedings of the 12th International Conference on Enterprise Information Systems (ICEIS), Funchal, Madeira, Portugal: SciTePress, 2010, p. 5-12. (Qualis: B1, Capes-CC-2013)

35 [***] Silva, M. F.; Gimenes, I. M. S.; Fantinato, M.; Toledo, M. B. F.; Garcia, A. F. Improving QoS monitoring based on the aspect-oriented paradigm. In: Lecture Notes in Business Information Processing - Enterprise Information Systems - Revised Selected Papers (LNBIP), Funchal, Madeira, Portugal: Springer-Verlag, 2011, p. 421-435. (Qualis: B1, Capes-CC-2013) 


\subsubsection{Processos colaborativos para pesquisas médicas}

Um dos projetos de pesquisa que este autor trabalhou cooperativamente com outros pesquisadores se refere a tecnologias de internet em uma plataforma de colaboração para a pesquisa médica - chamado de Projeto WebInVivo. No campo da saúde, a pesquisa médica demanda muito investimento, esforço e informações para a comercialização segura de um fármaco novo. O projeto WebInVivo teve o objetivo de investigar o fornecimento de apoio automatizado à pesquisa médica, alicerçado em tecnologias de internet. Isso inclui mecanismos para o compartilhamento e a reúso de informações de pesquisas médicas, tais como protocolos, dados de protocolos, fluxos de trabalho e metadados de fluxos de trabalho para o controle do ciclo de vida do protocolo, da modelagem à execução. Neste projeto, o conhecimento da área biomédica permeia três segmentos da sociedade brasileira: (i) pesquisa e desenvolvimento; (ii) agentes de saúde; e (iii) a população. O projeto tinha como objetivo disponibilizar o conhecimento adquirido em redes sociais, para esses segmentos da sociedade brasileira.

O Projeto WebInVivo buscou incorporar em sua arquitetura, conforme apresentado na Figura 17, uma série de tecnologias associadas a internet úteis a esse contexto, tais como: SOA e serviços web, incluindo composição de serviços para a formação de processos de negócio; web 2.0; e web semântica, incluindo ontologias. Um elemento de destaque nesse contexto de pesquisas médicas, que norteiam o desenvolvimento dessa arquitetura e ferramentas associadas, é o "protocolo" da pesquisa médica. As fases da pesquisa médica têm de ser descritas com clareza, apresentar rigor científico, ser passíveis de verificação, e todas as alterações têm de ser relatadas. Para garantir que essas exigências sejam atendidas, um protocolo deve ser elaborado, aprovado e registrado antes do início da pesquisa. Uma pesquisa médica envolve coleta de informações, registro da evolução do tratamento e análise de dados.

Esse processo de execução de um protocolo como um todo pode beneficiar-se do desenvolvimento e do uso de novas ferramentas de software para a entrada de dados, coleta de dados, acompanhamento dos procedimentos e visualização dos resultados. A solução antevista engloba a automação da execução do protocolo, como um processo de negócio usando os conceitos da área de BPM - e o suporte à colaboração entre as possíveis partes interessadas, incluindo o governo, entidades normativas, pesquisadores, agentes de saúde e cidadãos. O uso de uma notação típica de processo de negócio (BPMN - Business Process 
Model and Notation) para representar um protocolo médico é apresentado na Figura 18. Assim como ocorre em organizações típicas, com base neste modelo de processo, uma versão executável do mesmo pode ser gerada usando as linguagens WS-BPEL/WSDL.

Figura 17 - Arquitetura proposta para o Projeto WebInVivo, em notação livre.

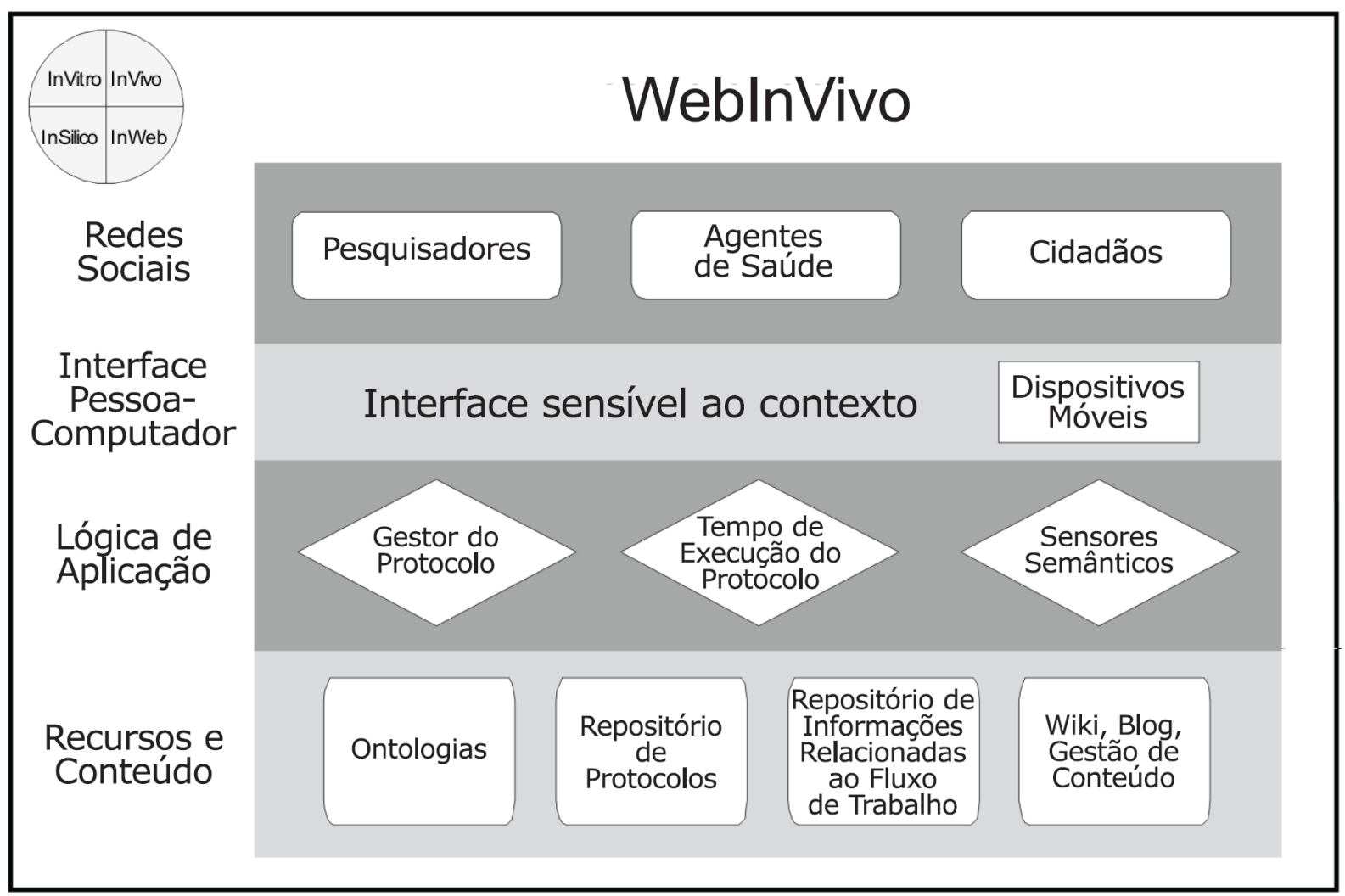

Fonte: (CAPRETZ et al., 2009)

Este projeto de pesquisa foi iniciado como um esforço amplo de um grande grupo de pesquisadores, dos quais este autor fez parte. A intenção era definir um objetivo comum de pesquisa que todos os envolvidos pudessem contribuir em suas respectivas áreas de especialidade, na forma de um projeto multidisciplinar de SIs, ao mesmo tempo que o objetivo final era melhorar uma outra área - no caso a área de pesquisa médica, o que tornava o projeto interdisciplinar. Como resultados dos primeiros esforços deste grupo, dois artigos foram publicados na forma de apresentação dos objetivos do projeto. Primeiramente, uma versão bastante preliminar foi publicada em um workshop internacional dá área de SOA (TOLEDO et al., 2009) ${ }^{36}$. Em seguida, uma versão mais elaborada foi publicada em um

36 Toledo, M. B. F.; Nabuco, O.; Nabuco, M.; Garcia, D.; Capretz, M. A. M.; Fantinato, M.; Gimenes, I. M. S.; Bonacin, R.; Guerra, A.; Rocha, T.; Viana, L. A SOA-based collaborative environment for clinical trials on neglected diseases. In: Proceedings of the 4th International IEEE Workshop on 
periódico nacional da área de pesquisa médica (CAPRETZ et al., 2009) ${ }^{37}$. Embora o grupo tenha se interessado bastante pelo projeto, e bons resultados tenham sido alcançados logo em seu início, infelizmente o mesmo acabou não se desenvolvendo no ritmo esperado, e não há perspectivas de retomada, considerando que vários membros iniciais se desligaram do projeto.

Figura 18 - Exemplo de protocolo médico como processo, em BPMN.

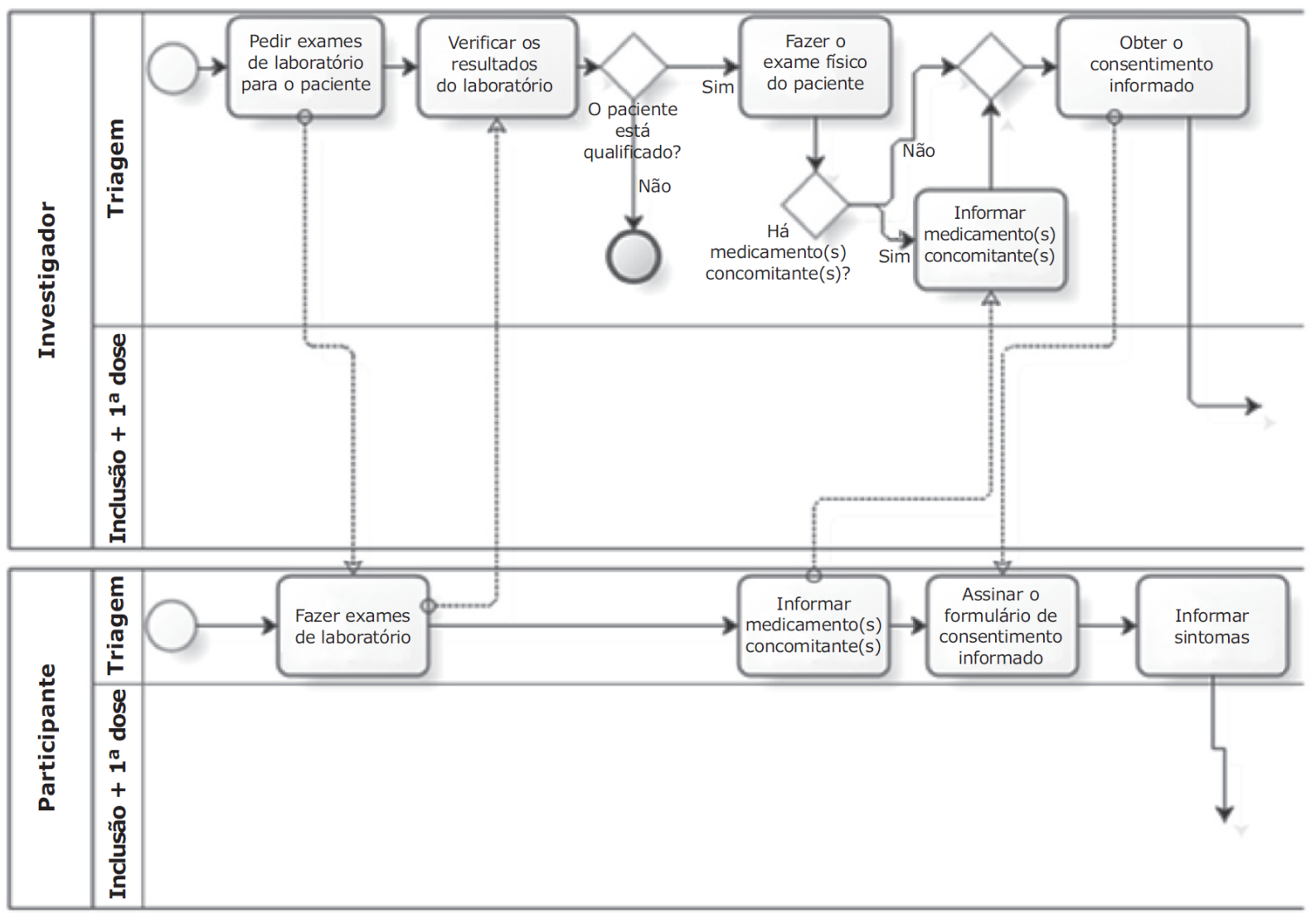

Fonte: (CAPRETZ et al., 2009)

\subsubsection{Alinhamento estratégico apoiado por BPM}

Considerando a importância do alinhamento estratégico dentro de organizações (HENDERSON; VENKATRAMAN, 1993), conforme já explorado no trabalho apresentado

Service Oriented Architectures in Converging Networked Environments (SOCNE), Bradford, Reino Unido: IEEE Computer Society, 2009, p. 518-523. (Qualis: B5, calculado de acordo com as regras Capes-CC-2013)

37 Capretz, M. A. M.; Toledo, M. B. F.; Fantinato, M.; Garcia, D. Z. G.; Wang, S.; Allison, D.; Nabuco, O.; Rodrigues, M.; Bonacin, R.; Sasse, E. C.; Gimenes, I. M. S.; Cunha, A. B. Web technologies in a collaborative platform for clinical trial. Electronic Journal of Communication Information and Innovation in Health (RECIIS), v. 3, n. 4, p. 209-223, 2009. (Qualis: C, Capes-CC-2013) 
na Seção 2.1.8, um trabalho adicional foi realizado visando contribuir com a melhoria do alinhamento estratégico em organizações com o uso de conceitos de BPM, porém de uma forma independente da abordagem PL4BPM, e também de forma independente de contratos eletrônicos de uma forma geral. O alinhamento estratégico entre as áreas de negócios e de TI é motivado pela necessidade das grandes organizações em aproveitar a capacidade da TI em transformar processos de negócio e disponibilizar bons produtos e serviços, destacando-se em um cenário competitivo. Neste contexto, BPM e SOA ganham espaço nas organizações por serem capazes de automatizar e aperfeiçoar os processos e os serviços necessários ao negócio (BRUIN; ROSEMANN, 2006).

No tratamento de processos e serviços, é importante atentar-se não apenas a propriedades funcionais (ou seja, as atividades que devem ser realizadas), mas também a propriedades não funcionais, tais como restrições de operação e de qualidade; dessa forma, é possível minimizar o desperdício de investimentos em TI com ineficiência e retrabalho. Porém, as linguagens mais conceituadas para modelagem de processos de negócio, incluindo BPMN, carecem da representação dessas propriedades não funcionais, criando uma lacuna entre a identificação de propriedades funcionais e não funcionais e também entre a modelagem do processo e sua implementação. Este trabalho de pesquisa buscou contribuir para o preenchimento dessa lacuna, propondo a abordagem StrAli-BPM (Strategic Aligment with BPM), que se subdivide nas partes BLA@BPMN e BLA2SLA: a primeira para estender a linguagem BPMN visando incorporar propriedades não funcionais, na forma de BLAs enriquecidos com KPIs (Key Performance Indicators), em sua estrutura de modelagem de processos; e a segunda para derivar semiautomaticamente um conjunto de SLAs, associados a serviços web, a partir de um BLA predefinido. Com isso, as áreas de TI e de Negócio compartilham uma linguagem comum, facilitando o diálogo e o alinhamento entre os objetivos organizacionais e as obrigações da TI - ou seja, contribuindo para a obtenção do almejando alinhamento estratégico.

O conceito de BLA foi amplamente investigado e usado no contexto deste trabalho. Ainda mais do que já havia sido realiazado no contexto do trabalho apresentado na Seção 2.1.8. BLA e SLA são conceitos intimamente ligados, e ambos ligados ao conceito de requisitos ou propriedades não funcionais. Porém, enquanto SLA são amplamente explorados, por meio de atributos de QoS, na definição de serviços web, o mesmo não ocorre com BLAs, no nível de processo de negócio. A justificativa de realização deste trabalho é que o alinhamento estratégico, para ser mais bem alcançado, precisa do 
tratamento de requisitos funcionais desde a definição do processo de negócio, e não apenas no momento de implementação dos serviços web que comporão esse processo de negócio (BRATANIS; DRANIDIS; SIMONS, 2010).

Este trabalho produziu uma ampla e robusta abordagem - a StrAli-BPM - que inclui dois protótipos de ferramentas que dão apoio computacional às suas duas fases: BLA@BPMN e BLA2SLA. A Figura 19 apresenta o framework geral que resume a ideia conceitual por trás da abordagem StrAli-BPM, tal como ela foi concebida depois de uma série de estudos e propostas incrementais. Os elementos que estão destacados em cinza são aqueles que representam os novos elementos propostos pela abordagem StrAli-BPM, enquanto os outros já existem no contexto de ciclo de vida de processos de negócio. Nessa figura, fica representado como StrAli-BPM visa fechar um ciclo em termos de contribuição com o alcance do alinhamento estratégico, fazendo uso de BPMN, BLAs e KPIs, além de WS-BPEL/WSDL e SLAs. Quanto às fases mencionadas, a primeira (análise e modelagem) normalmente é de responsabilidade das áreas de negócio, enquanto a segunda (implementação e execução) é normalmente de responsabilidade da área de TI. Para ambas as fases, espera-se que tanto as propriedades funcionais quanto as não funcionais (representadas por KPIs) possam ser definidas em uma abordagem top-down e de forma inter-relacionada.

Para a primeira parte da abordagem StrAli-BPM - ou seja, a BL@BPMN - uma extensão da linguagem de modelagem BPMN é proposto para a representação de propriedades não funcionais por meio de BLAs. A Figura 20 ilustra como pode ser realizada essa representação. Nesse exemplo, o BLA "Criação de contratos em até 6 horas" está associado a um subprocesso formado por quatro atividades, assim, todas os atributos associados a esse BLA se referem a todo o subprocesso marcado dentro do grupo referido. Existe uma regra formal de criação da estrutura de um BLA, tanto em termos de atributos internos quanto de ligação com outros elementos já existentes de BPMN. Essas regras foram definidas por meio de um metamodelo, o qual está apresentado na Figura 21.

Além desses artefatos, vários outros foram gerados em relação à segunda parte da abordagem, ou seja, a BLA2SLA, em que um BLA criado em nível de modelagem de processo de negócio pode ser derivado de forma semiautomática para um conjunto de SLAs relacionados especificados em WS-Agreement. Além disso, como já mencionados, dois protótipos de ferramentas foram também desenvolvidos para apoiar essas duas 
partes da abordagem proposta e assim realizar uma prova de conceito de sua viabilidade computacional.

Figura 19 - Framework conceitual da abordagem StrAli-BPM (novos elementos adicionados para BLA destacados em cinza), em notação livre.

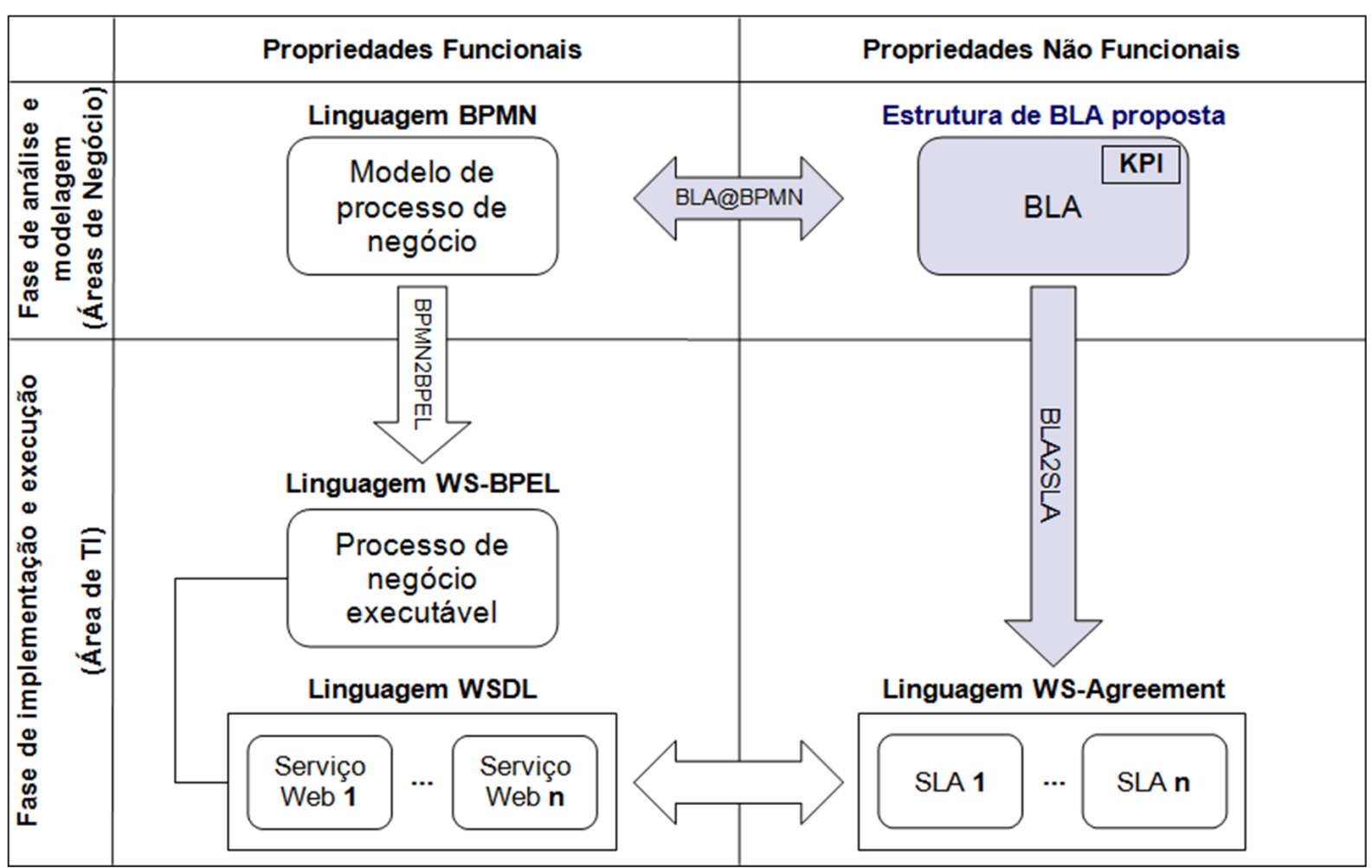

Fonte: (SALLES et al., 2013)

Este trabalho está sendo realizado no contexto de um projeto de mestrado, realizado no PPgSI da EACH-USP. O referido projeto de mestrado está em fase de finalização, as validações da abordagem proposta já foram realizadas, a dissertação já foi escrita e encontra-se em fase de revisão. A expectativa é que a defesa ocorra dentro de um prazo de três meses. Os resultados parciais deste trabalho já geraram duas publicações: a primeira delas, com os resultados de uma Revisão Sistemática da Literatura (RSL) realizada para embasar o início do trabalho, publicada em uma conferência brasileira, na qualidade de artigo completo (SALLES; FANTINATO, 2012) ${ }^{38}$; a segunda, já relacionada com a abordagem propriamente dita, mas focando ainda apenas a primeira parte dela, ou seja, a BLA@SLA,

38 Salles, G. B. M.; Fantinato, M. Análise da incorporação de requisitos não funcionais na modelagem de processos de negócio. In: Anais do VIII Simpósio Brasileiro de Sistemas de Informação : Trilhas Técnicas (SBSI), São Paulo, Brasil: SBC, 2012, p. 79-90. (Qualis: B4, Capes-CC-2013) 
foi publicada em uma conferência internacional, na qualidade de artigo completo (SALLES et al., 2013) ${ }^{39}$.

Figura 20 - Exemplo de modelo de processo de negócio com novo elemento BLA ("Criação de contratos em até 6 horas"), em BPMN.

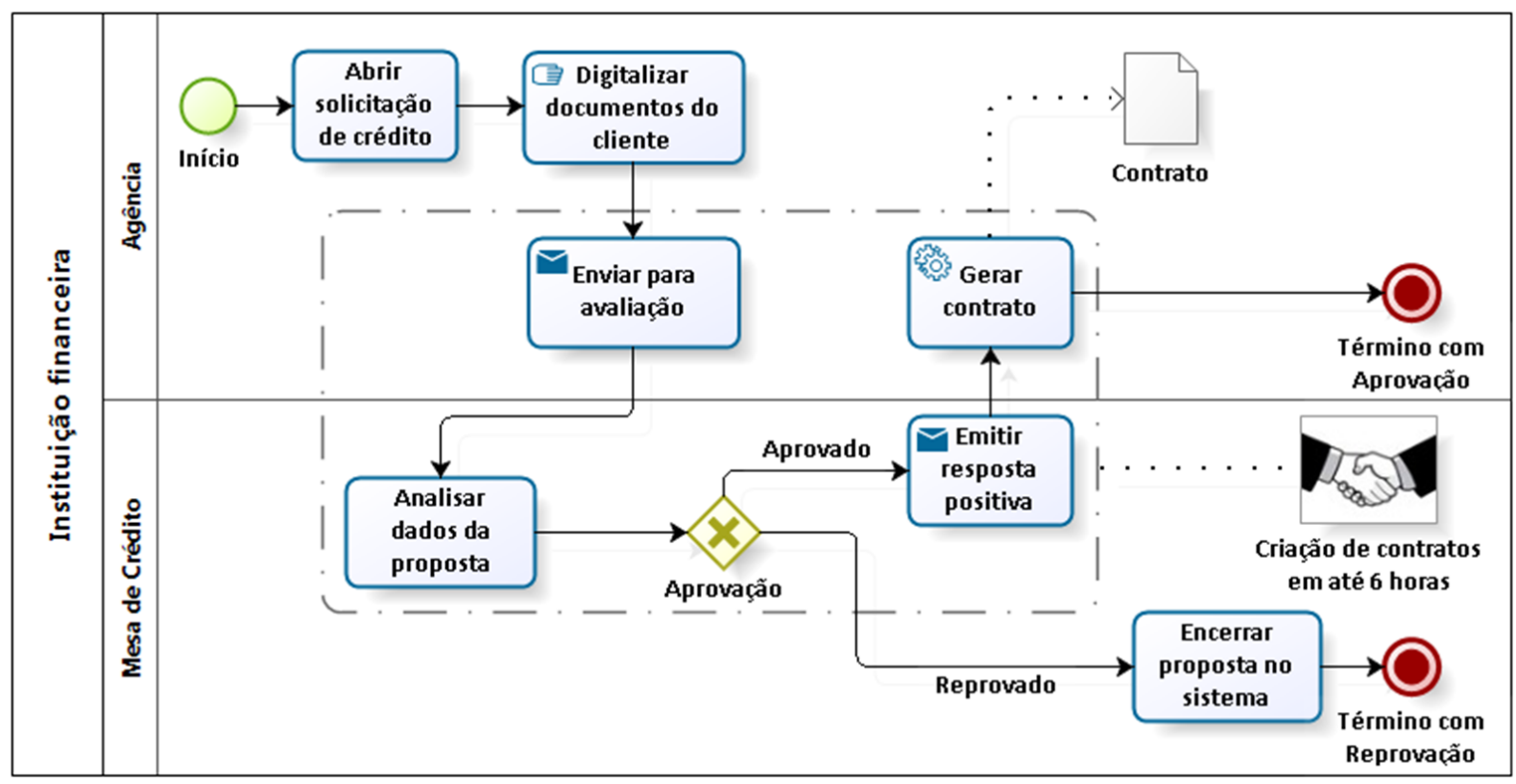

Fonte: (SALLES et al., 2013)

\subsubsection{Análise de técnicas de reúso em BPM}

O estudo e aplicação de técnicas de reúso, de uma forma geral, no domínio de BPM tem sido um interesse constante nos projetos de pesquisa deste autor. Embora sua principal linha de pesquisa aplique especificamente conceitos de LP - considerada uma abordagem de reúso de software, outras técnicas de reúso também têm sido de seu interesse de uma forma geral, normalmente aplicadas ao contexto de BPM. Como resultado disso, o autor tem sido um dos principais organizadores de uma série de workshops internacionais focados no assunto de "Reúso em BPM", ocorridos em conjunto com a principal conferência internacional da área de BPM. Foram quatro edições realizadas até este momento:

- 1st Int'l Workshop on Reuse in Business Process Management (rBPM 2010);

$39 \quad\left[{ }^{* * *}\right]$ Salles, G.; Fantinato, M.; Nishijima, M.; de Albuquerque, J. P. A contribution to organizational and operational strategic alignment: Incorporating business level agreements into business process modeling. In: Proceedings of the 2013 IEEE 10th International Conference on Services Computing (SCC), Santa Clara Marriott, EUA: IEEE Computer Society, 2013, p. 17-24. (Qualis: B1, Capes-CC2013) 
Figura 21 - Metamodelo de BPMN resumido estendido com novo elemento BLA (novos elementos adicionados para BLA destacados em cinza), em Diagramas de Classes da UML.

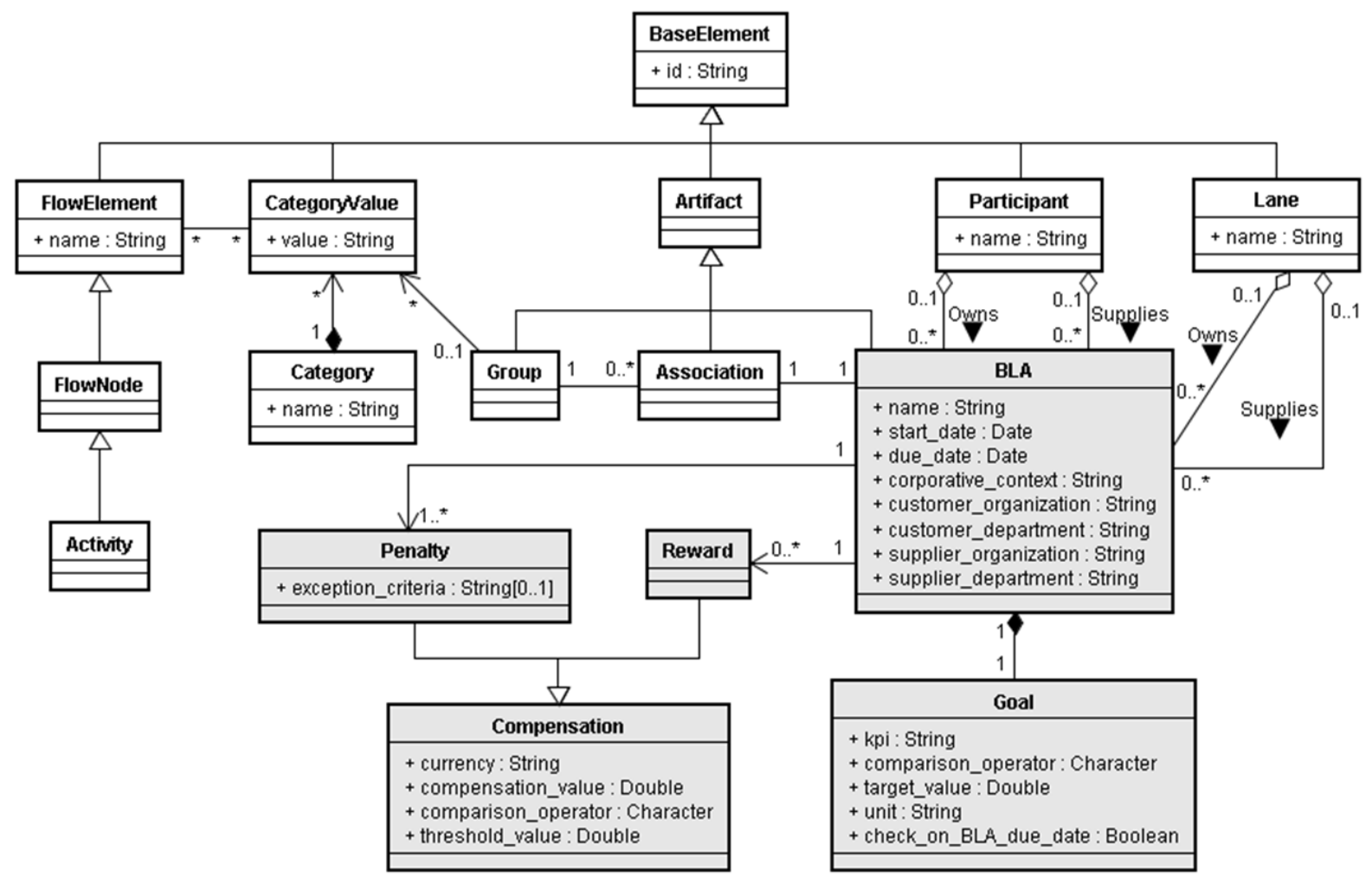

Fonte: (SALLES et al., 2013)

- 2nd Int'l Workshop on Reuse in Business Process Management (rBPM 2011);

- 3rd Int'l Workshop on Reuse in Business Process Management (rBPM 2012); e

- 4th Int'l Workshop on Process Model Collections: Management and Reuse (PMC-MR $2013)^{40}$.

No total, foram mais de 20 artigos publicados relacionados ao tema de reúso no domínio de BPM, incluindo duas edições especiais no periódico internacional "International Journal of Business Process Integration and Management (IJBPIM)" relativas às duas primeiras edições do workshop, para as quais este autor foi um dos editores convidados.

O trabalho com essas edições da série de workshops assim como das edições especiais do periódico IJBPIM despertou ainda mais o interesse no estudo de técnicas de reúso para o domínio de BPM. Assim, um dos trabalhos realizados pelo autor, em cooperação com outros pesquisadores, foi um levantamento sistemático dos principais trabalhos já $\overline{40}$ a mudança de nome é devida a junção com outro workshop similar 
publicados com esta finalidade. O resultado desse estudo resultou em uma publicação também no periódico internacional IJBPIM (FANTINATO et al., 2012) ${ }^{41}$.

BPM pode se beneficiar de abordagens e técnicas de reúso em várias fases de seu ciclo de vida, a fim de aumentar o dinamismo, flexibilidade e competitividade. Técnicas de reúso de áreas como Engenharia de Software podem ser estendidas para este domínio emergente. Dentro deste contexto, o objetivo do trabalho realizado foi fornecer uma visão geral e uma discussão geral dos projetos de pesquisa mais relevantes que têm sido desenvolvidos aplicando reúso em BPM. Para isso, três questões de pesquisa principais nortearam a realização deste trabalho: $Q 1$ - quais são as principais técnicas de reúso presentes nos trabalhos relacionados ao domínio de BPM? Q2 - os trabalhos relacionados a reúso no domínio BPM são decorrentes de projetos de pesquisa recentes ou de projetos já maduros? Q3 - quais são as principais vantagens/benefícios e as principais desvantagens/limitações dos trabalhos selecionadas?

Como resultado desta investigação, 52 artigos relevantes foram selecionados. Esses artigos foram agrupados em cinco categorias, em função do principal mecanismo de reúso sendo aplicado: SOA (14 trabalhos); padrões (14 trabalhos); ontologias (11 trabalhos); $\mathrm{LP} /$ variantes (nove trabalhos); e outros (quatro trabalhos). Em termos das técnicas usadas, os resultados mostraram principalmente que: o uso de LP - principal interesse deste pesquisador no contexto de BPM - não é tão abrangente considerando outros tipos de abordagens; e o uso de SOA e de padrões são as formas mais frequentes, seguidas por ontologias. Outros resultados foram encontrados, conforme discutidos na publicação realizada.

\subsubsection{Métricas de tamanho para BPM}

Outro trabalho em que conceitos da Engenharia de Software foram aplicados no domínio de BPM se refere à exploração de métricas de software no contexto de processos de negócio, mais especificamente a bastante conhecida métrica de Pontos de Função $\left(\mathrm{FP}^{42}\right)$.

Embora o uso de BPM tenha aumentado nos últimos tempos, há uma falta de ferramentas e técnicas que podem ser usados para medir os projetos de BPM em relação à

\footnotetext{
41 Fantinato, M.; Toledo, M. B. F.; Thom, L. H.; Gimenes, I. M. S.; Rocha, R. S.; Garcia, D. Z. G. A survey on reuse in the business process management domain. International Journal of Business Process Integration and Management (IJBPIM), v. 6, n. 1, p. 52-76, 2012. (Qualis: B4, Capes-CC-2013) 
complexidade funcional (GONZÁLEZ et al., 2010b). Por exemplo, não existe uma técnica que forneça informações importantes para os gerentes de projeto para lhes permitir compreender e controlar os recursos necessários, esforços, custos e tempo para projetos de BPM. Em contraste, no contexto da Engenharia de Software, há uma vasta gama de métricas de software para estimar diferentes tipos de variáveis de projeto (INSTITUTE, 2008). FP é uma das métricas de software mais usadas, funcionando como uma unidade para medir o tamanho de um projeto de software (GROUP, 2010). E a técnica mais usada para a produção de FPs é a Análise de Pontos de Função (FPA $\left.{ }^{43}\right)$. FPA é empregada sobre a documentação de projeto de software para calcular seu tamanho funcional. Bem como na Engenharia de Software, os gerentes de projetos de BPM também precisam de uma métrica para produzir informações valiosas sobre os tamanhos de projeto - de forma semelhante como tamanhos funcionais são calculados para projetos de software - a fim de obter outras variáveis importantes para o gerenciamento de projetos de BPM.

Assim, o principal objetivo deste projeto foi propor uma métrica e técnica específica para o domínio de BPM, baseadas respectivamente na FP e na FPA. A nova métrica recebeu o nome de Pontos de Processo de Negócio $\left(\mathrm{BBP}^{44}\right)$, e a nova técnica recebeu o nome de Análise de Pontos de Processo de Negócio $\left(\mathrm{BBPA}^{45}\right)$. Da mesma forma como a documentação do projeto de software é a entrada para a FPA, a documentação do projeto de BPM é a entrada para BPPA. A documentação do projeto de BPM é composta basicamente por modelos de processo de negócio. BPPA só incide sobre processos de negócio especificados em BPMN - versão 2.0, considerada uma notação de modelagem padrão para processos de negócio. O objetivo de BPPA é fornecer uma técnica que possa ajudar os gerentes de projetos de BPM nas principais atividades relacionadas ao controle e monitoramento desses projetos.

Embora os detalhes para o cálculo da métrica BPP sejam consideravelmente diferentes do que da métrica FP, houve a tentativa de manter a similaridade o máximo possível entre as duas técnicas, visto que a técnica FPA já é amplamente conhecida e usada pela comunidade de Engenharia de Software, o que daria uma maior aplicabilidade da nova técnica BPPA sendo proposta. A Figura 22 apresenta uma visão geral do processo proposto para a técnica BPPA. Alguns dos estágios/passos da nova técnica puderam

\footnotetext{
43 do inglês "Function Point Analysis"

44 do inglês "Business Process Points"

45 do inglês "Business Process Point Analysis"
} 
ser mantidos de forma muito similar àqueles da técnica base FPA, enquanto que outros precisaram sobre mudanças leves e outros grandes mudanças. O impacto no número de mudanças necessárias está representada na figura em função da escala de cor, conforme legenda apresentada na própria figura. O detalhamento de cada um desses estágios e passos está apresentado em um relatório técnico (BAKLIZKY; FANTINATO, 2012).

Esta pesquisa foi realizada no contexto de um Trabalho de Conclusão de Curso, do curso de BSI da EACH-USP. Como resultado parcial, uma publicação foi gerada até o momento, em uma conferência internacional, na qualidade de artigo completo (BAKLIZKY et al., 2013) ${ }^{46}$. Depois dessa primeira publicação, houve uma continuidade do trabalho, visando uma avaliação experimental da técnica proposta, visando compará-la com a técnica base usada em sua definição. Os resultados desse estudo estão sendo consolidados para serem publicados em um periódico internacional.

Figura 22 - Estágios e passos do processo proposto para a técnica BPPA, em notação livre.

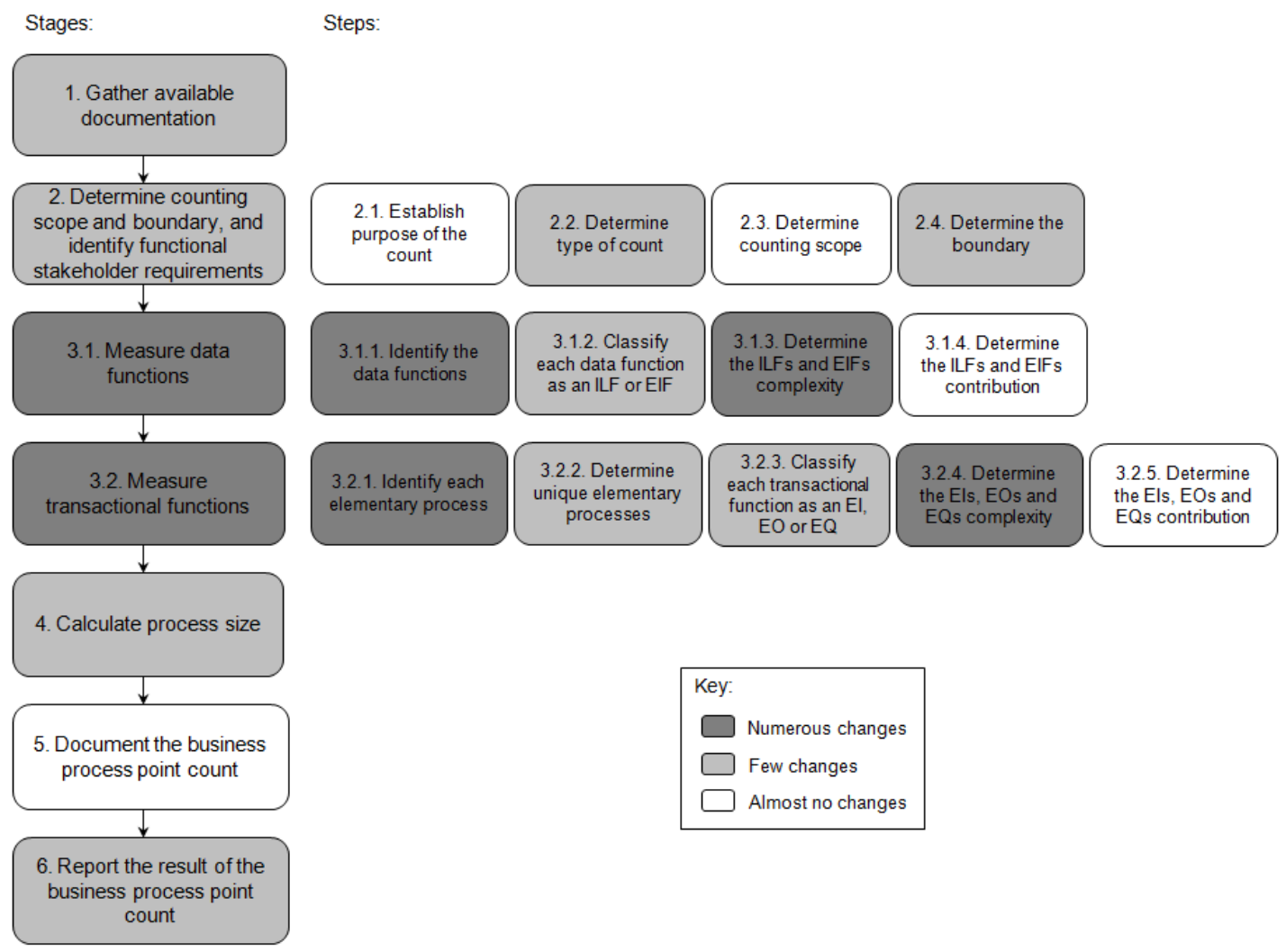

Fonte: ECIS-2013

$\overline{46} \quad\left[{ }^{* * *}\right]$ Baklizky, M.; Fantinato, M.; Thom, L. H.; Sun, V.; Prado, E. P. V.; Hung, P. Business process points - A proposal to measure BPM projects. In: Proceedings of the 21th European Conference on Information Systems (ECIS), Utrecht, Holanda: AIS Press, 2013, p. 121.1-121.12. (Qualis: B1, Capes-CC-2013) 


\subsubsection{Engenharia de requisitos para composição de serviços}

Mais recentemente, um trabalho no contexto de um projeto de mestrado do PPgSI da EACH-USP foi iniciado com o objetivo de investigar o contexto de Engenharia de Requisitos especificamente para o contexto de SOA. A Engenharia de Requisitos Orientada a Serviços trata da definição de processos e metodologias para captar os requisitos de serviços tanto do ponto de vista de consumidores de serviços quanto de fornecedores de serviços. Existem vários desafios a serem trabalhos dentro desse contexto, considerando que a área de Engenharia de Requisitos por si só já é uma área bastante complexa, e a SOC é ainda uma área em que muitos desafios encontram-se abertos.

Considerando esse objetivo, primeiramente uma Revisão Sistemática da Literatura (RSL) foi realizada visando compreender as lacunas da área. Essa RSL da publicada em uma conferência brasileira, na qualidade de artigo completo (SOUZA; FANTINATO, 2013) ${ }^{47}$, gerando um primeiro resultado parcial deste projeto de mestrado. Foram identificados 52 estudos primários, classificados em três dimensões: aspectos de serviços eletrônicos, aspectos relacionados à engenharia de requisitos tradicional e aspectos emergentes de Engenharia de Requisitos Orientada a Serviços. Os resultados encontrados apontam para o crescimento de trabalhos nessa área nos últimos anos, além de evidenciar as lacunas e tendências de pesquisas.

O projeto de mestrado encontra-se atualmente em fase de qualificação. A proposta está sendo apresenta para uma banca. Em função dos resultados encontrados na RSL realizada, a proposta deste projeto de mestrado sendo apresentada na qualificação pretende explorar alternativas às descrições sugeridas para os metamodelos RGPS ${ }^{48}$ - Papel, Meta, Processo e Serviço (WANG et al., 2008), propondo uma nova definição que visa, principalmente, incorporar a RGPS as vantagens de outros modelos já estabelecidos na literatura, conforme apresentado na Figura 23. Sendo assim, para a descrição das camadas Papel e Meta, propõe-se o uso do framework i* (YU; MYLOPOULOS; LESPÉRANCE, 1996). E, para a descrição das camadas Processo e Serviço, propõe-se o uso de WS-BPEL/WSDL. O framework $i^{*}$ promove o uso de metas para gerenciar diferentes aspectos do processo de especificação do sistema. Entre suas vantagens estão estabilidade, apoio à detecção de

\footnotetext{
47 Souza, K. S.; Fantinato, M. Explorando a engenharia de requisitos orientada a serviços: Uma revisão sistemática da literatura. In: Anais do IX Simpósio Brasileiro de Sistemas de Informação : Trilhas Técnicas (SBSI), João Pessoa, Brasil: SBC, 2013, p. 272-283. (Qualis: B4, Capes-CC-2013) 
conflitos, análise e negociação. Já a escolha de WS-BPEL/WSDL para a definição das camadas Processo e Serviço se deve por sua maturidade e largo uso no estado da prática, aumentando as chances de que a abordagem aqui proposta possa ser adotada também na indústria.

Figura 23 - Framework da abordagem sendo proposta: extensão da RGPS baseada em framework i* e linguagens WS-BPEL/WSDL, em notação livre.

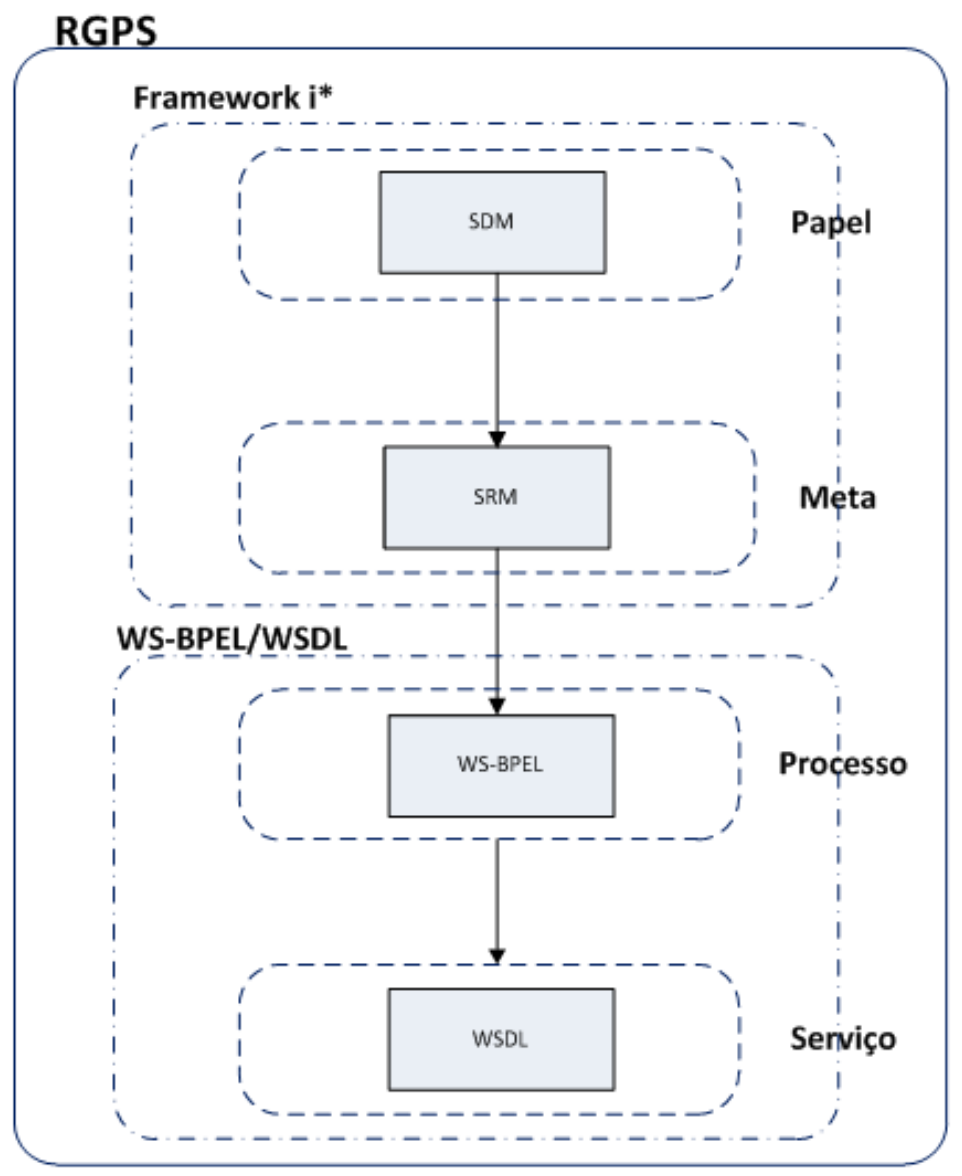

Fonte: Marcelo Fantinato, 2015

\subsection{Considerações finais}

Esses seis anos de trabalho acadêmico, posterior a conclusão do doutorado, levaram a publicação de 32 trabalhos científicos, incluindo artigos em periódicos, artigos completos e artigos resumidos em anais de conferência, e artigos como capítulos de livro. Para a geração dessas 32 publicações, foram realizados no período 17 trabalhos de pesquisa, ou podendo ser chamados também de projetos de pesquisa, que foram agrupados em três principais linhas de pesquisa. Isso leva a uma média aproximada de duas publicações por 
trabalho, embora alguns deles tenham gerado menos e outros mais publicações. A Tabela 1 apresenta um resumo da distribuição dessas 32 publicações científicas em função dos trabalhos e das linhas de pesquisa em que elas foram geradas e também em função do ano em que elas foram publicadas, para um panorama geral possa ser visualizado.

Tabela 1 - Resumo das Publicações - de 2008 a 2013. Publicações em negrito: destaque para as 11 mais relevantes; publicações sublinhadas: destaque para as nove realizadas em periódicos.

\begin{tabular}{|c|c|c|c|c|c|c|}
\hline $\begin{array}{l}\text { Linha de Pesquisa / } \\
\text { Trabalho de Pesquisa }\end{array}$ & 2008 & 2009 & 2010 & 2011 & 2012 & 2013 \\
\hline \multicolumn{7}{|l|}{ LP para BPM } \\
\hline Seção 2.1.1 & $5 / 6 / \underline{7}$ & & & & & \\
\hline Seção 2.1.2 & & 8 & & $\underline{9}$ & & \\
\hline Seção 2.1 .3 & & & & $\underline{12}$ & & \\
\hline Seção 2.1 .4 & & $13 / 14$ & $\underline{15}$ & & & \\
\hline Seção 2.1 .5 & & 16 & 17 & & 18 & \\
\hline Seção 2.1.6 & & & $19 / \mathbf{2 0}$ & $\underline{21}$ & & \\
\hline Seção 2.1 .7 & & & 22 & & & \\
\hline Seção 2.1.8 & & & & & $25 / \underline{26}$ & \\
\hline Seção 2.1 .9 & & & & & 28 & $\underline{29}$ \\
\hline \multicolumn{7}{|l|}{ Contratos Eletrônicos } \\
\hline Seção 2.2 .1 & & & $31 / 32$ & & & \\
\hline Seção 2.2 .2 & & & 33 & & & \\
\hline Seção 2.2.3 & & & 34 & 35 & & \\
\hline \multicolumn{7}{|l|}{ Outras Linhas } \\
\hline Seção 2.3.1 & & $36 / \underline{37}$ & & & & \\
\hline Seção 2.3 .2 & & & & & 38 & 39 \\
\hline Seção 2.3 .3 & & & & & $\underline{41}$ & \\
\hline Seção 2.3.4 & & & & & & 46 \\
\hline Seção 2.3.5 & & & & & & 47 \\
\hline \multicolumn{7}{|l|}{ [Totais] } \\
\hline [Incluindo todas] & {$[3]$} & {$[6]$} & {$[9]$} & {$[4]$} & {$[6]$} & {$[4]$} \\
\hline [Apenas mais relevantes] & {$[2]$} & {$[0]$} & {$[4]$} & {$[2]$} & {$[0]$} & {$[3]$} \\
\hline [Apenas periódicos] & {$[1]$} & {$[1]$} & [1] & {$[3]$} & {$[2]$} & {$[1]$} \\
\hline
\end{tabular}

Fonte: Marcelo Fantinato, 2015

Na tabela apresentada, as 32 publicações são apresentadas usando os mesmos números em que elas foram apresentadas no decorrer deste capítulo, como notas de rodapé. Aquelas 11 mais relevantes, destacadas anteriormente com três asteríscos dentro de colchetes são destacadas agora com a fonte em negrito. E as nove publicações realizadas em periódicos são destacadas com um sublinhado. Outros detalhes a respeito das publicações não são apresentados nessa tabela, visto que seu objetivo é apenas traçar um panorama geral a respeito das publicações realizadas no período. 
Algumas considerações podem ser realizadas em função desse panorama geral. Os dados apresentados na tabela mostram que a produção do autor tem se mostrado regular durante o período, com algumas variações em função das três grandes áreas de pesquisa apresentadas neste capítulo. Sem considerar nenhum tipo de nível mínimo de relevância, a média de produção no período foi de pouco mais de cinco artigos por ano, tendo o menor número de publicações no ano de 2008 (três publicações) e o maior número no ano de 2010 (nove publicações). Considerando apenas as publicações mais relevantes, a média foi de quase duas por ano no período, tendo algumas variações de ano para ano. Por fim, considerando apenas as publicações realizadas em periódicos, sem levar em conta um nível mínimo de relevância, a média de produção no período foi de 1,5 por ano.

Quando se oberva as três linhas de pesquisa apresentadas no capítulo, é possível observar uma variação na concentração de publicações realizadas. Para o primeiro grupo, "Linha de Produto para Gestão de Processos de Negócio", houve publicações regulares durante todo o período. Cada um dos nove trabalhos realizados dentro desse grupo apresentou um conjunto de publicações concentrado em momento diferente deste período, culminando recentemente nas produções do trabalho descrito na Seção 2.1.9, relativo a LPD para BPM. Já em relação ao segundo grupo, "Contratos Eletrônicos para Gestão de Processos de Negócio", as produções realizadas se concentraram no ano de 2010, momento intermediário do período, o que caracteriza este grupo como um grupo de apoio aos demais grupos. Por fim, em relação ao terceiro grupo, "Outras Linhas de Pesquisa em Gestão de Processos de Negócio", por exceção do primeiro trabalho que produziu publicações no início do período, todos os outros quatro trabalhos tiveram suas publicações realizadas nos últimos dois anos do período relatado, o que indica a prospeção de novas frentes de pesquisa por parte do autor. 


\section{Conclusões}

Neste capítulo, são apresentadas as considerações finais deste documento. Três seções são apresentadas: (i) uma discussão do trabalho realizado no período relatado neste documento, por meio de algumas reflexões; (ii) perspectivas futuras em função dos trabalhos já em andamento e também trabalhos futuros vislumbrados; e, por fim, (iii) alguns agradecimentos.

\subsection{Discussão e reflexões}

Após a conclusão de seu doutorado, o autor continuou a desenvolver trabalhos de pesquisa fundamentalmente na área de BPM. Várias linhas de pesquisa dentro dessa grande área foram tratadas. A maior ênfase foi dada a aplicação de princípios de LP no contexto de BPM, o que caracteriza a linha de pesquisa principal do autor. De forma bastante relacionada a esta primeira linha de pesquisa, o autor também desenvolveu alguns trabalhos relacionados exclusivamente a contratos eletrônicos para serviços web. Considerando essas duas linhas, vários resultados relevantes foram obtidos, com a proposta de abordagens que buscam aplicar os SIs de forma ágil e dinâmica nas organizações que dependem altamente de uma boa gestão de seus processos de negócio via técnicas e ferramentas automatizadas.

Mais recentemente, principalmente nos últimos dois anos, o autor tem buscado trabalhar também em alguns outros projetos de pesquisa na área de BPM, porém não ligados a LP ou a contratos eletrônicos. A realização desses novos trabalhos se deve principalmente a dois fatores: o início de orientações no curso de mestrado do PPgSI na EACH-USP - que faz com que novos trabalhos, mais adequados a outros perfis de alunos sejam realizados; e a busca por parcerias externas a EACH-USP - considerando outros pesquisadores que também atuam na área de BPM. Embora sejam trabalhos mais recentes, e na maioria dos casos independentes entre si, vários deles já produziram resultados relevantes, inclusive em termos de publicações. Isso demonstra que pelo menos parte desses novos projetos de pesquisa possuem grande potencial para apresentar resultados ainda mais relevantes futuramente.

Além disso, houve também no período relatado alguns outros trabalhos de pesquisa que, por não estarem relacionados ao contexto de BPM, não foram cobertos neste documento. Esses trabalhos foram desenvolvidos por diferentes motivações, incluindo, por 
exemplo, a experiência do autor com a área de Teste de Software, na qual seu projeto de mestrado foi desenvolvido. Além disso, algumas parcerias pontuais, em temais mais amplos na área de SI e Engenharia de Software, levaram a realização de alguns trabalhos colaborativos. No total, foram publicados outros 14 artigos científicos em diferentes veículos como resultado desses outros trabalhos não relacionados a BPM, complementando os 32 trabalhos cobertos neste documento.

Como resultado do trabalho do autor, atualmente o mesmo possui uma boa inserção no cenário acadêmico, principalmente no contexto nacional, mas também no contexto internacional. Em termos nacionais, o autor foi o coordenador geral de duas importantes conferências brasileiras - uma na área de Engenharia de Software e uma na área de Sistemas de Informação - o que lhe permitiu melhorar substancialmente sua rede de relacionamentos com outros pesquisadores brasileiros. Em função desses trabalhos, o autor integrou o comitê diretor de ambos os eventos. Além disso, o autor foi Coordenador do Comitê de Programa da sexta edição do Simpósio Brasileiro de Componentes, Arquiteturas e Reutilização de Software (SBCARS 2012), tornando-se membro do comitê diretivo deste evento por um período de cinco anos. Em termos internacionais, o autor foi co-organizador de uma série de quatro workshops internacionais na área de reúso em BPM, realizados juntamente com a principal conferência internacional em BPM. Além disso, ele participa como membro de diversos comitês de programa, tanto nacionais como internacionais.

\subsection{Trabalhos em andamento e trabalhos futuros}

Atualmente, o autor está orientando três trabalhos de mestrado, um trabalho de IC e um trabalho de TCC. Além disso, há também um trabalho de pós-doutorado sob sua supervisão. Todos esses trabalhos estão relacionados à área de BPM.

Dois trabalhos de mestrado em andamento já possuem resultados apresentados neste documento. O primeiro deles, apresentado na Seção 2.3.2, está em fase final de revisão do texto da dissertação, de modo que a defesa deve ocorrer ainda no ano de 2013. Espera-se que um novo artigo, contemplando os resultados completos deste projeto, seja publicado em um periódico internacional a ser submetido também ainda em 2013; além das publicações já derivadas deste projeto. O trabalho de TCC sendo atualmente orientado está diretamente relacionado a este projeto de mestrado, tendo ficado restrito ao desenvolvimento do protótipo de ferramenta de uma das partes da estratégia sendo 
proposta. O trabalho de TCC já está sendo finalizado, e um artigo com os resultados específicos deste projeto será submetido a uma conferência internacional ainda em 2013.

O segundo trabalho de mestrado com resultados já existentes, apresentado na Seção 2.3.5, está em fase intermediária, tendo passado recentemente pela fase de exame de qualificação. Assim, espera-se que a defesa da dissertação ocorra apenas em 2014. Além disso, espera-se que publicações mais completas sejam derivadas futuramente a partir deste trabalho.

O terceiro trabalho de mestrado assim como o trabalho de IC, ambos iniciados muito recentemente, estão ligados a uma área de BPM ainda não explorada pelo autor e, portanto, não apresentada ainda neste documento. Trata-se da área de mineração de processos de negócio ${ }^{1}$. A mineração de processos é uma área de pesquisa relativamente recente que se situa entre a mineração de dados e aprendizado de máquina, de um lado, e a modelagem e a análise de processos de negócio, de outro lado (AALST, 2011). A mineração de processos visa descobrir, monitorar e melhorar processos de negócio reais por meio da extração de conhecimento a partir de logs de eventos disponíveis em sistemas de informação orientados a processos. O principal objetivo do projeto de mestrado que está se iniciando, apoiado pelo projeto de IC, é avaliar o contexto de aplicação de técnicas inteligentes, incluindo, por exemplo, redes neurais, em mineração de processos. Considerando que essas técnicas são, atualmente, as mais aplicadas nas tarefas de mineração de dados, seria esperado que elas também estivessem sendo majoritariamente aplicadas nas tarefas de mineração de processos, o que não tem sido demonstrado na literatura recente. Busca-se compreender porque essas técnicas não têm sido amplamente usadas e realizar experimentos para investigar se elas apresentam potencial para apresentar melhores resultados neste contexto.

Por fim, a supervisão de pós-doutorado, se refere a um projeto ligado a reprojeto de processos de consultoria em TI para incorporar enfoques de reúso ao paradigma de BPM. Refere-se à extensão do trabalho de doutorado do pesquisador com técnicas de reúso em BPM conforme trabalhos de pesquisa realizado por este autor, mais especificamente em relação aos resultados do trabalho apresentado na Seção 2.3.3.

É possível notar que esses trabalhos em andamento estão todos relacionados a trabalhos apresentados na Seção 2.3 deste documento, ou seja, trabalhos relacionados a outras linhas de pesquisa em BPM que não àquela que tem sido até então minha principal 
linha de pesquisa - aplicação de princípios de LP ao contexto de BPM. Apesar disso, há ainda a intenção clara de continuar trabalhos nesta linha de pesquisa considerando os importantes resultados já alcançados até este momento. Como evidência dessa intenção, há um projeto de pesquisa financiado submetido ao $\mathrm{CNPq}$ no edital "Universal" relacionado exclusivamente a esta linha, sendo uma continuação do trabalho apresentado na Seção 2.1.9. Caso o projeto "Universal" não seja aceito, está planejada a submissão do projeto à Fapesp, na linha Auxílio Regular.

Dessa forma, pode-se destacar como trabalhos futuros na área de BPM os seguintes trabalhos:

- Linha de Produto Dinâmica para Gestão de Processos de Negócio - Abordagem e Infraestrutura: como continuação do trabalho apresentado na Seção 2.1, de forma geral, e na Seção 2.1.9, de forma mais específica. Existe um projeto submetido ao CNPq, e outro pode ser submetido à Fapesp. Não há atualmente nenhum aluno alocado para trabalhar neste projeto, mas uma vez que o projeto financiado seja aprovado, novos alunos deverão ser alocados para ele.

- Alinhamento Estratégico Apoiado por BPM: como continuação do trabalho apresentado na Seção 2.3.2, o qual já está praticamente finalizado considerando seus objetivos iniciais, mas que despertou grande interesse no autor para pesquisas adicionais. $\mathrm{O}$ aluno de mestrado demonstra grande interesse na realização de um curso de doutorado, que ainda não está disponível no PPgSI da EACH-USP, mas é possível que isso gere novas colaborações com outras unidades da USP, por exemplo.

- Métricas para BPM: como continuação do trabalho apresentado na Seção 2.3.4, que já está finalizado considerando seus objetivos iniciais, mas que também despertou grande interesse no autor para pesquisas adicionais. A aluna da graduação que realizou o TCC possivelmente ingressará no curso de mestrado do PPgSI da EACH-USP para a continuação do trabalho;

- Engenharia de Requisitos em SOC: como continuação do trabalho apresentado na Seção 2.3.5, que está ainda em andamento. O objetivo atual em relação a esse trabalho é sua finalização no contexto do projeto de mestrado, para que, dependendo dos resultados alcançados, o autor faça uma avaliação sobre uma possível continuação.

- Mineração de Processos: como uma área de pesquisa totalmente nova para o autor, em que já há dois alunos - um de mestrado e um de IC - trabalhando em 
fase inicial de seus projetos. Trata-se de uma área que aparenta ter muito interesse de pesquisa da comunidade internacional, tanto acadêmica quanto industrial. Além disso, o interesse em investir nessa área deve-se ao fato de que na EACH-USP há vários pesquisadores especialistas na área de Mineração de Dados e Aprendizado de Máquina, que podem colaborar neste trabalho.

O principal desafio para a realização desses trabalhos futuros, em relação ao trabalho deste pesquisador, está relacionada à validação das técnicas, abordages e modelos propostos. Por ser uma área de pesquisa cujas técnicas propostas estão diretamente voltadas para a indústria de desevolvimento de sistemas de informação e demais organizações usuárias e clientes desses sistemas, a validação dos trabalhos de pesquisa desenvolvidos por esse pesquisador passa necessariamente pela realização de estudos de caso em ambientes o mais próximos possível das organizações que serão clientes desses resultados, o que é um grade desafio metódologico para essas pesquisas.

\subsection{Agradecimentos}

Agradeço a todos os coautores dos trabalhos aqui citados, incluindo alunos de graduação e de pós-graduação, e outros colegadas docentes pesquisadores de outras instituições. Eles tiveram papel fundamental nos trabalhos de pesquisa realizados, cujos resultados estão aqui apresentados.

Agradeço também aos auxílios financeiros recebidos via órgãos de fomento que possibilitaram a realização desses trabalhos, incluindo Fapesp, Capes, CNPq e programas especiais da USP. 


\section{Referências $^{2}$}

AALST, W. M. P. van der. Process Mining - Discovery, Conformance and Enhancement of Business Processes. Berlin, Alemanha: Springer, 2011. Citado na página 68.

AALST, W. M. P. van der; HOFSTEDE, A. H. M. t.; WESKE, M. Business process management: A survey. In: Proceedings of the International Conference on Business Process Management (BPM). Eindhoven, Holanda: Springer-Verlag, 2003. p. 1-12. Citado 2 vezes nas páginas 11 e 12.

AALST, W. van der; LEYMANN, F.; REISIG, W. The role of business processes in service oriented architectures (editorial). International Journal of Business Process Integration and Management (IJBPIM), v. 2, n. 2, p. 75-80, 2007. Citado 2 vezes nas páginas 12 e 13.

ABURUB, F.; ODEH, M.; BEESON, I. Modelling non-functional requirements of business processes. Information and Software Technology (INFSOF), v. 49, n. 11-12, p. 1162-1171, 2007. Citado na página 14.

ALLEN, P. Service orientation: Winning strategies and best practices. 1st. ed. Reino Unido: Cambridge University Press, 2006. Citado na página 37.

ALOnSO, G. et al. Web Services: Concepts, Architectures and Applications. 1st. ed. Berlin, Alemanha: Springer, 2004. Citado 2 vezes nas páginas 12 e 18.

ANTKIEWICZ, M.; CZARNECKI, K. Featureplugin: Feature modeling plug-in for Eclipse. In: Proceedings of the 2004 OOPSLA workshop on Eclipse Technology eXchange (ETX). Vancouver, Canadá: ACM Press, 2004. p. 67-72. Citado na página 25.

AO, N. M.; PIDD, M. Using component technology to develop a simulation library for business process modelling. European Journal of Operational Research, v. 172, n. 1, p. 163-178, 2006. Citado na página 13.

BAKLIZKY, M.; FANTINATO, M. FPA4BPM - Function Point Analysis for Business Process Management (v.1.0). São Paulo, SP, Brasil, 2012. Disponível em: $<$ http://ppgsi.each.usp.br/arquivos/RelTec/PPgSI-003_2012.pdf>. Citado na página 61.

BAKLIZKY, M. et al. Business process points - A proposal to measure BPM projects. In: Proceedings of the 21th European Conference on Information Systems (ECIS). Utrecht, Holanda: AIS Press, 2013. p. 121.1-121.12. Citado na página 61.

BARESI, L.; GUINEA, S.; PLEBANI, P. WS-policy for service monitoring. In: Proceedings of the 6th International Workshop on Technologies for E-Services (TES). Trondheim, Noruega: Springer, 2005. p. 72-83. Citado na página 34.

BORST, W. N. Construction of Engineering Ontologies for Knowledge Sharing and Reuse. Tese (Tese de Doutorado) — Universidade de Twente, Holanda, Enschede, Holanda, 1997. Citado na página 47.

2 De acordo com a Associação Brasileira de Normas Técnicas. NBR 6023. 
BRATANIS, K.; DRANIDIS, D.; SIMONS, A. J. Towards run-time monitoring of business-level agreements for web services. In: Proceedings of the 5th Annual South East European Doctoral Student Conference. Thessaloniki, Grécia: [s.n.], 2010. p. 370-379. Citado na página 55.

BRUIN, T. D.; ROSEMANN, M. Towards understanding strategic alignment of business process management. In: Proceedings of the 17th Australasian Conference on Information Systems (ACIS). Adelaide, Austrália: Australasian Association for Information Systems, 2006. p. 1-10. Citado na página 54.

CAPPELLI, C. et al. Reflections on the modularity of business process models: The case for introducing the aspect-oriented paradigm. Business Process Management Journal (BPMJ), v. 16, n. 4, p. 662-687, 2010. Citado na página 13.

CAPRETZ, M. A. M. et al. Web technologies in a collaborative platform for clinical trial. Electronic Journal of Communication Information and Innovation in Health (RECIIS), v. 3, n. 4, p. 209-223, 2009. Citado 2 vezes nas páginas 52 e 53.

CHARFI, A.; MEZINI, M. Aspect-oriented web service composition with AO4BPEL. In: Proceedings of the 2nd European Conference on Web Services (ECOWS). Erfurt, Alemanha: Springer, 2004. p. 168-182. Citado na página 48.

CLEMENTS, P.; NORTHROP, L. Software Product Lines: Practices and Patterns. 3rd. ed. Boston, EUA: Addison-Wesley, 2001. Citado 2 vezes nas páginas 13 e 19.

CRNKOVIC, I.; LARSSON, M. Challenges of component-based development. Journal of Systems and Software (JSS), v. 61, n. 3, p. 201-212, 2002. Citado na página 13.

CZARNECKI, K.; HELSEN, S.; EISENECKER, U. Staged configuration through specialization and multilevel configuration of feature models. Software Process Improvement and Practice (SPIP), v. 10, n. 2, p. 143-169, 2005. Citado na página 13.

ERL, T. SOA: Principles of Service Design. 1st. ed. Upper Saddle River, NJ, EUA: Prentice Hall Press, 2007. Citado 2 vezes nas páginas 12 e 18.

FANTINATO, M.; GIMENES, I. M. S.; TOLEDO, M. B. F. Contratos eletrônicos no contexto de BPM e SOA. In: PRADO, S. G. D.; AL. et (Ed.). VII Escola Regional de Informática - São Paulo/Oeste 2010. [S.l.]: Bauru, Brasil: SBC, 2010, (1a edição, v. 1). p. 19-40. Citado na página 46.

FAntinAtO, M.; GIMENES, I. M. S.; TOLEDO, M. B. F. Product line in the business process management domain. In: KANG, K. C.; SUGUMARAN, V.; PARK, S. (Ed.). Applied Software Product Line Engineering. [S.l.]: Boca Raton - EUA: Auerbach Publications, 2010, (1st edition, v. 1). p. 497-530. Citado na página 21.

FANTINATO, M.; GIMENES, I. M. S.; TOLEDO, M. B. F. Web services e-contract and reuse. In: LEE, I. (Ed.). Encyclopedia of E-business Development and Management in the Global Economy. [S.l.]: Hershey - EUA: IGI Global, 2010, (1st edition, v. 1). p. 883-891. Citado 3 vezes nas páginas 12, 44 e 46.

FANTINATO, M.; SILVA, L. F.; SALLES, G. B. M. Contratos eletrônicos estendidos com acordos em nível de negócio visando apoiar o alinhamento estratégico entre negócio e TI. Revista Eletrônica de Sistemas de Informação (RESI), v. 11, n. 2, p. 2.01-2.21, 2012. Citado 2 vezes nas páginas 38 e 39. 
FANTINATO, M.; TOLEDO, M. B. F.; GIMENES, I. M. S. WS-contract establishment with QoS: An approach based on feature modeling. International Journal of Cooperative Information Systems (IJCIS), v. 17, n. 3, p. 373-407, 2008. Citado na página 21.

FANTINATO, M. et al. A survey on reuse in the business process management domain. International Journal of Business Process Integration and Management (IJBPIM), v. 6, n. 1, p. 52-76, 2012. Citado 2 vezes nas páginas 13 e 59.

FILMAN, R. E. et al. Aspect-Oriented Software Development. 1st. ed. Upper Saddle River, NJ, EUA: Addison-Wesley Professional, 2004. Citado 2 vezes nas páginas 13 e 48.

FRAGAL, V. H. et al. O estabelecimento de contratos eletrônicos com o ambiente FeatureContract. Revista Eletrônica de Iniciação Científica (REIC), v. 11, n. 1, p. 1-15, 2011. Citado 2 vezes nas páginas 25 e 26.

GARCIA, A. F. et al. Modularizing design patterns with aspects: A quantitative study. Transactions on Aspect-Oriented Software Development, v. 1, p. 36-74, 2006. Citado na página 50.

GIMENES, I. M. S.; FANTINATO, M.; TOLEDO, M. B. F. A product line for business process management. In: Proceedings of the 12th International Software Product Line Conference (SPLC). Limerick, Irlanda: IEEE Computer Society, 2008. p. 265-274. Citado na página 21.

GONCALVES, T. L. et al. Estabelecimento de contratos eletrônicos: Uma avaliação com estudos experimentais. In: Proceedings of the 35th Latin American Informatics Conference (CLEI). Pelotas, Brasil: SBC, 2009. p. ST.16.e.01-ST.16.e.10. Citado na página 23.

GONCALVES, T. L. et al. Experimental studies of e-contract establishment in the PL4BPM context. International Journal of Web Engineering and Technology (IJWET), v. 6, n. 3, p. 243-265, 2011. Citado na página 23.

GONZÁLEZ, L. et al. Measurement in business processes: A systematic review. Business Process Management Journal (BPMJ), v. 16, n. 1, p. 114-134, 2010. Citado na página 14.

GONZÁLEZ, L. S. et al. Measurement in business processes: A systematic review. Business Process Management Journal, v. 16, n. 1, p. 114-134, 2010. Citado na página 60.

GRGIC, I.; ROHNE, M. Agreements in IP-based networks. Telektronikk, v. 2, n. 3, p. 186-212, 2001. Citado na página 37.

GROUP, I. F. P. U. Function Point Counting Practices Manual. 4.3.1. ed. Westerville, Ohio, EUA: IFPUG, 2010. Citado na página 60.

GUARINO, N. Formal ontology and information systems. In: Proceedings of the 1st International Conference on Formal Ontology in Information Systems (FOIS). Trento, Itália: IOS Press, 1998. p. 3-15. Citado na página 48.

HALLSTEINSEN, S. et al. Dynamic software product lines. Computer, v. 41, n. 4, p. 93-95, 2008. Citado 2 vezes nas páginas 13 e 19.

HANSON, J. E.; MILOSEVIC, Z. Conversation-oriented protocols for contract negotiations. In: Proceedings of the 7th International Enterprise Distributed Object Computing Conference (EDOC). Brisbane, Austrália: IEEE Computer Society, 2003. p. 40-49. Citado na página 31. 
HENDERSON, J. C.; VENKATRAMAN, N. Strategic alignment: Leveraging information technology for transforming organizations. IBM Systems Journal, v. 32, n. 1, p. 4-16, 1993. Citado na página 53.

IFPUG. Function Point Counting Practices Manual - Release 4.1.1. 2013. Disponível em: $<$ http://perun.pmf.uns.ac.rs/old/repository/research/se/functionpoints.pdf $>$. Citado na página 14.

INSTITUTE, P. M. A Guide to the Project Management Body of Knowledge (PMBoK Guide). 4th. ed. Pennsylvania, EUA: Project Management Institute, Inc., 2008. Citado na página 60.

KANG, K. C. et al. Feature-Oriented Domain Analysis (FODA) Feasibility Study. Pittsburgh - PA, EUA, 1990. Disponível em: <http://www.sei.cmu.edu/reports/90tr021.pdf $>$. Citado na página 13.

KANG, K. C. et al. FORM: A feature-oriented reuse method with domain-specific reference architectures. Annals of Software Engineering (ASE), v. 5, n. 1, p. 143-168, 1998. Citado na página 19.

KRISHNA, P.; KARLAPALEM, K. Electronic contracts. IEEE Internet Computing, v. 12, n. 4, p. 60-68, 2008. Citado 2 vezes nas páginas 12 e 43.

LEE, Y.-C.; CHU, P.-Y.; TSENG, H.-L. Corporate performance of ICT-enabled business process re-engineering. Industrial Management and Data Systems (IMDS), v. 111, n. 5, p. 735-754, 2011. Citado na página 11.

LUDWIG, H.; DAN, A.; KEARNEY, R. Cremona: An architecture and library for creation and monitoring of WS-agreements. In: Proceedings of the 2nd International Conference Service-Oriented Computing (ICSOC). Nova York, NY, EUA: Springer, 2004. p. 65-74. Citado 2 vezes nas páginas 32 e 34.

MARCHIONE, F. G.; FANTINATO, M. Requisitos e apoio computacional para negociação e contratação de serviços web baseadas em preço. In: Anais do III Workshop de Gestão de Processos de Negócio (WBPM). Fortaleza, Brasil: SBC, 2009. p. 196-201. Citado na página 28.

MARCHIONE, F. G. et al. Price definition in the establishment of electronic contracts for web services. In: Proceedings of the 11th International Conference on Information Integration and Web-based Applications and Services (iiWAS). Kuala Lumpur, Malásia: ACM Press, 2009. p. 217-224. Citado 2 vezes nas páginas 28 e 29.

MARCHIONE, F. G. et al. E-contracting with price configuration for web services and QoS. International Journal of Web and Grid Services (IJWGS), v. 6, n. 4, p. 357-384, 2010. Citado 2 vezes nas páginas 28 e 29.

MATHEW, G. E.; SHIELDS, J.; VERMA, V. QoS based pricing for web services. In: Proceedings of the 1st Workshop on Web Information Systems Modelgin (WISM). Brisbane, Austrália: Springer, 2004. p. 264-276. Citado na página 27.

MIKKONEN, T. Formalizing design patterns. In: Proceedings of the 20th International Conference on Software Engineering (ICSE). Kyoto, Japão: IEEE Computer Society, 1998. p. 115-124. Citado na página 13. 
NORTA, A.; GREFEN, P. Discovering patterns for inter-organizational business process collaboration. International Journal of Cooperative Information Systems (IJCIS), v. 16, n. 3-4, p. 507-544, 2007. Citado na página 13.

O'SUlLIVAN, J.; EDMOND, D.; HOFSTEDE, A. H. M. ter. The price of services. In: Proceedings of the 3rd International Conference Service-Oriented Computing (ICSOC). Amsterdã, Holanda: Springer, 2005. p. 564-569. Citado na página 27.

OVERBY, E.; BHARADWAJ, A.; SAMBAMURTHY, V. Enterprise agility and the enabling role of information technology. European Journal of Information Systems (EJIS), v. 15, n. 2, p. 120-131, 2006. Citado na página 11.

PAPAZOGLOU, M. Web Services: Principles and Technology. 1st. ed. Upper Saddle River, New Jersey, EUA: Prentice Hall, 2008. Citado na página 12.

PAPAZOGLOU, M. P. et al. Service-oriented computing: A research roadmap. International Journal of Cooperative Information Systems (IJCIS), v. 17, n. 2, p. 223-255, 2008. Citado 3 vezes nas páginas 12, 13 e 18.

POHL, K.; BÖCKLE, G.; LINDEN, F. J. van der. Software Product Line Engineering: Foundations, Principles and Techniques. 1st. ed. Berlin, Alemanha: Springer, 2005. Citado 2 vezes nas páginas 13 e 19.

PUliER, E.; TAYLOE, H. Compreendendo SOA corporativa. 1st. ed. São Paulo, SP, Brasil: Ciência Moderna, 2008. Citado na página 37.

RINDERLE, S.; BENYOUCEF, M. Towards the automation of e-negotiation processes based on web services - A modeling approach. In: Proceedings of the 6th International Conference on Web Information Systems Engineering (WISE). Nova York, NY, EUA: Springer, 2005. p. 443-453. Citado na página 31.

ROCHA, R. S. Linha de Produto para Gestão de Processos de Negócio Incluindo Aspectos Dinâmicos. Dissertação (Dissertação de Mestrado) — Escola de Artes, Ciências e Humanidades, Universidade de São Paulo (EACH-USP), São Paulo, Brasil, 2012. Citado 2 vezes nas páginas 41 e 43.

ROCHA, R. S.; FANTINATO, M. The use of software product lines for business process management: A systematic literature review. Information and Software Technology (INFSOF), v. 55, n. 8, p. 1355-1373, 2013. Citado 4 vezes nas páginas 13, 21, 42 e 43.

ROCHA, R. S.; FANTINATO, M.; BARROS, V. A. Contribuições de linha de produto e orientação a serviços no desenvolvimento de sistemas de informação. In: Anais do VIII Simpósio Brasileiro de Sistemas de Informação : Trilhas Técnicas (SBSI). São Paulo, Brasil: SBC, 2012. p. 91-102. Citado na página 43.

SALLES, G. et al. A contribution to organizational and operational strategic alignment: Incorporating business level agreements into business process modeling. In: Proceedings of the 2013 IEEE 10th International Conference on Services Computing (SCC). Santa Clara Marriott, EUA: IEEE Computer Society, 2013. p. 17-24. Citado 3 vezes nas páginas 56, 57 e 58. 
SALLES, G. B. M.; FANTINATO, M. Análise da incorporação de requisitos não funcionais na modelagem de processos de negócio. In: Anais do VIII Simpósio Brasileiro de Sistemas de Informação : Trilhas Técnicas (SBSI). São Paulo, Brasil: SBC, 2012. p. 79-90. Citado na página 56.

SANTOS, L. L. et al. E-contract monitoring in an infrastructure for business process management. In: Proceedings of the 7th International Conference on Information Systems and Technology Management (CONTECSI). São Paulo, Brasil: USP, 2010. p. 2816-2836. Citado 2 vezes nas páginas 35 e 36.

SENGUPTA, B.; CHANDRA, S.; SINHA, V. A research agenda for distributed software development. In: Proceedings of the 28th International Conference on Software Engineering (ICSE). Shanghai, China: ACM Press, 2006. p. 731-740. Citado na página 29.

SHULL, F.; CARVER, J.; TRAVASSOS, G. An empirical methodology for introducing software processes. In: Proceedings of the 8th European Software Engineering Conference held jointly with 9th ACM SIGSOFT International Symposium on Foundations of Software Engineering (SIGSOFT FSE/ESEC). Viena, áustria: ACM Press, 2001. p. 288-296. Citado na página 22.

SILVA, G. C. et al. Aplicação de apoio computacional baseado em processos de negócio e serviços web para o desenvolvimento distribuído de software. In: Anais do III Workshop de Desenvolvimento Distribuido de Software (WDDS). Fortaleza, Brasil: SBC, 2009. p. 41-50. Citado na página 30.

SILVA, G. C. et al. Negotiating software acquisition supported by web services in a distributed software development process. In: Proceedings of the 22nd International Conference on Software Engineering \& Knowledge Engineering (SEKE). Redwood, CA, EUA: [s.n.], 2010. p. 221-224. Citado na página 30.

SILVA, G. C. et al. Towards a process for negotiation of e-contracts involving web services. In: Anais do VIII Simpósio Brasileiro de Sistemas de Informação : Trilhas Técnicas (SBSI). São Paulo, Brasil: SBC, 2012. p. 267-278. Citado 3 vezes nas páginas 30, 31 e 32.

SILVA, L. F.; FANTINATO, M.; SALLES, G. B. M. Apoiando alinhamento estratégico em organizações usando contratos eletrônicos estendidos com BLA. In: Anais do VIII Simpósio Brasileiro de Sistemas de Informação : Trilhas Técnicas (SBSI). São Paulo, Brasil: SBC, 2012. p. 348-359. Citado 2 vezes nas páginas 38 e 39.

SILVA, M. F. et al. Aspect-monitor: An aspect-based approach to WS-contract monitoring. In: Proceedings of the 12th International Conference on Enterprise Information Systems (ICEIS). Funchal, Madeira, Portugal: SciTePress, 2010. v. 4-SAIC, p. 5-12. Citado 2 vezes nas páginas 49 e 50.

SILVA, M. F. et al. Improving QoS monitoring based on the aspect-orientated paradigm. In: Lecture Notes in Business Information Processing - Enterprise Information Systems Revised Selected Papers (LNBIP). Funchal, Madeira, Portugal: Springer-Verlag, 2011. v. 73 LNBIP, p. 421-435. Citado 2 vezes nas páginas 49 e 50.

SILVA, Y. R. M.; FANTINATO, M. Uso de ontologia no estabelecimento de contratos eletrônicos para processos interorganizacionais em DDS. In: Anais do IV Workshop de Desenvolvimento Distribuído de Software (WDDS). Salvador, Brasil: SBC, 2010. p. 18-25. Citado na página 48. 
SIVESS, V. Non-functional requirements in the software development process. Software Quality Journal (SQJ), v. 5, n. 4, p. 285-294, 1996. Citado na página 14.

SOUZA, K. S.; FANTINATO, M. Explorando a engenharia de requisitos orientada a serviços: Uma revisão sistemática da literatura. In: Anais do IX Simpósio Brasileiro de Sistemas de Informação : Trilhas Técnicas (SBSI). João Pessoa, Brasil: SBC, 2013. p. 272-283. Citado na página 62.

STURM, R.; MORRIS, W. Foundations of service level management. 1st. ed. EUA: Sams, 2000. Citado na página 37.

TALLON, P. P. Inside the adaptive enterprise: An information technology capabilities perspective on business process agility. Information Technology and Management (ITM), v. 9, n. 1, p. 21-36, 2008. Citado na página 11.

TOLEDO, M. B. F. et al. A SOA-based collaborative environment for clinical trials on neglected diseases. In: Proceedings of the 4th International IEEE Workshop on Service Oriented Architectures in Converging Networked Environments (SOCNE). Bradford, Reino Unido: IEEE Computer Society, 2009. p. 518-523. Citado na página 52.

TRAVASSOS, G. H.; GUROV, D.; AMARAL, E. Introdução à engenharia de software experimental. [S.1.], 2002. Disponível em: <http://www2.ufpa.br/cdesouza/teaching/topes/4-ES-Experimental.pdf>. Citado na página 23.

VECCHIATO, D. A. et al. A feature-based toolkit for electronic contract negotiation and renegotiation. In: Proceedings of the IADIS International Conference $W W W /$ Internet 2010 (ICWI). Timissoara, Romênia: IADIS Press, 2010. p. 3-10. Citado 2 vezes nas páginas 33 e 34.

VECCHIATO, D. A. et al. From negotiation to renegotiation using a feature-based BPM infrastructure. IADIS International Journal on $W W W /$ Internet (IJWI), v. 9, n. 2, p. 1-16, 2011. Citado 2 vezes nas páginas 33 e 34.

VECCHIATO, D. A. et al. Electronic contract negotiation and renegotiation using features. In: Proceedings of the 6th International Conference on Web Information Systems and Technologies (WEBIST). Valência, Espanha: [s.n.], 2010. p. 313-318. Citado na página 33.

WANG, J. et al. RGPS: A unified requirements meta-modeling frame for networked software. In: Proceedings of the 3rd International Workshop on Applications and Advances of Problem Frames (IWAAPF). Leipzig, Alemanha: ACM Press, 2008. p. 29-35. Citado na página 62.

WEERAWARANA, S. et al. Web Services Platform Architecture: SOAP, WSDL, WS-Policy, WS-Addressing, WS-BPEL, WS-Reliable Messaging, and More. 1st. ed. Upper Saddle River, New Jersey, EUA: Prentice Hall, 2005. Citado 2 vezes nas páginas 12 e 18.

WESKE, M. Business Process Management: Concepts, Languages, Architectures. 1st. ed. Berlin, Alemanha: Springer, 2007. Citado 2 vezes nas páginas 12 e 18.

WESKE, M.; AALST, W. van der; VERBEEK, H. Advances in business process management. Data \& Knowledge Engineering (DKE), v. 50, n. 1, p. 1-8, 2004. Citado na página 11. 
WfMC. Workflow Management Coalition's Website. 2013. Disponível em: <http://www.wfmc.org/>. Citado na página 11.

WOHLIN, C. et al. Experimentation in software engineering: An introduction. 1st. ed. Norwell, MA, EUA: Kluwer Academic Publishers, 2000. Citado na página 22.

YU, E. S. K.; MYLOPOULOS, J.; LESPÉRANCE, Y. Ai models for business process reengineering. IEEE Expert, v. 11, n. 4, p. 16-23, 1996. Citado na página 62.

ZELKOWITZ, M. V.; WALLACE, D. R.; BINKLEY, D. W. Experimental validation of new software technology. In: JURISTO, N.; MORENO, A. M. (Ed.). Lecture notes on empirical software engineering. [S.l.]: World Scientific Publishing Co., Inc., 2003. p. 229-263. Citado na página 22. 